Terpenoid Biosynthesis in Eliphorbia lathyris and Copaifera ssp.

Cynthia Louise Skrukrud

LBL- -23915

DE8B 001463

Ph.D. Thesis

Lawrence Berkeley Laboratory

University of California

Berkeley, California 94720

July 1987

The United States Department of Energy has the right to use this thesis for any purpose whatsoever including the right to reproduce alf or any part thereof.

This work was supported by the U.S. Department of Energy under Contract Number DE-AC03-76SF00098 


\title{
Terpenoid Biosynthesis in Euphorbia lathyris and Copaifera ssp.
}

\author{
Copyright 1987
}

\section{Cynthis Louise Skrukrud}

\section{DISCLAIMER}

\begin{abstract}
This repurt was prepared as an account of work sponsured by an afency of the United Stistes Guvernment Neither the United States Government nor any agency thereof, nur any of thelr empleyees, makes any warranty, express or implied, or assumes any legal liability or respons. bilin: for the accuracy, completeness, or usefulness of any information. appasatus, product, ur proct is disclused, or represents that its use wisuld not infringe privalefy owned rights Refer. ence herein to any specific ommereral preduct, process, os service by tsade name. trademark manulacturer. os otberwise does not necessaraly constulute as anply th endorsement, recom. mendation, is favoring by the United States Government of any agency thereof Tho weth and opiniess of authors expressed herem of not necessartily tate or fellect thase of the iuted States (jovernment or an; agency theseof
\end{abstract}


Terpenoid Biosynthesis in Euphorbia lathyris and Copaifera spp.

Cynthia Louise Skrukrud

\section{ABSTRACT}

Biosynthesis of triterpenoids (triterpene esters and triterpenols) by isolated latex of Euphorbia lathyris was investigated. The rate of in vitro incorporation of mevalonic acid $(0.55$ $\mathrm{nmol} 100 \mu$ latex $\left.^{-1} \mathrm{~h}^{-1}\right)$ into triterpenoids was thirty times greater than acetate incorporation $(0.02$ nmol $100 \mu$ latex $x^{-1} \mathrm{~h}^{-1}$ ), indicating that the rate-limiting step in the pathway occurs prior to mevalonate. A particulate fraction, capable of converting mevalonate but not acetate into triterpenoids $(15,000 \mathrm{~g}$ pellet), showed a linear rate of triterpenoid biosynthesis over a period of four hours. No evidence was found to indicate that soluble latex proteins had an effect on either the biosynthesis or the removal of triterpenoids from this fraction. Electron micrographs of isolated $E$. lathyris latex showed the presence of latex particles and rod-shaped starch grains as well as a single-membrane-bounded structure which comigrated on Percoll gradients with the mevalonate to triterpenoids converting activity.

Both HMG-CoA reductase (EC 1.1.1.34) and HMG-COA lyase (EC 4.1.3.4) activities were detected in isolated latex. HMG-COA refuctase was localized to a membrane-bound fraction of a $5000 \mathrm{~g}$ pellet of latex. The rate of conversion of HMG-COA to mevalonate by this enzyme 10.02 nmol $100 \mu$ latex ${ }^{-1} \mathrm{~h}^{-1}$ ) is comparable to the overall rate of acetate incorporation into the triterpenoids suggesting that this enzyme is rate-determining in the biosynthesis of triterpenoids in E. lathyris latex.

HMG-CoA reductase of $E$. lathyris vegetative tissue was localized to the membrane-bound portion of a particulate fraction $(18,000 \mathrm{~g})$, and was solubilized by treatment with $2 \%$ polyoxyethylene ether $W-1$. Differences in the optimal pH for activity of HMG-CoA reductase from the latex and vegetative tissue suggest that isozymes of the enzyme may be present in the two 
tissue types.

Studies of the incorporation of various precursors into leaf discs and cuttings taken from Copaifera spp. show differences in the rate of incorporation into Copaitera sesquiterpenes suggesting that the site of sesquiterpene biosynthesis may differ in its accessability to the different substrates and/or reflecting the metabolic controls on carbon allocation to the terpenes. Mevalonate incorporation by Copaifera langsdorfii cultings into sesquiterpenes was a hundred-fold greater than either acetate or glucose incorporation, however, its incorporation into squalene and triterpenoids was also a hundred-fold greater than the incorporation into sesquiterpenes. 


\section{ACKNOWLEDGEMENTS}

I thank Professor Melvin Calvin for providing me with the opportunity and the support to learn plant biochemistry in his labs. Members of the Calvin group not only helped me with my research but also ensured that it was not serious science at all times. I thank all those who spent time in the Calvin labs while I was there for their friendship, especially Doug Hawkins, Scott Taylor, Janice Grant, Lewis Reich, Eva Penzes, Gen Gordon, Esther Nemethy and George Piazza.

Others outside of my immediate lab environment were important both as colleagues and friends. I thank the Staft of the Electron Microscopy Laboratory-Caroline Schooley, Doug Davis, Don Pardoe and Lynn Alves for making my experiences with electron microscopy one of the most enjoyable aspects of my graduate career. Fellow Comparative Biochemistry students Debbie Scott, Natasha Neihart and Marc Donsky shared their knowledge and frustrations with me and were real corifiatriots. Possibly the best home a Berkeley student could ask for was provided by Felicia Etzkorn, Nancy Kato, Eileen Kumetat, Margaret Archuleta, Diana Hsieh, Hector, Vida and Tyrone of 5121 Miles. Craft Circle members Bruce Rehlaender and Wendy Zimmerman helped me maintain my touch with the world beyond science. Kathy Hug kept me interested in plants (orchids) outside of something which you can grind up and study! I thank Robert Wilhelm Jor breakfasts and Loren and Francis Johnson for those wonderful Sunday dinners. I appreciate greatly the care taken and the suggestions given by Profs. James Seiber and Eugene Zavarin in their reading of my dissenation.

Nothing I could write would be sufficient to thank Tom von Geldern for his love, friendship, support and patience over the last 5 years. I can only promise that I will try to be a more sane person A.T. (after thesis)!

Lastly I would like to thank the members of my tamily, Dad. Mom, Dori and Elizabeth for putting up with me these 30 -odd years. They are me, so this thesis is as much a product of them as it is of me. Being Skrukruds, they understand my belief that it is certainly not good enough. With that apology, I especially want to note the role my mother often forgets she has played in the accomplishments of her family; this work is dedicated to her--Beveriy Beryl Bowersox Skrukrud. 


\section{TABLE OF CONTENTS}

Introduction

page

1

Chapter l. Metabolism of Terpenoid Pathway Intermediates

by Euphorbia lathyris latex

Chapter II. Location and Solubilization of Hydroxy-methylglutaryl-

Coenzyme A Reductase from extracts of Euphorbia lath;ris stem and leaf tissue

Chapter ill. Ultrastructure of Euphorbia Lathyris latex 


\section{INTRODUCTION}

Among the many aftershocks of the OPEC oil embargo of 1973 and 1974 was renewed interest in biomass as a source of energy and chemicals. The main attraction of biomass is that it is a renewable source of energy. It has the advantage over other forms of renewable energy, such as wind and solar, that it is stored energy. In addition, it is the only substitute for petroleum in its role as a feedstock for a multitude of products such as plastics and polymers.

The concept of biomass as a source of fuel is neither new nor novel; after all, oil and coal are nothing but very old biomass. The reliance of industrialized nations on fossil fuels is a relatively recent occurrence, within the last two hundred years. Before that wood was the main fuel supply for centuries; it was the major fuel surce in the United States up until 1875 (12). Even today with the seeming utter dependence of the world on fossil fuels, wood still accounts for $10 \%$ of worldwide fuel consumption, primarily among the less developed countries where it provides over $50 \%$ of the consumed energy (23).

The shift of industrialized nations to a petroleum-based energy structure was due in part to the relative ease of obtaining fossil fuels. The convenience of transportation of petroleum products has also been one of the hallmarks of the oil and gas era. A third strong point for these fossil fuels as well as for coal is their low oxygen content giving them the high energy content that makes them excellent fuels. While it was cheap and abundant, petroleum easily fueled modern society. Today with it becoming more scarce and ditficult, politically, environmentally, and economically, to obtain, fossil fuel does not stand as high above the attematives as it once did. Biomass, the original source of petroleum, is a logical choice for investigation as a substitute.

In recent years, different avenues of research have explored possibilities for developing biomass as a tuel for industrialized countries and for the 21st century. Notable examples among these are the development of "energy cane," high biomass sugar cane(2), and the use of fermentation technology to produce ethanol from high biomass crops such as energy cane and corn. These projects exemplify two difierent approaches to biomass development. The first is 
directed at increasing the output of total biomass of a crop; the second is concerned with a process to convert the biomass into the more convenient alcohol fuel.

A third approach to the use of biomass as a substitute tor fossil fuels emphasizes not only the quantity but quality of the biomass product. Some plants confain a greater percentage of more highly reduced compounds which like petrochemicals have greater fuel value, making them more valuable for use as fuel stock. Many plants contain unique chemical constituents that could be utilized instead of petrochemical-derived substances, both as final products and as precursors for the manufacture of synthetics. As an example, the use of both vegetable oils and waxes has been limited by the availability of cheap petroleum-derived synthetics but could conceivably play a more prominent role in the future (21).

Among those plants high in hydrocarbon content, it is otten their terpenoid compounds that are the constituents of interest. In terms of energy content, terpenoids are highly desirable. Their heat of combustion of ca $40 \mathrm{GJ} \mathrm{t}^{-1}$ make them as energy-rich as gasoline, higher than oils, fats, and lignins at ca $35 \mathrm{GJ} \mathrm{t}^{-1}$, biomass-derived alcohols and ketones at 20 to $30 \mathrm{GJ} \mathrm{t}^{-1}$, and celluioses, starch, and sugars at $15 \mathrm{GJ} \mathrm{t}^{-1}$ (18). Plant resins of the Pinaceae and the essential oils of various plant tamilies are examples of isoprenoids that also have the potential to replace petraleum-based feedstocks as industrial raw materials (21).

Terpenoids are commonly considered secondary plant products because the majority of these compounds appear to play no role in the primary processes essential to plant life. Important exceptions include the phytyl side chain of chlorophyll, ubiquinone involved in mitochondrial electron transport, and the normonal gibberellins and abscisic acid (Fig. 1). Members of the terpenoid class of compounds are recognized as related by their shared structural teature, the isoprene unit (Fig. 2). The common route of their biosynthesis has been established in both animals and plants (Schemes $1-3$ ). It is the 5 -carbon isopentenyl pyrophosphate that is the building block of all terpenes, but the formation of its 6-carbon precursor mevalonic acid is generally considered to be the point on the isoprenoid pathway at which the committment to terpenoid biosynthesis is made. 

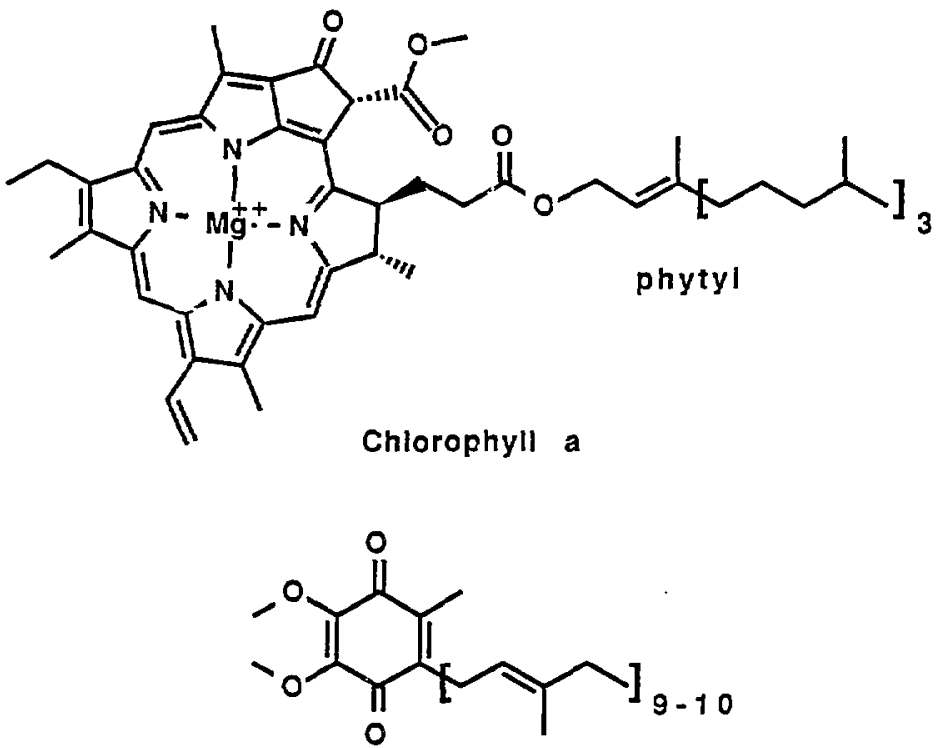

Ubiquinone

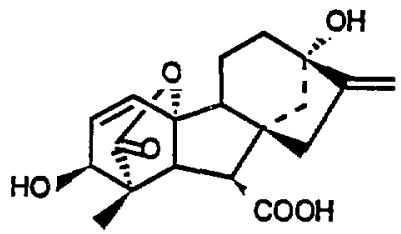

Gibberellic Acid

$\left(\mathrm{GA}_{3}\right)$

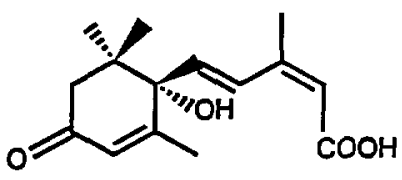

Abscisic Acid

Fig. 1. Terpenoid compounds important in primary plant metabolism. 


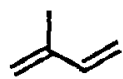

Fig. 2. Isoprene, the basic unit of terpenoid compounds.

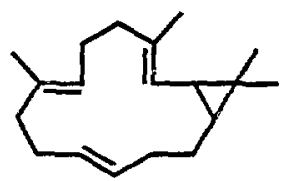

Fig. 3. Casbene, a diterpenoid phytoalexin. 


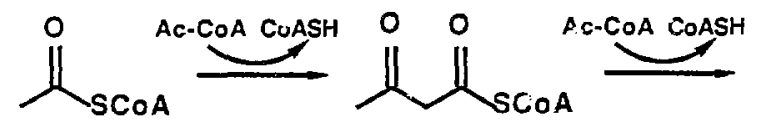

Acetyl-CoA Acetoacetyl-COA

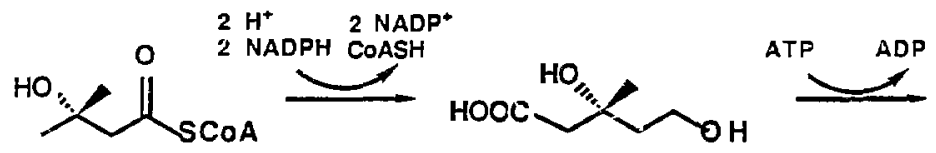

Hydroxymethylglutaryl-CoA Mevalonic Acid (HMG-COA)

(MVA)

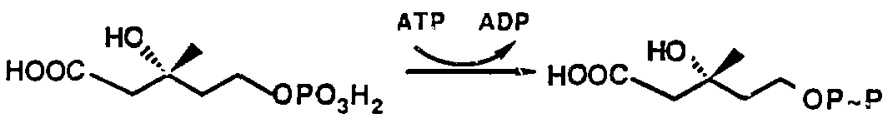

Mevalonate Phosphate

Mevalonate Pyrophosphate
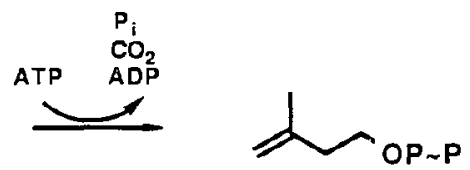

Isopentenyl Pyrophosphate (IPP)

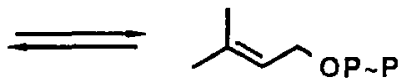

Dimethylallyl Pyrophosphate

Scheme 1. Pathway of terpenoid biosynthesis: formation of 5-carbon building block IFP. 
<smiles>CC(C)=CCOP</smiles>

Dimethylallyl Pyrophosphate<smiles>PPC1CC1PP</smiles><smiles>CC(C)=CCC/C(C)=C/COP</smiles>

Geranyl Pyropinosphate<smiles>CC1CC(P)C(PP)C1C</smiles><smiles>CC(C)=CCC/C(C)=C/CC/C(C)=C/COP</smiles>

Farnesyl Pyrophosphate (FPP)<smiles>PP[I-]P</smiles><smiles>CC(C)=CCCC(C)=CCOP</smiles>

Geranylgeranyl Pyrophosphate (GGPP)

\section{RUBBER}

poly cis isoprene

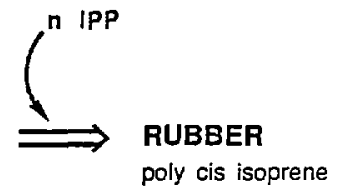

$\Longrightarrow$ MONOTERPENES

$\Longrightarrow$ SESQUITERPENES 
<smiles>CC(C)=CCC/C(C)=C/CC/C(C)=C/COP</smiles>

Farnesyl Pyrophosphate

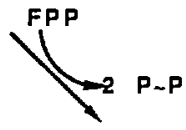<smiles>CC(C)=CCC/C(C)=C/CC/C(C)=C/CC/C=C(\C)CC/C=C(\C)CCC=C(C)C</smiles>

Squalene $\Longrightarrow$ TRITERPENES<smiles>CC(C)=CCC/C(C)=C/CC/C(C)=C/CC/C(C)=C/COPP</smiles>

Geranylgeranyl Pyrophosphate

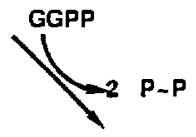

H

Phytoene $\Longrightarrow$ CAROTENOIDS

Scheme 3. Pathway of terpenoid biosynthesis: formation of $C_{30}$ and $\mathrm{C}_{40}$ compounds. 
Large quantities of terpenoids are found in certain plants, making them desirable as a biomass resource for fuels and chemicals. Often the terpenes are stored in specialized cells such as the rubber-containing laticifers of Hevea brasiliensis and the glands or ducts containing the mono and sesquiterpene essential oils found in herbs of the families Labiatae and Umbelliferae (7). The large quantity and the sequestration of these pools of terpenoids led to speculation that they were non-essential waste products, yet the energy required to manufacture these highly reduced compounds trom fixed $\mathrm{CO}_{2}$ is an arguntent against such a squanderous process (10). Discovery of the role of some terpenoids such as the diterpene casbene (Fig. 3), a phytoalexin anti-fungal agent whose production is enhanced in castor bean seedlings by attack by potentially pathogenic fungi, has promoted the view that defense is a major role of terpenes in plants (19), but the carotenoids and essential oils of flowers serve respectively as color and odor attractants tor pollinators(9). Clearly no single role for so diverse a group of compounds as isoprenoids can be ascribed, yet many seem to be important in a plant's interactions with other plant and anı al species. The function of each of the multitude of structures that have been found and the explanation for the quantities stored in some species remain unclear.

Development of plants high in hydrocarbon comtent for uSa as biomass can be approached in a number of ways. Potential hydrocarbon-producing crops have been identified through screening programs (3), and improvement of yields in species such as Grindelia camporum are being pursued by classical agronomic practices and genetic selection of outstanding strains (13). The promise of this plan of action is substantiated by the six-fold increase in natural rubber production achieved by Malaysian growers of Hevea over a period of 35 years of selection and cultivatiorial improvements (8).

A different focus is required to take advantage of the recent advances in genetic manipulation that is the basis of the emerging field of biotechnology. The idea here is to alter the plant or microbe directly at the gene level to increase the yield of a desired product. However, while the development of the techniques required to pertorm this type of genetic engineering has flourished, the understanding of what should be altered in a plant is scant. in order to use 
either genetic or chemical technology rationally to improve plant products for biomass, Rabson and Rogers have urged support of projects involved in fundamental biological research designed to improve understanding of the distribution of fixed energy within plants (18). Primary among the knowledge that is hoped to be gained is insight into the signals and controls that govern the metabolic partitioning of photosynthetically-fixed carbon into various classes of compounds. This involves an understanding of the factors that regulate the flux of metabolites through a given pathway, including any compartmentation of pathway enzymes, rate-limiting steps, end-product inhibition, and environmental or metabolic regulation. Further sophistication will result from insight into the branch point controls of carton allocation, the transport of assimilates, and the genetic controls of these processes. With this foundation of knowledge, manipulation of the plant genome to increase yields of cesired products can be pursued in a logical manner.

Euphorbia lathyris was one of the first species proposed as an energy crop (4). It is a member of the Euphorbiaceae, subfamily Euphorboideae, a group of plants characterized by the presence of laticifer cells which contain a milky sap, the latex. Heptane extraction yields a hydrocarbon-like fraction, comprising 4 to $5 \%$ of the dry weight of the plant, composed almost exclusively of triterperoids (14). This fraction has a heat value of ca $42 \mathrm{GJ} t \mathrm{dry}$ weight ${ }^{-1}$ and has been catalytically converted on a zeolite catalyst to yield a product similar to gasoline in both fuel value and product size distribution (11).

Triterpenoids are also the major constituents of the latex; it has been estimated that latex isoprenoids account for 15 to $20 \%$ of the whole plant heptane extract (15). Fifty percent of the dry weight of the latex is made up of six major triterpenols and their fatty acid esters $(16,20)$ (Fig. 4). Tapped latex is capable of biosynthesis of triterpenoids from acetate indicating that laticifer cells are active in the production of these compounds as well as in their starage (17). Consequently. the latex is a convenient in vitro system in which to study factors affecting the biosynthesis of the triterpenoids.

A second potential biomass producer of large quantities of terpenes is the genus Copaifera, whose member leguminous tropical trees produce the oleoresin copaiba balsam. Up 


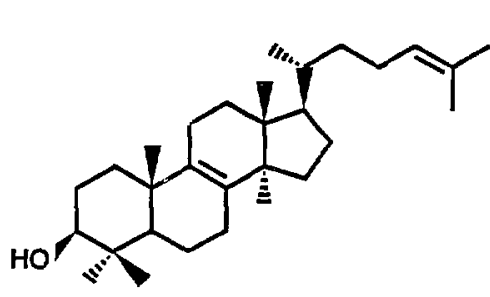

lanosterol

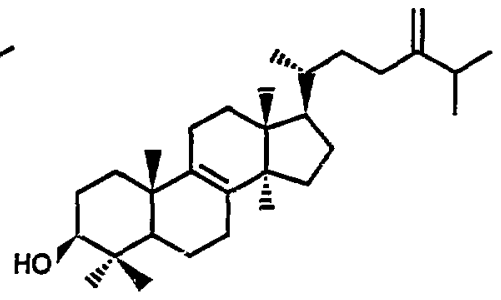

24-methylenelanosterol

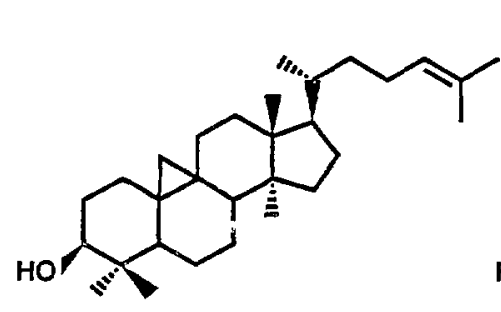

cycloartenol

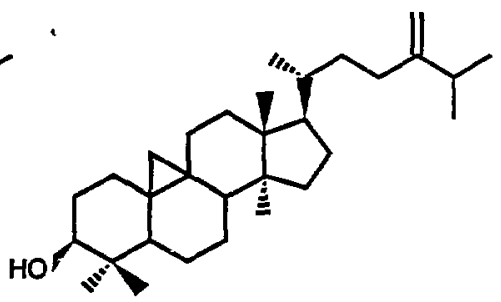

24-methylenecycloartenol

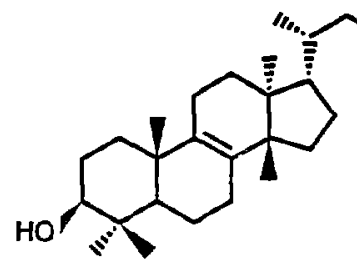

euphol

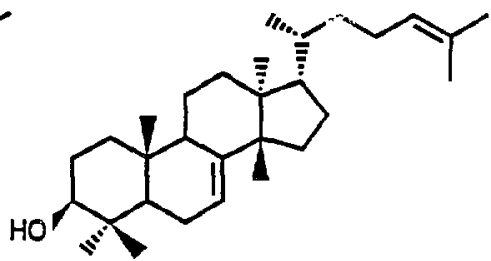

butyrospermol

Fig. 4. Triterpenoids of Euphorbia lathyris latex. 
to $90 \%$ of this oil, obtained by tapping the tree trunk, consists of sesquiterpene hydrocarbons (22). A mature tree can yield 40 to 60 liters of oil annually, which has been used directly as fuel in diesel engines $(1,5)$. Both the wood and leat resins contain a suite of sesquiterpene hydrocarons whose biosynthetic interrelationships have yet to be fully understood (6).

The focus of the work described here was to gain understanding of biosynthesis of terpenes in plants. As the enzymes of the isoprenoid biosynthetic pathway have been detected in various other plants, it was accepted that these same steps are involved in biosynthesis of the terpenes found in the plants studied, although not all enzymes of the pathway have been analyzed in these specitic plants. Rather, this investigation focused on elucidation of levels of organization and regulation of this pathway. Specilically, the work outlined in Chapter 1 presents a model of the biosynthesis of triterpenoids in E. lathyris latex based on the metabolism of exogenously-supplied terpenoid pathway intermediates. This includes the current level of understanding of the grouping of the enzymes of the pathway in subcellular structures as well as evidence suggesting that the enzyme $\beta$-hydroxymethylglutaryl-coenzyme A reductase catalyzes the key rate-limiting step in the pathway. The presence of B-hydroxymethylglutaryl-coenzyme A lyase in latex is also described, and evidence indicating the absence in 4 . latex of the soluble protein factors found in mammalian systems that enhance but do not catalyze the final steps in the conversion of farnesyl pyrophosphate to triterpenoids is presented.

Chapter 2 details work exploring the location, solubilization, and partial purification of B-hydroxymethylglutaryl-coenzyme A reductase from whole plant extracts. In Chapter 3 electron microscopic studies undertaken to identily the subcellular structure in latex involved in the biosynthesis of triterpenoids are described. Experiments investigating the incorporation of various substrates into the hexane extracts of Copaifera leaf tissue are presented in Chapter 4. 


\section{LITERATURE CITED}

1. Alencar JC 1982 Estudos silviculturais de uma população natural de Copaifera multijuga Hayne-Leguminosae, na Amazónia Central. 2-Produçăo de oleo-resina. Acta Amazonica 12: 75-89

2. Alexander AG 1985 The Energy Cane Alternative, Elsevier, Amsterdam

3. Buchanan RA, IM Cuil, FH Otey, CR Russell 1978 Hydrocarbon- and rubber-producing crops: evaluation of 100 U.S. plant species. Econ Bot 32: 146-153

4. Calvin M 1977 Hydrocarbons via photosynthesis. Energy Res 1:299-327

5. Calvin M 1980 Hydrocartons from plants: anaiytical methods and observations. Naturwissenschaften $67: 525-533$

6. Cane DE 1981 Biosynthesis of sesquiterpenes. In JW Porter, SL Spurgeon, eds, Biosynthesis of Isoprenoid Compounds, Vol 1, John Wiley and Sons, Inc, New York

7. Fann A 1979 Secretory Tissues in Plants, Academic Press, London

8. Guayule: An Altemative Source of Natural Rubber 1977 National Acaderny of Sciences, Washington D.E.

9. Hartorne J8 1982 Iritroduction to Ecological Biochemistry, Academic Press, London

10. Herout $\vee 1970$ Some relations between plants, insects, and their isoprenoids. Progress in Phytochemistry 2: 143-202

11. Haag WO, PG Rodewald, PB Weisz 1980 Catalytic production of aromatics and olefins from plant materials. Second Chemical Congress of the American Chemical Society, Las Vegas

12. Lewis CW 1981 Biomass through the ages. Biomass $1: 5-15$

13. McLaughtin, SP 1986 Mass selection for increased resin yield in Grindelia camponm (Compositae). Econ Bot 40: 155-161

14. Nemethy EK, JW Orvos, M Calvin 1979 Analysis of extractables from one Euphorbia. J Amer Oil Chem Soc 56: $957-960$

15. Nemethy E\& 1984 Biomass as a source of liquid tuel. CRC Crit Rev Plant Sci 2: 117-129 
16. Nielsen PE, H Nishimura, JW Otvos, M Calvin 1977 Plant crops as a source of fuel and hydrocarbon-ljke materials. Science 198: $942-944$

17. Ponsinet G, G Ourisson 1: 368 Aspects particuliers de la biosynthèse des triterpènes dans le latex d'Euphobia. Phytochem 7: 757-764

18. Pabson R, P Rogers 1981 The role of fundamental biological research in developing future biomass technologies. Biomass 1: 17-37

19. Sitton D, CA West 1975 Casbene: an anti-fungal diterpene produced in cell-free extracts of Ricinus communis seedlings. Phytochem 14: 1921-1925

20. Sknknud CL, SE Taylor, DA Hawkins, M Calvin 1987 Triterpenoid biosynthesis in Euphorbia lathyris. In PK Stumpf, JB Mudd, WD Nes, eds, Plant Lipids: Biochemistry, Structure, ano Function, Plenum Press, New York, in press

21. Wang S-C, JB Huttman 1981 Botanochemicals: supplements to petrochemicals. Econ Bot 35: $369-382$

22. Wenninger JA, RL Yates, M Dolinsky 1967 Sesquiterpene hydrocarbons of commercial copaiba balsam and American cedar wood oils. J Assoc Off Anal Chem 50: 1304-1313

23. Wood TS. S Baldwin 1985 Fuelwood and charcoal use in developing countries. Ann Rev Energy 10: $407-429$ 


\section{Chapter I. METABOLISM OF TERPENOID PATHWAY INTERMEDIATES BY EUPHORBIA}

\section{LATHYRIS LATEX}

Latex is the cell sap of specialized laticifer cells found in 12,500 species of plants, many of which are members of the families Apocynaceae. Euphorbiaceae. Asclepiadaceae, Compositae, Papaveraceae, and Sapotaceae. Laticifer celis penetrate through other cellular tissues and are often found associated with the phloem. They may be of two types: articulated and non-articulated. Articulated laticifers are a series of elongated cells whose end walls often ذecome porous or disappear forming a laticiferous vessel. Non-articulated laticifers develap from a single cell which elongates with the growth of the plant. Both lypes of laticifers are multinucleate and may be simple tubes or branched. Since the contents of laticifer cells are under high turgor pressure, latex is expeiled when an incision is made in plant tissue $(5,29)$.

Because of its importance as the source of natural nubber, the latex of Hevea brasiliensis is the best-studied plant latex. Hovea latex is capable of nubber biosynthesis in vitro. Numerous investigators have tested the ability of Hevea latex to convert various precursors into nubber. By comparing the activities of all the enzymes needed to convert acetate to rubber, Lynen suggested that HMG-COA reductase might represent the physiological bottleneck of rubber biosynthesis since the activity of that enzyme was much lower than inat of any of the other enzymes (17).

In vitro biosynthesis of the components of other plant latices has also been demonstrated. Morphinan alkaloid biosynthesis and storage occur in the latex of Papaver somniferum (6). Ponsinet and Ourisson demonstrated the ability of the latex of vanous species of Euphorbia to conver labelled acetate into their respective triterpenoid constituents and showed that it was the particulate fraction that was responsible for determining the structuie of newly-synthesized triterpenoids when the supernatant from a ten-minute centrifugation at $5000 \mathrm{~g}$ of one latex sample was mixed with the pellet of a like centrifugation of another latex containing a different suite of triterpenoid structures $(25,26)$. 
The first investigation of the metabolism of Euphorbia lathyris latex in vitro was reported by Ponsinet and Ourisson in 1968 who found cycloartenol, 24-methylene cycloartenol, and lanosterol were labelled upon incubation of latex with $[1-14 \mathrm{C}]$ sodium acetate(26). In 1976 , Groeneveld described the in vitro incorporation of $[2-14 \mathrm{C}]$ acetate into triterpenoids and ariterpene esters of latex as well as the labelling of these components of latex by [U-14 C]glucose injected into the hollow stem of the plant followed by analysis of the latex after a $24 \mathrm{~h}$ incubation(10). The ratio of labelled triterpenols to triterpene esters differed with the different treatments, 1:10 for the in vitro acetate incorporation and 2:1 for the "in vivo" glucose labelling. The second ratio more closely matched the measured triterperioid composition of latex: $47 \mathrm{mg}$ $\mathrm{mi}^{-1}, 73 \%$ triterpenols, $27 \%$ tritenpene esters. Groeneveld interpreted this as indicating that the tapped tatex was incomplete, lacking part of the biosynthetic capacity of the laticiter cell in vivo. More likely, this difference reflects the influence of controls working on steps involved in the metabolism of glucose before it or its product enters the laticifer and is incorporated into triterpenoids.

In 1983, a paper by Nemethy et al. reported the first biosynthetic studies performed on $E$. lathyris latex by this lab (20). Experiments testing the incorporation of various precursors showed that latex has the ability to convert pyruvate, acetate (AC), and mevalonate (MVA) but not glucose, glucose-6-phosphate, acetyl-CoA, hydroxymethylglutarate(HMG). HMG-CoA, mevalonolactone (MVAL), or isopentenylpyrophosphate (IPP) into triterpenoids. Time course incorporations of AC and/or MVA indicated no precursor/product relationship between the triterpenols and their fatty acid esters since no lag in the labelling of either component was seen, even with a 15 sec incubation of latex with [ ${ }^{3} \mathrm{H}$ IAc. The presence of mitochondria in latex was indicated by the detection of labelled TCA cycle acids when latex was incubated with radiolabelled AC and is substantiated by ultrastructural work of Groeneveld et al. demonstrating the regular occurrence of these organelles in laticifers of the cotyledons and hypocotyl of young seedings(11). Dilution of latex with buffer corrtairing various concentrations of sorbitol showed the sensitivity of triterpenoid biosynthesis to changes in osmolalily. A 10 -fold dilution of latex with $0.4 \mathrm{M}$ sorbitol 
restored tritemenol biosynthesis to its undiluted level but only $60 \%$ of triterpene ester biosynthesis was recovered. This result, as well as the inability of various intermediates along the established terpenoid pathway (AC-CoA, HMG-COA, IPP) to serve as precursors for triterpenoid biosynthesis, suggests compartmentation of terpenoid biosynthesis in latex. George Piazza was able to show that a particulate fraction was capable of converting MVA, but not acetate, into triterpenoids (24). Experimental results supporting this finding are reported in this chapter.

The rest of the experiments described were intended to further elucidate the organization and regulaiion of triterpenoid biosynthesis in latex. Much of the work focused on the metabolism of HMG-COA since the principle of comparative biochemistry would suggest that this could be an important control site since its reduction to MVA is the rate-limiting step in cholestero! biosynthesis in mammals and the activity of HMG-COA reductase was significantly lower than the other enzymes of the terpenoid pathway in Hevea latex (17). 


\section{MATERIAL AND METHODS}

Plant Material. Euphorbia lathyris L. plants were propagated from seed collected from wild plants growing near Healdsburg, Sonoma Co., CA. Plants were grown in a soil mixture of peat. sand, and Perlite in 6 inch clay pols in a growth chamber under conditions of a 16 h day at $600 \mu E$ $\mathrm{m}^{-2} \mathrm{~s}^{-1}$ provided by a combination of fluorescent and incandescent lights, $27^{\circ} \mathrm{C}$ day, $18^{\circ} \mathrm{C}$ night temperature. Latex was obtained by the collection of droplets expelled when shallow incisions were made with a razor blade at the bases of petioles. The latex was stored briefly on ice until it was used.

Materlats. DL-3-[glutaryl-3-14 C]hydrcxy-3-methylglutaryl coenzyme A; R-[5-ЭH] mevalonic acid, triethylammonium salt; and Aquassure were purchased from New England Nuclear. $\left.{ }^{3} \mathrm{H}\right]$ acetic acid, sodium sait was obtained from ICN Radiochemicals. Bradiord dye reagent was purchased from Bio-Rad. Silica gel plates were obtained from Analtech. All other biochemicals were from Sigma.

Solutions. The potassium salt of mevalonate was formed from mevalonolactone by incubating the lactone with $1.2 \mathrm{eq} \mathrm{KOH}$ for $30 \mathrm{~min}$ at $40^{\circ} \mathrm{C}$; tha solution was dilited to $1 \mathrm{mM}$ and kept frozen. REACTION BUFFER contained $10 \mathrm{mM}$ potassium phthalate, $\mathrm{pH} 5.5,0.4 \mathrm{M}$ sorbitol, $10 \mathrm{mM} \mathrm{KCl}, 10 \mathrm{mM} \mathrm{MgCl}_{2}$, and $30 \mathrm{mM} \mathrm{CaCl} 2.95 \%$ PEACOLL was prepared by mixing $9.5 \mathrm{mi}$ Percoll that had been dialysed against distilled water with $10 \mathrm{mI}$ REACTION BUFFER that had been concentrated to $0.5 \mathrm{ml}$ under a stream of $\mathrm{N}_{2}$.

Instruments. Any UV or visible absorbance of a sample was measured using a Hewlett-Packard 8450-A UVIVIS spectrophotometer. HPLC was performed using a Beckman 322 HPLC system equipped with a Hitachi 100-10 variable wavelength spectrophotometer detector and a Waters $\mathbf{A} \$ 10$ differential refractometer. Centrifugations were done either using a 50Ti or Type 21 rotor in a Beckman model L ultracentrifuge or, for samples of less than $1.5 \mathrm{ml}$ and $g$ values less than $12,000 \mathrm{~g}$, in a Beckman microfuge 11 . Fractions were collected using a LKB 2112 redirac fraction collector. All counting of radioactive samples was done using a Packard 
640-C scintillation counter.

Protein Analysis. PROTEIN ASSAY 1-- One part $4 \% \mathrm{CuSO}_{4} \cdot 5 \mathrm{H}_{2} \mathrm{O}$ was diluted 100 -fold with a solution of $2 \% \mathrm{Na}_{2} \mathrm{CO}_{3}, 0.16 \%$ sodium tartrate, and $1 \%$ SOS to give MIX 1 . One hundred microliters 1.2. $\mathrm{N} \mathrm{NaOH}$ was added to a volume of $0.5 \mathrm{ml}$ sample. If the sample tumed cloudy or geled, it was boiled briefly to clear the solution, then $2.5 \mathrm{ml} \mathrm{MIX} 1$ was added. The sample was altowed to sit for 10 to 30 min at which time $125 \mu 1: 1$ Sigma Folin-Ciocalteu $2 \mathrm{~N}$ phenol reagent: water was added, and the solution was rapidly mixed. The sample was allowed to develop for exactly $1 \mathrm{~h}$ and then its $\mathrm{A}_{420}$ and $\mathrm{A}_{750}$ were measured. A standard curve was developed using known amounts of a protein standard. This assay was develoyed based on the method of Folin and Ciocalteu ( 7$)$.

PROTEIN ASSAY 2- This assay was based on th, method of Bradford (2) as moditied by Vincent and Nadeau (31). A $30 \mu$ aliquot of sample and buffer in a total volume of $300 \mu$ was added to $120 \mu 0.1 \%$ Triton X-100. An aliquot of $50 \mu$ of this mixture was added to $1 \mathrm{ml} 5$-fold dilute Bradford dye reagent, and the $\mathrm{A}_{594}$ of the solution was measured. A stancard curve was constructed using the same procedure with a protein standard.

Analysis for labelled triterpenolds. TLC isolation of triterpenoids - The general method tor dete. mination of triterpenoid labelling involved extraction of a dried incubation mixture by stirring with acetone overnight. Incubations were quenched with ca $3 \mathrm{ml}$ methanol and were dried under a stream of $\mathrm{N}_{2}$. The dried sample was washed four times with 3-ml volumes of water then extracted with the acetone. In some experiments incubations were quenched by placing the sample in a soiling water bath for a few minutes; the sample was then centriluged, and the pellet was extracted with acetone. The acetone extract was spotted as a band and a marker spot on a $20 \times 20 \mathrm{~cm}$ silica gel G plate which was developed in a solvent mixture of 3:1 ether: petroleum ether. The triterpenols and triterpene esters have $R_{f} s$ of 0.60 and 0.85 , respectively, in this system. Marker spots were visualized with sulfuric acid spray and heat. The bands corresponding to the markers were scraped into scintillation vials,.sonicated with $5 \mathrm{ml}$ water, shaken with $15 \mathrm{ml}$ 
Aquassure to form sols, and counted.

HPLC analysis of triterpenols- Triterpenols were first chromatographed by $\mathrm{ZLC}$ and then eluted from the silica gel with acetone. The solvent was removed by evaporation under a stream of $\mathrm{N}_{2}$, and the triterpenols were redissolved in methanol. HPLC analysis was pertormed on two $4.6 \mathrm{~mm} \times 25 \mathrm{~cm}$ ODS columns (Altex) in $100 \%$ methanol at a flow rate of $1 \mathrm{ml} \mathrm{min}^{-1}$. The eluate was monitored by its absorbance at $2.14 \mathrm{~nm}$. Fractions were collected directiy into scintillation vials, were mixed with $15 \mathrm{ml}$ Aquassure, and were counted.

Analysis tor labelled MVA. ILC system 1- Sample was spotted on a silica gel G plate and developed in $\mathrm{CHCl}_{3}$ :acetone, 2:1. In this system, MVAL has a $\mathrm{R}_{f}$ of 0.38 to 0.43 (3).

TLC system 2- Sample is eluted with a 1:1 mixture of acetone and benzene on silica gel G plates where the $\mathrm{A}_{\mathrm{p}}$ of MVAL is $0.42(28)$.

Organic acid HPLC - Sample is chromatographed on an HPLC column designed for organic acid anaiysis (Bio-Rad Laboratories HPX-87H, $300 \times 7.8 \mathrm{~mm}$ ) equipped with a guard column (Bio-Rad 125-0129) in 0.0025 $\mathrm{N} \mathrm{H}_{2} \mathrm{SO}_{4}$ at a flow rate of $0.3 \mathrm{ml} \mathrm{min}^{-1}$. The eluant is monitored hy its absorbance at $214 \mathrm{~nm}$. The retention times of HMG, acetoacetate, Ac, and MVA are 22, 30, 31.5, and $41 \mathrm{~min}$ in this system.

ODS HPLC - In this system, a sample is chromatographed on a $250 \times 4.6 \mathrm{~mm}$ ODS column (Altex) in $10 \mathrm{mM}$ potassium phosphate $\mathrm{pH} 2.6$ at a flow rate of $1 \mathrm{ml} \mathrm{min}^{-1}$ where the retention times tor acetic acid, acetoacetic acid, mevalonic acid, HMG, and mevalonolactone are 5.5, 7.75. 11,14 , and $15 \mathrm{~min}$, respectively. The elution of sample components was determined by changes in the eluant's $A_{214}$

Substrate Saturation Experiments. A series of experiments were pertorriad in order to determine the concentrations of Ac and MVA that were saturating for the biosynthesis of iriterpenoids in latex. In each experiment latex was incubated with DTE and various concentrations of either radiolabelled AC or MVA, then the tritepenols and triterpene esters were isolated, and the amount of radiolabel that had been incorporated into each traction was 
determined.

Ac incoporation 1-- One hundred microliter volumes of latex were incubated with a combination of $10 \mu \mathrm{J} 0.1 \mathrm{M}$ DTE and various amounts of [ $\left.{ }^{3} \mathrm{H}\right] \mathrm{AC}$, Na salt $(5,10,20,40$, and $60 \mu \mathrm{l}$; $\mathrm{Ci} \mathrm{mmol} \mathrm{m}^{-1} ; 10 \mathrm{mCi} \mathrm{m}^{-1}$ ) that had been dried under a stream of $\mathrm{N}_{2}$. The final concentrations in the incubation mixture were $10 \mathrm{mM}$ DTE and varied from 0.25 to $3 \mathrm{mM} \mathrm{AC}$.

Samples were incubated for $1 \mathrm{~h}$ at room temperature $\left(20\right.$ to $\left.22^{\circ} \mathrm{C}\right)$ then were quenched by the addition of $c a 3 \mathrm{ml} \mathrm{MeOH}$ and dried under a stream of $\mathrm{N}_{2}$. The remaining residue was washed three times with water then extracted overnight with stirred acetone. The water wash was extracted with hexane; the hexane and acetone extracts were combined, and solvent was removed by evaporation under a stream of $\mathrm{N}_{2}$. The residue was redissolved in $0.5 \mathrm{ml}$ acetone, sonicated, and spotted onto a $20 \times 20 \mathrm{~cm} 250 \mu \mathrm{m}$ layer silica gel $\mathrm{G}$ plate as a band and an isolated marker spot. An acetone rinse of the spotting vial was also applists to the plate which was developed in a solvent mixture of 3:1 ether: petroleum ether. The region comtaining the marker spot was visualized with sulfuric acid spray and heat, and the bands containing the triterpenols and interpene esters were scraped from the rest of the plate. Five $\mathrm{ml}$ water was added to the silica gel of each fraction; the mixture was sonicated $5 \mathrm{~min} ; 15 \mathrm{ml}$ Aquassure was added, and the mixiure was shaken to form an unilorm gel. Samples were scintillation-counted.

AC incorpnration 2-- A second experiment was performed exactly as the first with one exception- the final concentration of $A c$ in the incubations ranged from $50 \mu \mathrm{M}$ to $1.5 \mathrm{mM}\langle 1,2,10$. 20. and $30 \mu !\left[{ }^{3} \mathrm{H}\left[\mathrm{AC} ; 2 \mathrm{Ci} \mathrm{mmol}^{-1} ; 10 \mathrm{mCi} \mathrm{ml}^{-1}\right.\right.$ ).

MUA. Incorporation 1- One $\mathrm{ml}$ latex was placed on top of $4 \mathrm{mt} 95 \%$ PERCOLL and centriflged at $130 \mathrm{~g}$ for $5 \mathrm{~min}$. The top layer was removed and diluted with an equal volume of REACTION BUFFER. The resulting solution was centrituged at $100.000 \mathrm{~g}$ for $10 \mathrm{~min}$; supernatant and pellet were mixed, and $400 \mu$ of the mixture was added to the incubation vial. Each incubation contained $50 \mu / 3 \mathrm{mM} \mathrm{NADPH}, 50 \mu / 104 \mathrm{mM}$ DTE, $50 \mu \mathrm{l} 20 \mathrm{mM}$ ATP, and $50 \mu$ $1 \%$ BSA added to the mixtures of unlabelled and $\left[{ }^{3} \mathrm{H}\right] \mathrm{MVA}\left(30 \mu \mathrm{l}^{3} \mathrm{H}\right] \mathrm{MVA}, 0.5 \mathrm{mCi} \mathrm{ml}^{-1}, 10.3 \mathrm{Ci}$ 
$\mathrm{mmol}^{-1}+50,75,100,150$, or $300 \mu 1 \mathrm{mM}$ MVA, potassium salt) that had been dried in the vial. The final concentrations of the incubation components were $0.25 \mathrm{mM} \mathrm{NADPH}, 8.7 \mathrm{mM}$ DTE, 1.7 mM ATP, $0.08 \%$ BSA, and from 86 to $502 \mu \mathrm{M}$ MVA. Samples were incubated at room temperature for $7.5 \mathrm{~h}$ then quenched with $2.5 \mathrm{~m} \mathrm{MeOH}$. An additisnal volume of $\mathrm{MeOH}$ was used to rinse the vial. The samples were dried under a stream of $\mathrm{N}_{2}$ overnight and extracted three times with $2.5 \mathrm{ml}$ acetone, the last volume containing $0.5 \mathrm{ml}$ of acetone extract of latex as a source of carrier triterpenoids. The acetone extracts were concentrated and applied to $20 \times 20$ $\mathrm{cm} 500 \mu \mathrm{m}$ silica gel $\mathrm{G}$ plates which were developed, scraped, and counted as in the acetate incorporation experiments.

MVA Incorporation 2- A second substrate saturation curve for MVA was determined as in incorporation 1 with the following exceptions: the tinal MVA concentration in the incubations varied from 0.077 to $1.06 \mathrm{mM}\left(30 \mu \mathrm{\mu}\left[{ }^{3} \mathrm{H}\right] \mathrm{MVA}\left(0.5 \mathrm{mCi} \mathrm{ml}^{-1}, 10.3 \mathrm{Ci} \mathrm{mmol}^{-1}\right)+25,100,150,250\right.$, 250 , or $350 \mathrm{~W} 1.8 \mathrm{mM}$ MVA, potassium salt); the incubation time was $6 \mathrm{~h}$; the dried samples were extracted twice with acetone.

MVA Incorporation 3-- Ten microliters $10 \mathrm{mM}$ DTE and a combination of unlabelled and $\left.\left[^{3} \mathrm{H}\right] M V A(\mu){ }^{3} \mathrm{H}\right] \mathrm{MVA}\left(10.3 \mathrm{mCi}^{\mathrm{mmol}}{ }^{-1}, 0.5 \mathrm{mCi} \mathrm{mt}^{-1}\right)+\mu 20 \mathrm{mM}$ MVA, potassium satt were $6+5$, $12+10,18+15,18+15,24+20$, and $30+25)$ were dried under a stream of $\mathrm{N}_{2}$ in each incubation vial. To each vial, $100 \mu$ latex was added giving final concentrations of $10 \mathrm{mM}$ DTE and MVA from 1 to $5 \mathrm{mM}$ with a specific activity of $30 \mathrm{mCi} \mathrm{mmol}^{-1}$. The samples were incubated at room temperature for $1 \mathrm{~h}$, quenched with $\mathrm{ca} 2 \mathrm{ml} \mathrm{MeOH}$, and dried overnight under a stream of $\mathrm{N}_{2}$. The residue was extracted, chromatographed, and counted as in Ac Incomporation 1.

AC and MVA Incorporation in the same latex sample-- One hundred microtiters aliquots of a latex sample were added to incubations vials containing DTE and either AC or MVA that had been dried under a stream of $\mathrm{N}_{2}$. To each vial was added $10 \mu 1100 \mathrm{mM}$ DTE $+1,2,5,10,15,20$, or 3 $\mu l\left[{ }^{3} \mathrm{H}\right] \mathrm{Ac}\left(2 \mathrm{Ci} \mathrm{mmol}^{-1}, 10 \mathrm{mCi} \mathrm{ml}^{-1}\right)$ or a combination of unlabelled $+\left[{ }^{3} \mathrm{H}\right] \mathrm{MVA}$ to give a final specilic activity of $50 \mathrm{mCi} \mathrm{mmor}^{-1}$ as shown in Tabje I. 
Table I. Quantity of MVA used as Substrate for Latex Incorporation Experiment

\begin{tabular}{|c|c|c|c|c|}
\hline \multirow[t]{2}{*}{ Incubation } & \multirow[t]{2}{*}{$\begin{array}{l}\text { Final Concentration } \\
\qquad \text { (mM MVA] }\end{array}$} & \multirow{2}{*}{$\begin{array}{c}10.3 \mathrm{Ci} \mathrm{mmol}^{-1}, 0.5 \mathrm{mCi} \mathrm{ml}^{-1} \\
\mu \mathrm{l}\end{array}$} & \multicolumn{2}{|c|}{$\begin{array}{c}\text { unlabelled MVA } \\
\boldsymbol{\mu}\end{array}$} \\
\hline & & & $2 \mathrm{mM}$ & $20 \mathrm{mM}$ \\
\hline 1 & 0.1 & 1 & 5 & - \\
\hline 2 & 0.25 & 2.5 & 12.5 & - \\
\hline 3 & 0.5 & 5 & - & 2.5 \\
\hline 4 & 1 & 10 & - & 5 \\
\hline 5 & 2 & 20 & - & 10 \\
\hline 6 & 3 & 30 & - & 15 \\
\hline
\end{tabular}

In each incubation the final concentration of DTE was $10 \mathrm{mM}$, and the Ac concentration varied from 0.05 to $1.5 \mathrm{mM}$. Samples were incubated for $1 \mathrm{~h}$ then quenched and analyzed as in Ac incorporation 1.

Elfect of Percoll on triterpenold blosynthesis. Dr. George Piazza was using Percoll gradients to try to isolate the organelle responsible for the biosynthesis of triterpenoids in latex. This experiment looked at the effect of Percoll and centrifugation on this biosynthesis. Aliquots of $0.4 \mathrm{ml}$ were taken from a single sample of latex and subjected to five different treatments betore they were incubated with $\left[{ }^{3} \mathrm{H}\right] \mathrm{MVA}$ and analyzed for labelled triterpenoids. The five treatments were:

1. latex mixed with $4 \mathrm{ml} 95 \%$ Percoll

2. latex placed on $4 \mathrm{ml} 95 \%$ Percoli, centriluged at $400 \mathrm{~g}$ for 5 min then mixed

3. latex placed on $4 \mathrm{mi} 95 \%$ Percoll and centrifuged at $400 \mathrm{~g}$ for $5 \mathrm{~min}$. The supernatant was removed and mixed with $0.5 \mathrm{ml} 95 \%$ Percoll, replacing the $0.5 \mathrm{ml}$ pellet left behind. 
4. latex placed on $4 \mathrm{ml} 95 \%$ Percoll and centrifuged at $130 \mathrm{~g}$ for $5 \mathrm{~min}$. The white latex layer remaining on top of the Percoll was removed and mixed with $4 \mathrm{ml} 95 \%$ Percoll.

5. latex mixed with 4 mI REACTION BUFFER

Each treatment was incubated with $50 \mu 20 \mathrm{mM}$ ATP pH 5.5, $50 \mu 100 \mathrm{mM}$ DTE, $50 \mu 1 \%$ BSA, and 50 w $3 \mathrm{mM}$ NADPH, all solutions were made up in reaction butfer. The tinal concentration of MVA was $11.4 \mu \mathrm{M}$ with a specific activity of $380 \mathrm{mCi} \mathrm{mmol}^{-1}$ derived from a combination of $50 \mu \mathrm{mM}$ MVA, potassium salt and $\left.40 \mu{ }^{3} \mathrm{H}\right] \mathrm{MVA}\left(10.3 \mathrm{Ci} \mathrm{mmal}^{-1}, 0.5 \mathrm{mCi}\right.$ $\mathrm{ml}^{-1}$ ). All substrates were combined and dried in the incubation tube under a stream of $\mathrm{N}_{2}$ belore the addition of the sample; the volume of each incubation was $4.4 \mathrm{ml}$. Samples were incubated 7 $\mathrm{h}$ and quenched with $3 \mathrm{ml}$ methanol. The dried samples were analyzed for labelled triterpenoids by TLC.

Recovery of site of triferpenold blosynthetic actlylty from Percoll gradlent. A $1.5 \mathrm{ml}$ sample of latex was collected, and $200 \mu$ was incubated with [ $\left.{ }^{3} \mathrm{H}\right] \mathrm{MVA}$. The remainder was placed in a test tube on $5 \mathrm{ml} \mathrm{95 \%} \mathrm{Percoll} \mathrm{and} \mathrm{cemrituged} \mathrm{at} 130 \mathrm{~g}$ for $5 \mathrm{~min}$. The white layer remaining on top of the Percoll was removed, and $250 \mu$ was incubated with [3 $\mathrm{H}$ ]MVA. The Percoll layer was removed and diluted 4-fold with REACTION BUFïER. Five 3-ml aliquots were taken, and each was centrifuged for $10 \mathrm{~min}$ at a different $g$ value $(1000,3000,5000,10,000$, and $15,000 \mathrm{~g})$. The supernatant of each was removed, and the bottom $300 \mu$ pellet was incubated together with 250 $\mu$ of the top white layer and [3H]MVA.

Each incubation contained $50 \mu 20 \mathrm{mM}$ ATP pH 5.5, $50 \mu$ 山 $100 \mathrm{mM}$ DTE, $50 \mu \mathrm{ll} 1 \%$ BSA, 50

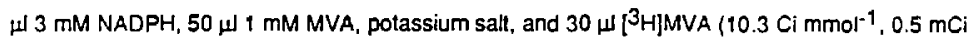
$\mathrm{mi}^{-1}$ ). These substrates and cofactors were dried under a stream of $\mathrm{N}_{2}$ in the incubation tube. Three hundred microliters of $95 \%$ Percoll diluted 4-fold with REACTION BUFFER was added to the whole latex and top layer incubations to substitute for the pellet volume present in the other incubations. The concentration of MVA in the incubations was $94 \mu \mathrm{M}$ at a specitic activity of 290 mCi mmol"1 Incubations were quenched atter $11.75 \mathrm{~h}$ with methanol and dried under a stream of 
$N_{2}$. The incubations were analyzed for labelled triterpenoids by TLC.

Distribution of site of tritterpenold blosynthesis from top layer of Percoll gradient. Latex was centrifuged at $130 \mathrm{~g}$ for $5 \mathrm{~min}$ on $5 \mathrm{ml} \mathrm{95 \%} \mathrm{Percoll,} \mathrm{and} \mathrm{the} \mathrm{layer} \mathrm{that} \mathrm{remained} \mathrm{on} \mathrm{top} \mathrm{of} \mathrm{the}$ Percoll was removed, diluted 2-fold with REACTION BUFFEF, and centrifuged at $100,000 \mathrm{~g}$ for $10 \mathrm{~min}$. Four incubations were performed: one containing $105 \mu \mathrm{l}$ of the $100,000 \mathrm{~g}$ pellet witt. 350 $\mu$ REACTION BUFFER, a second of $350 \mu 100,000 \mathrm{~g}$ supernatant with $105 \mu$ REACTION BUFFER, and duplicate incubations of $105 \mu 100,000 \mathrm{~g}$ pellet with $350 \mu 100,000 \mathrm{~g}$ supernatant. The latex samples were added to $25 \mu 1.8 \mathrm{mM}$ MVA, potassium salt and $30 \mu$ [ [ H]MVA (10.3 Ci $\mathrm{mmol}^{-1}, 0.5 \mathrm{mCi} \mathrm{ml}{ }^{-1}$ ) that had been dried under $\mathrm{N}_{2}$ in the incubation tubes. Fitty microliters 20 mM ATP pH 5.5, $50 \mu 100 \mathrm{mM}$ DTE, $50 \mu$ 1\% BSA, $50 \mu \mathrm{d} 3 \mathrm{mM}$ NADPH were added to each incubation, giving a final volume of each incubation of $655 \mu$ with a MVA concentration of $70 \mu \mathrm{M}$ at a specific activity of $0.32 \mathrm{Ci}^{\mathrm{mmol}} \mathrm{l}^{-1}$. The samples were incubated for $5 \mathrm{~h}$, then quenched with metmanol, and analyzed for labelled triterpenoids by TLC.

Distribution of triterpenold-blosynthetlc actlvlty between supernatant and pellet of latex centrifuged at different $g$ values. A sample of latex was divided into $3200-\mu l$ aliquots; two aliquots were diluted to $1.5 \mathrm{ml}$ with REACTION BUFFER. The diluted samples were centrifuged for $15 \mathrm{~min}$, one at $30,000 \mathrm{~g}$ and one at $60,000 \mathrm{~g}$. The supematants were removed and diluted to a total volume of $1.5 \mathrm{ml}$ with REACTION BUFFER. The pellets were resuspended in $0.5 \mathrm{ml}$ REACTION BUFFER. Nine hundred microliters of each supernatant was incubated with $40 \mu l$ [ ${ }^{3}$ HIMVA (10.3 $\mathrm{mCi} \mathrm{mmol}^{-1}, 0.5 \mathrm{mCi} \mathrm{m}^{-1}$ ) and $150 \mu$ ل 1 mM MVA, potassium salt that had been previously dried under a stream of $\mathrm{N}_{2}$ in the incubation tube. One hundred-fifty microliters each of $1 \%$ BSA, $104 \mathrm{mM}$ DTE, $20 \mathrm{mM}$ ATP pH 5.5, and $3 \mathrm{mM}$ NADPH were added to each incubation. A $300 \mu$ aliquot of each pellet and $200 \mu$ whole latex dilufed $10300 \mu$ with REACTION BUFFER were incubated with $30 \mu \mathrm{l}\left[{ }^{3} \mathrm{H}\right.$ MMVA and $50 \mu \mathrm{l} 1 \mathrm{mM}$ MVA, potassium salt that had been previously dried under a stream of $\mathrm{N}_{2}$ in the incubation tube. Fifty microliters each of $1 \%$ BSA, $104 \mathrm{mM}$ DTE, $20 \mathrm{mM}$ ATP pH 5.5, and $3 \mathrm{mM}$ NADPH were added to these three incubations. The final volume 
of the supernatant incubations was $1.5 \mathrm{ml}$; the volume of the pellet and whole latex incubations were each $0.5 \mathrm{ml}$. The final concentrations of cofactors and MVA were the same in all incubations, but the specific activity of MVA was $0.13 \mathrm{Ci} \mathrm{mmol}^{-1}$ and $0.29 \mathrm{Ci} \mathrm{mmol}^{-1}$ in the supernatant and pellet ( $\&$ whole latex) incubations, respectively. The samples were incubated for $3 \mathrm{~h}$ then diluted with water and quenched by placing in a boiling water bath for 5 to $10 \mathrm{~min}$. The samples were centrifuged for $15 \mathrm{~min}$ at $180,000 \mathrm{~g}$ to obtain a firm pellet. The supernatam was removed: the pellat was dried under a stream of $\mathrm{N}_{2}$, extracted with acetone, and analyzed for labelled triterpenoids by TLC.

A second experiment was performed following the same procedures. Here three samples were centrifuged at $5000 \mathrm{~g}, 15000 \mathrm{~g}$, and $20,000 \mathrm{~g}$, and the pellets and supernatants were incubated as described above. A whole latex sample was incubated as before.

Acetate versus MVA metabolism by $15,000 \mathrm{~g}$ pellet. Two $200 \mu \mathrm{l}$ aliquots were each diluted to $1.5 \mathrm{ml}$ with REACTION BUFFER and centriluged at $15,000 \mathrm{~g}$ for $15 \mathrm{~min}$. The supernatant was removed, and the pellet was resuspended in $1.5 \mathrm{ml}$ REACTION BUFFER and recentrifuged. The pellets were then each resuspended in $50 \mu$ ل $20 \mathrm{mM}$ ATP, $50 \mu 104 \mathrm{mM} \mathrm{DTE}, 50 \mu$ 1\% BSA, and $50 \mu 3 \mathrm{mM}$ NADPH. The suspensions were transfered to incubation tubes in which the labelled substrate had been dried under a stream of $\mathrm{N}_{2}$. One tube contained $\left.30 \mu\right]^{3} \mathrm{H}$ ]MVA (10.3 Ci $\mathrm{mmol}^{-1}, 0.5 \mathrm{mCi} \mathrm{mi}^{-1}$ ) and $25 \mu \mathrm{mM}$ MVA, potassium salt, giving a final incubation concentration . of $0.25 \mathrm{mM}$ mevalonate at a specific activity of $0.29 \mathrm{Ci} \mathrm{mmol}^{-1}$. The second incubation had an acetate concentration of $0.25 \mathrm{mM}$ provided by $10 \mu \mathrm{fof}\left[{ }^{3} \mathrm{H}\right.$ lacetate $\left(2 \mathrm{Ci} \mathrm{mmol}^{-1}, 10 \mathrm{mCi} \mathrm{ml}^{-1}\right)$. The samples were incubated for $3 \mathrm{~h}$ and quenched in a boiling water bath. Each was analyzed for labelled triterpenoids by TLC.

Lliet $1 m$ of $15,000 \mathrm{~g}$ pellet. The lifetime of the triterpenoid-biosynthetic capability of the pellet was tested. A $\mathrm{ml}$ of latex was divided into $5200 \mu$ aliquots which were each diluted to 1.5 mi with REACTION BUFFER and centrifuged at $15,000 \mathrm{~g}$ for $15 \mathrm{~min}$. The supernatants were removed, and the pellets were each resuspended in $0.5 \mathrm{ml} \mathrm{REACTION} \mathrm{BUFFER.} \mathrm{Each} \mathrm{pellet}$ was added to a reaction iube in which $50 \mu 1 \mathrm{mM}$ MVA, potassium salt and $30 \mu \mathrm{H}\left[^{3} \mathrm{H}\right.$ MVA $(10.3 \mathrm{Ci}$ 
$\mathrm{mmol}^{-1}, 0.5 \mathrm{mCi} \mathrm{ml}^{-1}$ ) had been dried under a stream of $\mathrm{N}_{2}$. Fifty microliters $20 \mathrm{mM}$ ATP pH 5.5 , $50 \mu 100 \mathrm{mM} \mathrm{DTE}, 50 \mu \mathrm{l}$ 1\% BSA, $50 \mu \mathrm{l} 3 \mathrm{mM} \mathrm{NADPH}$ were added to each incubation, giving a final volume of each incubation of $700 \mu$ with a MVA concentration of $0.1 \mathrm{mM}$ at a specific activity of $0.29 \mathrm{Ci} \mathrm{mmot}^{-1}$. Each sample was incubated for a different period of time $(0.5,1,2,3$, and 4.5 h) then quenched in a boiling water bath. The sample was centrifuged at $180,000 \mathrm{~g}$ for $15 \mathrm{~min}$, and the pellet was analyzed for labelled triterpenoids by $\mathrm{TLC}$.

Comparison of triterpenold blosynthesis by whole latex, $15,000 \mathrm{~g}$ pellet, and washed $15,000 \mathrm{~g}$ pellet. Some experiments require that whole latex be incubated for a period of time and then centrifuged. The recovered pellet is incubated for an additional period of time. Four $175 \mu$ samples of latex were incubated for $2 \mathrm{~h}$ with $\left.25 \mu \mathrm{l}^{14} \mathrm{C}\right] \mathrm{MVA}\left(50.1 \mathrm{mCi} \mathrm{mmol}^{-1}, 0.1 \mathrm{mCi} \mathrm{ml}^{-1}\right)$ that had been dried in the incubation tube. Fifteen microliters each of $145 \mathrm{mM} \mathrm{DTE}$ and $58 \mathrm{mM} \mathrm{MgCl} 2$ were added to each latex sample. The final concentrations of DTE, $\mathrm{MgCl}_{2}$, and MVA were 9.5 , 3.8 , and $0.22 \mathrm{mM}$, respectively.

At the end of the initial incubation period, one sample (205 $\mu$ l) was transfered to a tube in which $30 \mu\left[{ }^{3} \mathrm{H}\right] \mathrm{MVA}\left(10.3 \mathrm{mCi} \mathrm{mmol}^{-1}, 0.5 \mathrm{mCi} \mathrm{ml}^{-1}\right)$ had been taken to dryness under a stream of $\mathrm{N}_{2}$. Fifty microliters each of $20 \mathrm{mM}$ ATP pH 5.5, $1 \%$ BSA, and $3 \mathrm{mM}$ NADPH were added, and the sample was incubated an additional $2 \mathrm{~h}$. With the addition of the [ $\left.{ }^{3} \mathrm{H}\right] \mathrm{MVA}$, the specific activity of [ ${ }^{14} \mathrm{C}$ ]MVA changed little, from 50.1 to $48.6 \mathrm{mCi} \mathrm{mmol}^{-1}$; the specific activity of $\left[{ }^{3} \mathrm{H}\right.$ ]MVA was $291 \mathrm{mCi} \mathrm{mmol}^{-1}$.

The remaining three incubations were diluted to $1.5 \mathrm{ml}$ with REACTION BUFFER and centrifuged at $15,000 \mathrm{~g}$ for $15 \mathrm{~min}$. The supernatants and pellets were separated in each case. One set was immediately quenched in a toiling water bath. All supernatants were quenched. The pellet of the next sampie was resuspended in $200 \mu$ I REACTION BUFFER and placed in a tube in which $30 \mu \mathrm{l}\left[{ }^{3} \mathrm{H}\right] \mathrm{MVA}\left(10.3 \mathrm{mCi} \mathrm{mmol}^{-1}, 0.5 \mathrm{mCi} \mathrm{mi}^{-1}\right)$ and $50 \mu 11 \mathrm{mM} \mathrm{MVA}^{2}$, potassium salt had been dried under a stream of $\mathrm{N}_{2}$. Fifty microliters $20 \mathrm{mM}$ ATP pH 5.5, $50 \mu \mathrm{l} 100 \mathrm{mM}$ DTE. 50 $\mu 1 \%$ BSA, and 50 p 3 mM NADPH were added, and the sample was incubated for $2 \mathrm{~h}$. The tinat 
pellet was resuspended in $1.5 \mathrm{mI}$ REACTION BUFFER and recentrifuged as an additional wash of the pellet. The washed pellet was resuspended in $200 \mu$ REACTION BUFFER and incubated for $2 \mathrm{~h}$ with the same components as the third sample.

At the end of the second $2 \mathrm{~h}$ incubation period, all samples were quenched in a boiling water bath, and all samples were centrifuged to pellet the water-insoluble terpenes. The peilets were extracted with acetone and analyzed for labelled triterpenoids by $\pi L C$.

LIfetime of a prelncubated, washed $15,000 \mathrm{~g}$ pellet. Four $200 \mu \mathrm{l}$ latex samples were incubated for $2 \mathrm{~h}$ with $25 \mathrm{H} 2 \mathrm{mM}$ MVA, potassium salt and $\left.30 \mu \mathrm{l}^{3} \mathrm{H}\right] \mathrm{MVA}\left(10.3 \mathrm{mCl} \mathrm{mmol}^{-1}, 0.5\right.$ $\mathrm{mCi} \mathrm{ml} \mathrm{m}^{-1}$ ), dried in the incubation tube, and $15 \mu 145 \mathrm{mM}$ DTE and $15 \mu \mathrm{L} 58 \mathrm{mM} \mathrm{MgCl}$. The samples were diluted to $1.5 \mathrm{ml}$ with REACTION BUFFER and centrifuged at $15.000 \mathrm{~g}$ for $15 \mathrm{~min}$. The supematants were removed, and the pellet was resuspended in $1.5 \mathrm{ml}$ REACTION BUFFER, was transfered to a second tube, and recentrifuged. The final pellet was resusperided in $50 \mu l 20$ mM ATP pH 5.5, $50 \mu$ ل $104 \mathrm{mM}$ DTE, $50 \mu$ 1\% BSA, and $50 \mu \mathrm{J}$ mM NADPH and transfered to an incubation tube containing a dried sample of $25 \mu\left[\left[^{14} \mathrm{C}\right] M V A\left(50.1 \mathrm{mCi} \mathrm{mmol}^{-1}, 0.1 \mathrm{mCi} \mathrm{ml}^{-1}\right)\right.$. The incubations were quenched in a boiling water bath after $0.75,1.5,2.5$, and $4 \mathrm{~h}$ and analyzed for labelled triterpenoids by TLC.

Distribution of labelled trtterpenolds among fractions of latex first incubated as whole latex wit: [ [ $\left.{ }^{3} \mathrm{H}\right]$ acetate. Two $250 \mu$ aliquots of latex were each incubated with $20 \mu / 58 \mathrm{mM} \mathrm{MgCl}, 20 \mu l$ $145 \mathrm{mM} \mathrm{DTE}$, and $10 \mu\left[{ }^{3} \mathrm{H}\right]$ acetate $\left(2 \mathrm{Ci} \mathrm{mmol}^{-1}, 10 \mathrm{mCi} \mathrm{m}^{-1}\right)$, giving final concentrations of 4 $\mathrm{mM} \mathrm{MgCl} 2,10 \mathrm{mM} \mathrm{DTE}$, and $0.17 \mathrm{mM}$ acetate. After $3 \mathrm{~h}$ incubation, one of the samples was fractionated as shown in Fig. 1, and at $3.5 \mathrm{~h}$ all samples were quenched with methanol. Each Iraction was analyzed for labelted triterpenoids by TLC.

Test for soluble protein effectors of triterpenoid biosynthesis In latex. A $250 \mu$ sample of latex was incubated with $20 \mu 58 \mathrm{mM} \mathrm{MgCl} 2,20 \mu 145 \mathrm{mM}$ DTE, and MVA. The $30 \mu \mathrm{l}\left[{ }^{3} \mathrm{H}\right] \mathrm{MVA}$ (10.3 mCi mmol-1,0.5 $\mathrm{mCi} \mathrm{ml}^{-1}$ ), and $50 \mu 1 \mathrm{mM}$ MVA, potassium salt had been dried in the incubation tube belore the addition of latex and colactors; the final concentration of MVA was 


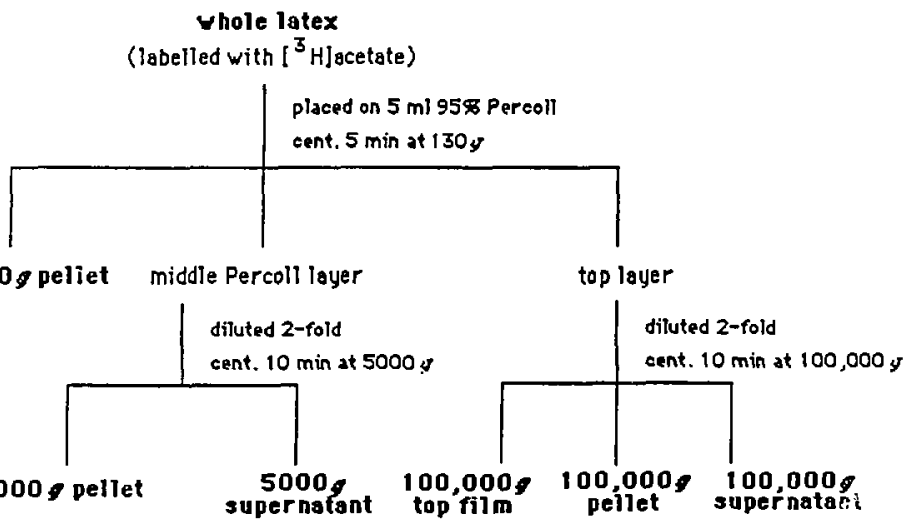

Fig. 1 Prepargtion of latex fractions for anelygis of distribution of labelled triterpenoids. 
$177 \mu \mathrm{M}$ at a specific activity of $0.29 \mathrm{Ci} \mathrm{mmol}^{-1}$. At $2 \mathrm{~h}$ a second 300 to $400 \mu$ of latex was diluted to ca $3 \mathrm{mil}$ with REACTION BUFFEF. The latex incubation was also diluted to $\mathrm{ca} 3 \mathrm{ml}$ with the buffer, and both samples were centrifuged at $100,000 \mathrm{~g}$ for $10 \mathrm{~min}$. The pellet from the labelled sample $(0.8 \mathrm{ml})$ was divided among four incubation fubes containing $50 \mu 1 \mathrm{mM}$ MVA, potassium salt. One milliliter of supematant from the unlabelled sample was added to two tubes; the third tube received $1 \mathrm{mI}$ REACTION BUFFER, and $\uparrow \mathrm{ml}$ REACTION BUFFER containing $30 \mathrm{mg} \mathrm{m}^{-1}$ BSA was added to the fourth. The first sample containing supernatant was immediately diluted to $3 \mathrm{ml}$ with REACTION BUFFER and centriluged at $100,000 \mathrm{~g}$ for $10 \mathrm{~min}$, and the supernatant and pellet were separated. One milliliter of the supematant and the pellet were quenched with methanol and analyzed by TLC for labelled triterpenoids. The remaining incubations were diluted, centrifuged, quenched, and analyzed as the first was after $2 \mathrm{~h}$ of incubation.

In a second experiment testing the effect of supernatant on the biosynthesis and distribution of labelled triterpenoids, a $250 \mu$ l sample of latex was incubated with $20 \mu / 58 \mathrm{mM}$

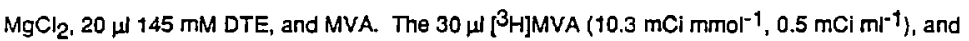
$50 \mu 11 \mathrm{mM}$ MVA, potassium salt had been dried in the incubation tube belore the addition of latex and cofactors; the final concentration of MVA was $\uparrow 77 \mu \mathrm{M}$ at a specific activity of $0.29 \mathrm{Ci} \mathrm{mmol}^{-1}$. After $3 \mathrm{~h}$ incubation, the latex incubation and a second $250 \mu$ of latex were diluted to $1.5 \mathrm{mi}$ with REACTION BUFFER. Both samples were centrifuged at $100,000 \mathrm{~g}$ for $15 \mathrm{~min}$. The pellet from the labelled sample was resuspended in $1 \mathrm{ml}$ REACTION BUFFER, and $200 \mu \mathrm{l}$ aliquots were subjected to four different treatments:

1. + 300 الـ unlabelled 100,000g supernatant + 108 ال 1 mM MVA, 2 h

$2 .+300 \mu$ unlabelled $100,000 \mathrm{~g}$ supematant $+108 \mu$ FEACTION BUFFER, $2 \mathrm{~h}$

3. + $300 \mu 130 \mathrm{mg} \mathrm{ml}^{-1}$ BSA in REACTION BUFFER + $108 \mu \mathrm{l} 1 \mathrm{mM} \mathrm{MVA,} 2 \mathrm{~h}$

4. $+300 \mu$ unlabelled $100,000 \mathrm{~g}$ supernatant + $108 \mu \mathrm{l} 1 \mathrm{mM} \mathrm{MVA}, 0 \mathrm{~h}$

Al the end of each incubation period, the sample was diluted to $1.5 \mathrm{ml}$ with REACTION BUFFEF and centrifuged at $100,000 \mathrm{~g}$ for $10 \mathrm{~min}$. The supernatants and pellets were separated and quenched in a boiling water bath. Each sample was centrifuged at $100,000 \mathrm{~g}$ for $10 \mathrm{~min}$, and 
the pellet was extracted with acetone and analyzed for labelled iriterpenoids by TLC.

Time course of affect of $100,000 \mathrm{~g}$ supernatant on triterpenold blosynthesis by $15,000 \mathrm{~g}$ pellet. Eight $200 \mu$ samples of latex were added together with $15 \mu / 45 \mathrm{mM}$ DTE and $15 \mu \mathrm{l} 58$ $\mathrm{mM} \mathrm{MgCl} 2$ to incubation tubes containing $25 \mu\left[^{14} \mathrm{C}\right] \mathrm{MVA}\left(50.1 \mathrm{mCi} \mathrm{mmol}^{-1}, 0.1 \mathrm{mCi} \mathrm{mi}^{-1}\right)$ that had been taken to dryness under a stream of $\mathrm{N}_{2}$. The samples were incubated $2 \mathrm{~h}$, diluted to 1.5 $\mathrm{ml}$ with REACTION BUFFER then centrifuged at $15,000 \mathrm{~g}$ for $15 \mathrm{~min}$. The supernatant of each sample was saved; the pellet was resuspended in $1.5 \mathrm{~m}$ REACTION BUFFER and recentrifuged. Each supernatant was again removed and combined with the first supernatant. The pellets were resuspended in a solution of $50 \mu 20 \mathrm{mM}$ ATP pH 5.5, $50 \mu 104 \mathrm{mM}$ DTE, $50 \mu 1 \%$ BSA, and 50 $\mu l 3 \mathrm{mM}$ NADPH and were transfered to a tube in which $25 \mu \mathrm{HM}$ MVA, potassium salt and $30 \mu \mathrm{ll}$ [H HIMVA (10.3 $\left.\mathrm{Ci} \mathrm{mmol}^{-1}, 0.5 \mathrm{mCi} \mathrm{ml}^{-1}\right)$ had been dried. Five hundred microliters REACTION BUFFER were added to four tubes designated as controls. The other four tubes received $500 \mu$ l of supernatant obtained by centriluging latex at $100,000 \mathrm{~g}$ for $15 \mathrm{~min}$.

At time points of $0.5,1,1.5$, and $2 h$, a control incubation ans a $100,000 \mathrm{~g}$ supernatant incubation were each diluted tc $1.5 \mathrm{ml}$ with REACTION BUFFER and centrifuged at $15,000 \mathrm{~g}$ for 15 min. The supernatant and pellet were separated, and each sample was quenched in a boiling water bath. Analysis of an acetone extract of each sample for labellod triterpenoids was done by TLC.

Effect of concentratlun of $100,000 \mathrm{~g}$ supematant on triterpenold biosynthesis by a $15,000 \mathrm{~g}$ pellet. One milliliter latex was diluted to $1.5 \mathrm{ml}$ with REACTION BUFFER and centrifuged for 15 min at $100,000 \mathrm{~g}$, providing the $100,000 \mathrm{~g}$ supematant for this experiment. A second milliiter of latex was divided among 5 tubes; each sample was diluted to $1.5 \mathrm{ml}$ with REACTION BUFFER and centrifuged for $15 \mathrm{~min}$ at $15,000 \mathrm{~g}$. The supernatant was removed, and the pellet was resuspended in $1.5 \mathrm{ml}$ REACTION BUFFER and recentrifuged. Each of these washed pellets was resuspended in a different combination of REACTION BUFFER and 100,000 g supernatant (Table II). Fifty microliters $20 \mathrm{mM}$ ATP pH 5.5, $50 \mu 104 \mathrm{mM}$ DTE, $50 \mu \mathrm{l}$ 1\% BSA, and $50 \mu \mathrm{l} 2.75$ mM NADPH were also added to each pellet, and each sample was placed in an incubation tube in 
which $25 \mu \mathrm{mM}$ MVA, potassium salt and $30 \mu \mathrm{l}\left[^{3} \mathrm{H}\right] \mathrm{MVA}\left(10.3 \mathrm{Ci} \mathrm{mmol}^{-1}, 0.5 \mathrm{mCi} \mathrm{mi}^{-1}\right)$ had been dried. After $1.5 \mathrm{~h}$ incubation, the samples were quenched by boiling and were analyzed for labelled triterpenoids (TLC).

Table II. Combination of $100,000 \mathrm{~g}$ supematant and REACTION BUFFEA incubated with $15,000 \mathrm{~g}$ pellet

\begin{tabular}{|c|c|c|c|c|}
\hline Sample & $\begin{array}{l}山 100,000 g \\
\text { supernatant }\end{array}$ & $\begin{array}{c}\mu \text { REACTION } \\
\text { BUFFER }\end{array}$ & $\begin{array}{l}\text {-fold dilution of } \\
\text { supematant }\end{array}$ & $\begin{array}{l}\text {-fold dilution of } \\
\text { pellet }\end{array}$ \\
\hline 1 & 0 & 300 & $\infty$ & 2.5 \\
\hline 2 & 50 & 250 & 15 & 2.5 \\
\hline 3 & 100 & 200 & 7.5 & 2.5 \\
\hline 4 & 200 & 100 & 3.75 & 2.5 \\
\hline 5 & 300 & 0 & 2.5 & 2.5 \\
\hline
\end{tabular}

HMG-Co A metabolism in latex. Once it was established that the conversion of MVA into tritemenoids took place in a particulate fraction of latex, a number of experiments were pertormed to locate the site of the enzyme HMG-CoA reductase.

HMG-CoA incubation 1-- Two hundred microliters latex was diluted to a volume of $1.5 \mathrm{ml}$ with REACTION BUFFER and was centrifuged $15 \mathrm{~min}$ at $15,000 \mathrm{~g}$. The cloudy supermatant was removed and recentrifuged at $100,000 \mathrm{~g}$ for 20 min giving a clear supernatant and a firm white pellet. The pellet was resuspended in $140 \mu$ REACTION BUFFER. The resuspended pellet and $140 \mu$ supernatant were each incubated with $20 \mu 104 \mathrm{mM}$ DTE, $40 \mu \mathrm{l} 10 \mathrm{mM}$ NADPH added to tube in which $\left.10 \mu \mathrm{l}^{3} \mathrm{H}\right] \mathrm{HMG}-\mathrm{CoA}\left(0.1 \mathrm{mCi} \mathrm{ml}^{-1}, 12.2 \mathrm{Ci} \mathrm{mmol}^{-1}\right)$ and $25 \mu \mathrm{l} 2 \mathrm{mM} \mathrm{HMG}-\mathrm{CoA}$ had been dried under a stream of $\mathrm{N}_{2}$. The total volume of each incubation was $200 \mu$ containing 2 mM NADPH and $260 \mu M$ HMG-CoA with a specific activity of $19.7 \mathrm{mCi}^{-1} \mathrm{~mol}^{-1}$. The samples were incubated $1.5 \mathrm{~h}$, were quenched by immersion in a boiling water bath for $1 \mathrm{~min}$, and were diluted 
to $1.5 \mathrm{ml}$ with $400 \mathrm{\mu l}$ each of $1 \mathrm{mg} \mathrm{ml}^{-1}$ sodium acetate, $1 \mathrm{mg} \mathrm{ml}^{-1} \mathrm{HMG}, 10 \mathrm{mM} \mathrm{MVA}^{-}$and $100 \mathrm{\mu l}$ REACTION BUFFER. They were centrifuged to pellet the denatured protein and were filtered through a $0.45 \mu \mathrm{m}$ filter. Fifty microliters of each sample was analyzerd for MVA production by Organic Acid HPLC.

HMG-CoA incubation 2- Tys $200 \mu l$ samples of latex were each diluted to $1.5 \mathrm{ml}$ with buffe one with REACTION BUFFER (PH 5.5) and second with buffer identical to REACTION BUFFER with the exception that the phthalate pH 5.5 was replaced by $10 \mathrm{mM} \mathrm{MOPS} \mathrm{pH} 7.2$. The measured pHs of the diluted latex samples were 5.5 and 6.7, respectively. Earh sample was centrifuged for $15 \mathrm{~min}$ at $15,000 \mathrm{~g}$, the supernatant was removed, mixed with $50 \mu 104 \mathrm{mM} \mathrm{DTE}$, and centriluged at $100,000 \mathrm{~g}$ for $\mathrm{f} \mathrm{h}$. The supernatant was removed, and the pellet was resuspended in $150 \mu \mathrm{l}$ buffer. The pellet and $150 \mu \mathrm{l}$ of the supematant of each pH treatment were incubated with $10 \mu \mathrm{l}\left[{ }^{3} \mathrm{H}\right] \mathrm{HMG}-\mathrm{COA}\left(0.1 \mathrm{mCi} \mathrm{mi}^{-1}, 12.2 \mathrm{Ci} \mathrm{mmol}^{-1}\right)$ and $25 \mu \mathrm{L} 2 \mathrm{mM} \mathrm{HMG-COA}$ had been dried under a stream of $\mathrm{N}_{2}$. In addition, $20 \mu 104 \mathrm{mM}$ DTE and $40 \mu 10 \mathrm{mM}$ NADPH were added to the incubation. The final concentrations of NADPH and HMG-CoA were $2 \mathrm{mM}$ and $254 \mu \mathrm{M}$ at a specific activity of $20 \mathrm{mCi} \mathrm{mil}^{-1}$. Samples were incubated $1.5 \mathrm{~h}$, quenched in a boiling water bath, and diluted to $1,5 \mathrm{ml}$ with with $325 \mu$ each of $1 \mathrm{mg} \mathrm{ml}^{-1}$ sodium acetate, $1 \mathrm{mg} \mathrm{mi} \mathrm{i}^{-1}$ HMG, $1 \mathrm{mg} \mathrm{ml}^{-1} \mathrm{MVA}_{\text {, and }} 200 \mu \mathrm{l} 0.25 \mathrm{mg} \mathrm{ml}^{-1}$ lithium acetoacetate. Samples were titrated to $\mathrm{pH}$ 11 with $\mathrm{KOH}$ and heated for 10 min at $55^{\circ} \mathrm{C}$ to hydrolyze the thiol esters. Next the pH was lowered to 3 with $\mathrm{H}_{2} \mathrm{SO}_{4}$ to allow formation of mevalonolactone and to ensure that the sample's $\mathrm{pH}$ was compatable with the $\mathrm{pH}$ of the organic acid HPLC column. Samples were fittered through a $0.45 \mu \mathrm{m}$ filter and analyzed by organic acid HPLC.

Effect of EDTA on HMG-COA metabollsm In Iatex. HMG-COA Incubation 3- Incubation of HMG-COA with $5000 \mathrm{~g}$ pellet and supernatant in the presence of $30 \mathrm{mM}$ EDTA-- Five hundred microliters latex was diluted with $1 \mathrm{ml}$ bulfer $10.4 \mathrm{M}$ sorbitol, $10 \mathrm{mM}$ phthalate $\mathrm{pH} 5.5,30 \mathrm{mM}$ EDTA, $1 \%$ BSA, $10 \mathrm{mM}$ DTE) and centrifuged $15 \mathrm{~min}$ at $5000 \mathrm{~g}$. The supernatant was removed, and the pellet was resuspended in $200 \mu$ butter. The pellet and $200 \mu /$ of the supernatant were each combined with $0.6 \mathrm{mg} \mathrm{NADPH}$, giving a NADPH concentration of $3.3 \mathrm{mM}$. Each sample was 
transtered to a tube in which $35 \mu \mathrm{d} 2 \mathrm{mM} \mathrm{HMG-CoA}$ and $\left.20 \mu \mathrm{l}^{3} \mathrm{H}\right] \mathrm{HMG}-\mathrm{CoA}\left(12.2 \mathrm{mCi}^{\mathrm{mmol}}{ }^{-1}\right.$, $0.1 \mathrm{mCi} \mathrm{ml}{ }^{-1}$ h had been taken to dryness under a stream of ive. The final concentration of HMG-CoA was $350 \mu \mathrm{M}$ at a specific activity of $28.5 \mathrm{mCi} \mathrm{mmol} \mathrm{m}^{-1}$.

The samples were incubated $1.5 \mathrm{~h}$ and were quenched in a boiling water bath. One hundred microliters each of $1 \mathrm{mg} \mathrm{ml}^{-1}$ solutions of MVAL, sodium acetate, and HMG anv $50 \mu$ of $1 \mathrm{mg} \mathrm{m}^{-1}$ lithium acetoacetate were added to the quenched incubations. Each sample was centrituged, and the supematants were recovered. The volume of each was brought to $1 \mathrm{ml}$, atd the samples were filtered through a $0.45 \mu \mathrm{m}$ titter before being analyzed by organic acid HPLC.

In addition, four injections of the $5000 \mathrm{~g}$ sample were chromatographed on the organic acid HPLC column, and the region where MVA elutes was collected and combined. An aliquot of $\left[{ }^{14} \mathrm{C}\right.$ MVA $(31500 \mathrm{dpm})$ was added as carrier, and the sample was brought to $\mathrm{pH} 11$ with $\mathrm{KOH}$ and heated at 30 to $40 \mathrm{C}$ for 30 min to open the lactone. The sample was divided into halves and

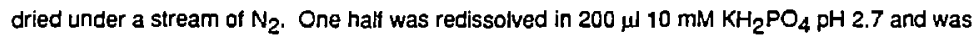
analyzed for labelled MVA by ODS-HPLC. The second hall was redissolved in a mixture of $5 \mu$ M MVA, potassium salt, $25 \mu$ concentrated $\mathrm{HCL}$, and $175 \mu$ water and allowed to sit $2 \mathrm{~h}$ to allow the WiVA to lactonize. It was analyzed for labelled MVA by TLC method 2. A second TLC analysis was pertormed on the remaining sample from the ODS-HPLC analysis, after aciditying the sample to form the lactone.

The residue from the $5000 \mathrm{~g}$ pellet incubation was extracted overnight with acetone and analyzed for labelled triterpenoids by $\mathrm{TLC}$.

HMG-CoA Incubation 4- Incubation of HMG-CoA with $7500 \mathrm{~g}$ pellet, $40.000 \mathrm{~g}$ pellet and supematant in the presence of 50 mM EDTA-- Eight hundred microliters latex was diluted to 1.5 $\mathrm{ml}$ with butfer ( $0.4 \mathrm{M}$ sorbitol, $10 \mathrm{mM}$ phthalate $\mathrm{pH} 5.5,50 \mathrm{mM}$ EDTA, $1 \%$ BSA, $10 \mathrm{mM}$ DTE) and centrifuged $15 \mathrm{~min}$ at $5000 \mathrm{~g}$. The supernatant was removed and recentrifuged at $7500 \mathrm{~g}$ for 30 min. The pellet was resuspended in $200 \mu$ buffer, and the supernatant was centrifuged for a third time at $40,000 \mathrm{~g}$ tor $30 \mathrm{~min}$. The $40,000 \mathrm{~g}$ pellet was also resuspended in $200 \mu \mathrm{l}$ buffer. The pellets and $200 \mu$ of the $40,000 \mathrm{~g}$ supernatant were each combined with $0.6 \mathrm{mg} \mathrm{NADPH}$, giving a 
NADPH concentration of $3.3 \mathrm{mM}$. Each sample was transfered to a tube in which $35 \mu \mathrm{m} 2 \mathrm{mM}$ HMG-COA and $20 \mu\left[\left[^{3} H\right] H M G-C O A\left(12.2 \mathrm{mCi} \mathrm{mmol}^{-1}, 0.1 \mathrm{mCi} \mathrm{ml}^{-1}\right)\right.$ had been taken to dryness under a stream of $\mathrm{N}_{2}$. The final concentration of HMG-CoA was $350 \mu \mathrm{M}$ at a specific activity of $28.5 \mathrm{mCi} \mathrm{mmol}^{-1}$.

The samples were incubated $1 \mathrm{~h}$ and were quenched in a boiling water bath. One hundred microliters each of $1 \mathrm{mg} \mathrm{mi}^{-1}$ solutions of MVAL, sodium acetate, and HMG anc $50 \mu \mathrm{f} \mathrm{of} 1 \mathrm{mg} \mathrm{ml}^{-1}$ lithium acetoacetate were added to the quenched incubations. Each sample was centriluged. and the supernatants were recovered. The volume of each was brought to $1.2 \mathrm{ml}$, and the samples were fittered through a $0.45 \mu \mathrm{m}$ filter before being analyzed by organic acid HPLC. The $40,000 \mathrm{~g}$ supematant was also analyzed for labelled MVA by TLC method 2.

HMG-CoA Incubations 5\&6- Incubation of HMG-CoA with $40,000 \mathrm{~g}$ supernatant, $100,000 \mathrm{~g}$ supernatant and pellet- One milliliter latex was diluted to $1.5 \mathrm{ml}$ with buffer $(0.4 \mathrm{M}$ sorbitol, $10 \mathrm{mM}$ phthalate pH 5.5, $50 \mathrm{mM}$ EDTA, $1 \%$ BSA, $10 \mathrm{mM} \mathrm{DTE}$ ) and centrifuged $30 \mathrm{~min}$ at $40,000 \mathrm{~g}$. The supematant was removed; a $200 \mu$ aliquot was taken for incubation with HMG-CoA; and the remainder was diluted to $1.5 \mathrm{ml}$ with buffer and recentrifuged at $100,000 \mathrm{~g}$ for $1 \mathrm{~h}$. The pellet was resuspended in $200 \mu$ buffer, and it and $200 \mu$ of the $100,000 \mathrm{~g}$ supematant were also taken for incubation with HMG-CoA. Each of the three different samples was combined with $0.6 \mathrm{mg}$ NADPH, giving a NADPH concentration of $3.3 \mathrm{mM}$. Each sample was transfered to a tube in which $35 \mathrm{H} 2 \mathrm{mM} \mathrm{HMG-COA}$ and $\left.20 \mathrm{H}^{3} \mathrm{H}^{3} \mathrm{H}\right] \mathrm{HMG}-\mathrm{CoA}\left(12.2 \mathrm{mcl} \mathrm{mmol}^{-1}, 0.1 \mathrm{mCi} \mathrm{mi}^{-1}\right)$ had been taken to dryness under a stream of $\mathrm{N}_{2}$. The final concentration of HMG-CoA was $350 \mu \mathrm{M}$ at a specific ac. sity of $28.5 \mathrm{mCl} \mathrm{mmol}{ }^{-1}$.

The samples were incubated $1.5 \mathrm{~h}$ and were quenched in a boiling water bath. Each sample was centrifuged, and the supernatants were recovered. [ ${ }^{14} \mathrm{C}$ MVAL (2380 dpm) and $1 \mu$ 1 M MVA, potassium salt were added as a merker and carrier. The samples were acidified to $\mathrm{pH} 3$ with $\mathrm{HCl}$ to promote formation of MVAL. Each sample was analyzed for labelled MVA by TLC method 2.

This experiment was repeated with the following exceptions: samples were incubated $1 \mathrm{~h}$ 
then quenched with $25 \mu$ concentrated $\mathrm{HCl}$. [ [ ${ }^{14} \mathrm{CIMVA}(41240 \mathrm{dpm})$ and $20 \mu \mathrm{l} 0.5 \mathrm{M} \mathrm{MVAL}$ were added as cartier. The samples were centrituged to obtain a clear supertatant. The pellets were washed in $200 \mu \mathrm{l}$ water, recentrifuged, and the wash was combined with the first supernatant. Each sample was divided in half; half was analyzed for labelled MVAL by TLC method 2. The MVAL band was eluted with ether: $10 \%$ was counted, and the remainder was dried under a stream of $\mathrm{N}_{2}$ then resuspended in $250 \mu \mathrm{\mu l} 10 \mathrm{mM}$ potassium phosphate $\mathrm{pH} 2.7$. A $50 \mu \mathrm{l}$ aliquot was analyzed by ODS HPLC.

HMG-COA reductase actlvity of buffered $100,000 \mathrm{~g} \mathrm{mix}$, supernatant, and pellet. HMG-COA Incubation 7 - One half milliliter of latex was diluted to $1 \mathrm{ml}$ with buffer $(20 \mathrm{mM}$ MES pH $6.5,0.4 \mathrm{M}$ sorbitol, $60 \mathrm{mM}$ EDTA, $20 \mathrm{mM}$ DTE, $5 \mathrm{mM}$ NADPH). The resulting solution was divided into two samples which were centrifuged at $100,000 \mathrm{~g}$ for $30 \mathrm{~min}$. The top lipid film was removed from each of the tubes; the supematant was removed from one tube, and the pellet was gently resuspended in $0.25 \mathrm{ml}$ buffer (10 mM MES pH 6.5, 0.4 M sorbitol, $30 \mathrm{mM}$ EDTA, $10 \mathrm{mM}$ DTE, $2.5 \mathrm{mM}$ NADPH). The supernatant and pellet of the second tube were gently mixed with a brush. Two hundred fifty microliters each of the supernatant, pellet, and mix were incubated with $10 \mu \mathrm{l}$ $\left[{ }^{3} \mathrm{H}\right] \mathrm{HMG}-\mathrm{CoA}\left(12.2 \mathrm{Ci} \mathrm{mmol}^{-1}\right)$ and $37.5 \mu \mathrm{l} 2 \mathrm{mM}$ HMG-CoA that had been dried under a stream of $\mathrm{N}_{2}$. The final concentration in the incubation mixture was $300 \mu \mathrm{MHMG-CoA}$. Samples were incubated $1.5 \mathrm{~h}$ and quenched with $50 \mu$ concentrated $\mathrm{HCl}, 100 \mu l$ standards $(1.25 \mathrm{mg} \mathrm{m})^{-1}$ HMG, $0.1 \mathrm{mg} \mathrm{m}^{-1}$ ACAC, $0.25 \mathrm{mg} \mathrm{ml}^{-1} \mathrm{AC}$ and $0.25 \mathrm{mg} \mathrm{ml}^{-1} \mathrm{MVA}$ ), and $100 \mu \mathrm{l}^{14} \mathrm{C} \mathrm{MVA,} \mathrm{DBEB}$ salt $(10,200 \mathrm{dpm})$. The samples were centrifuged to pellet the precipitated protein, and the supematants were analyzed for labelled MVA by OA-HPLC.

HMG-CoA reductase actlvity of latex fractions. HMG-CoA Incubation 8- One milliliter iatex was diluted to $1.5 \mathrm{ml}$ with buffer (10 $\mathrm{mM}$ MES, $10 \mathrm{mM}$ DTE, $30 \mathrm{mM}$ EDTA, $0.4 \mathrm{M}$ sorbitol, pH 6.5) and subjected to the centrifugation scheme outlired in Fig. 2. Before the next centrifugation step, $200 \mu \mathrm{l}$ of each supernatant was removed. Of this, half was sonicated for $30 \mathrm{~s}$ then incubated for $1 \mathrm{~h}$ v: $:$ h [ $3 \mathrm{H}$ HMG-CoA.

The $5000 \mathrm{~g}$ and $50,000 \mathrm{~g}$ pellets were resuspended in $1.6 \mathrm{ml}$ bulfer and were sonicated 30 


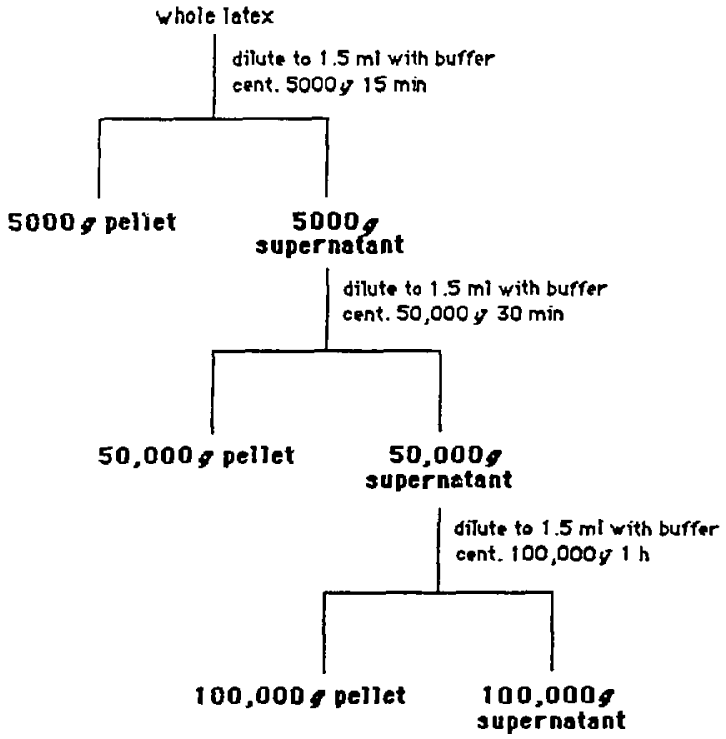

Fig. 2. Preperation of latex frections for angi ysis of distribution of HMG-COA reductese sctivity. 
s: a $100 \mathrm{\mu liquot}$ was removed, and the remaining volume was centrifuged at $100,000 \mathrm{~g}$ for $1 \mathrm{~h}$. The pellet was resuspended in $100 \mu$ buffer, sonicated $30 \mathrm{~s}$, and incubated $1 \mathrm{~h}$ with [ $\left.{ }^{3} \mathrm{H}\right] \mathrm{HMG}-\mathrm{COA}$. The $100,000 \mathrm{~g}$ pellet was resuspended in $100 \mu$ butfer, sonicated $30 \mathrm{~s}$, and incubated $1 \mathrm{~h}$ with $\left[{ }^{3} \mathrm{H}\right] \mathrm{HMG}-\mathrm{CoA}$.

The incubations were done in prepared vials containing $0.33 \mu \mathrm{mol}$ NADPH (Sigma) in which $15 \mathrm{\mu l} 2 \mathrm{mM}$ HMG-COA and $\left.10 \mu / l^{3} \mathrm{H}-\mathrm{HMG}-\mathrm{COA}\right]\left(12.2 \mathrm{Ci} \mathrm{mmol}^{-1}, 0.1 \mathrm{mCi} \mathrm{m}^{-1}\right)$ had been taken to dryness under a stream of $\mathrm{N}_{2}$. The tinal concentrations were $3,3 \mathrm{mM} \mathrm{NADPH}$ and $301 \mu \mathrm{M}$ HMG-COA at a specific activity of $33 \mathrm{mCi} \mathrm{mmol}^{-1}$.

The incubations were quenched with $50 \mu l 10 \mathrm{~N} \mathrm{KOH}$, then aciditied with $75 \mu \mathrm{l}$ concentrated HCl; $20 \mu$ l $0.5 \mathrm{M}$ mevalonolactone and $20 \mu$ [ $\left.^{14} \mathrm{C}\right] \mathrm{MVA}(8230 \mathrm{dpm}$ ) were added as carriers. The samples were centrifuged to pellet the precipitated protein, and the supernatants were spotted onto silica gel G $500 \mu \mathrm{m} 20 \times 20 \mathrm{~cm}$ plates which were dovaloped in 1:1 acetone: benzene. Neat MVAL was used as the marker spot; the band corresponding to the marker was scraped, and the MVAL was eluted from the silica gel with ether. A $10 \%$ aliquot of the eluant was counted, and the solvent was evaporated from the remaining sample under a stream of $\mathrm{N}_{2}$. The precipitate was resuspended in $150 \mu$ of $0.0025 \mathrm{~N} \mathrm{H}_{2} \mathrm{SO}_{4}$, and a $50 \mu$ sample was analyzed by OA HPLC.

HMGR In 5000g supematant and pellet. HMG-COA Incubations 9810 - One milliiter latex was diluted to $1.5 \mathrm{ml}$ with buffer (10 $\mathrm{mM}$ MES pH 6.5, $10 \mathrm{mM}$ DTE, $30 \mathrm{mM}$ EDTA, $0.4 \mathrm{M}$ sorbitol) and was centrituged at $5000 \mathrm{~g}$ for $15 \mathrm{~min}$. The supernatant was removed, and the pellet was resuspended in $1.5 \mathrm{ml}$ buffer and sonicated $30 \mathrm{sec}$. The pellet suspension was centriluged at $100,000 \mathrm{~g}$ for $1 \mathrm{~h}$. The $100.000 \mathrm{~g}$ supernatant was removed, and the pellet was resuspended in $250 \mu \mathrm{l}$ buffer. Four incubation vials were prepared by drying $30 \mu \mathrm{l} 2 \mathrm{mM} \mathrm{HMG-CoA}$ and $20 \mu \mathrm{l}$ $\left[{ }^{3} \mathrm{H}\right\} \mathrm{HMG}-\mathrm{COA}\left(12.2 \mathrm{Ci} \mathrm{mmor}^{-1}, 0.1 \mathrm{mCi} \mathrm{mi}^{-1}\right)$ under a stream of $\mathrm{N}_{2}$ in a vial containing $0.66 \mu \mathrm{mol}$ NADPH. The tour samples added to the vials were $100 \mu \mathrm{l} 5000 \mathrm{~g}$ supernatant $+100 \mu$ bulfer, $200 \mu 5000 \mathrm{~g}$ supematant, $200 \mu \mathrm{l} 100,000 \mathrm{~g}$ supernatant, and $200 \mu \mathrm{l} 100,000 \mathrm{~g}$ pellet. The 
$5000 \mathrm{~g}$ supernatant samples were sonicated prior to the incubation. The final concentrations were $3.3 \mathrm{mM} \mathrm{NADPH}$ and $300 \mu \mathrm{M}$ HMG-CoA at a specific activity of $33 \mathrm{mCl} \mathrm{mmol}^{-1}$.

Each sample was incubated $1 \mathrm{~h}$ then quenched with $50 \mu 10 \mathrm{~N} \mathrm{KOH}$; after 30 min, $75 \mu \mathrm{l}$ concentrated $\mathrm{HCl}, 10 \mu \mathrm{\mu} 0.5 \mathrm{M} \mathrm{MVAL}$, and $20 \mu$ I $^{14} \mathrm{CJMVA}(2540 \mathrm{dpm}$ ) were added. The samples were analyzed for labelled MVAL by TLC method 2. The MVAL band was eluted with ether of which a $10 \%$ aliquot was counted. The solvant of the remainder of the eluate was removed under a stream of $\mathrm{N}_{2}$, and the residue was redissolved in $150 \mu l 0.0025 \mathrm{~N} \mathrm{H}_{2} \mathrm{SO}_{4}$ and analyzed by organic acid HPLC. Samples were also analyzed by ODS-HPLC.

A second experiment looked at the HMGR activity of the $5000 \mathrm{~g}$ supernatant and $100,000 \mathrm{~g}$ pellet prepared in the same manner but without EDTA in the buffer. Samples were analyzed by TLC followed by ODS-HPLC.

Localization of HMGR In latex Iractions. HMG-COA Incubation 11 - Latex was subjected to the differential centrifugation scheme diagramed in Fig. 3. This scheme was based on work which localized Pisum seedlings HMGR in the neavy microsomal fraction (P3) (3). A volume of 1.5 $\mathrm{ml}$ latex was collected into a tube where $114 \mu \mathrm{J} 0.4 \mathrm{M}$ EDTA and $60 \mu \mathrm{J} 0.25 \mathrm{M}$ DTE had been dried under $\mathrm{N}_{2}$. making the final concentrations $30 \mathrm{mM}$ EDTA and $10 \mathrm{mM}$ DTE, and centrifuged as shown, with each pellet being resuspended in $300 \mu$ bufier (100 mM MES, $30 \mathrm{mM}$ EDTA, $10 \mathrm{mM}$ DTE, $0.4 \mathrm{M}$ sorbitol, pH 5.9). For each incubation, $150 \mu$ sample was added to 5 山l $\left[{ }^{3} \mathrm{H}\right] \mathrm{HMG} \cdot \mathrm{CoA}$ $\left(0.1 \mathrm{mCi} \mathrm{ml}^{-1}, 11.7 \mathrm{Ci} \mathrm{mmol}^{-1}\right), 45 \mu 2 \mathrm{mM} \mathrm{HMG}-\mathrm{COA}$, and $15 \mu 25 \mathrm{mM}$ NADPH which had been dried under $\mathrm{N}_{2}$ in the incubation tube. The final concentrations of the substrates were $600 \mu \mathrm{M}$ HMG-COA at a specific activity of $5.6 \mathrm{mCl} \mathrm{mmol}^{-1}$ and $2.5 \mathrm{mM} \mathrm{NADPH}$. The samples were incubated $2 \mathrm{~h}$ at $28^{\circ} \mathrm{C}$ then quenched by addition of $15 \mu 6 \mathrm{M} \mathrm{HCl}$ with $15 \mu \mathrm{M} \mathrm{M} \mathrm{MVA}$, potassium salt and $5 \mu\left({ }^{14} \mathrm{C}\right.$ )MVA, DBED salt (4998 dpm). The samples were allowed to sit 10 min to promote lactonization of the MVA and were then kept frozen overnight. Seventy live microliters water was added to each, and the samples were centriluged $30 \mathrm{~min}$ at $12,000 \mathrm{~g}$. The supernatants were filtered through $0.45 \mu \mathrm{m}$ filters, and their volume brought to $250 \mu \mathrm{l}$ with water. 


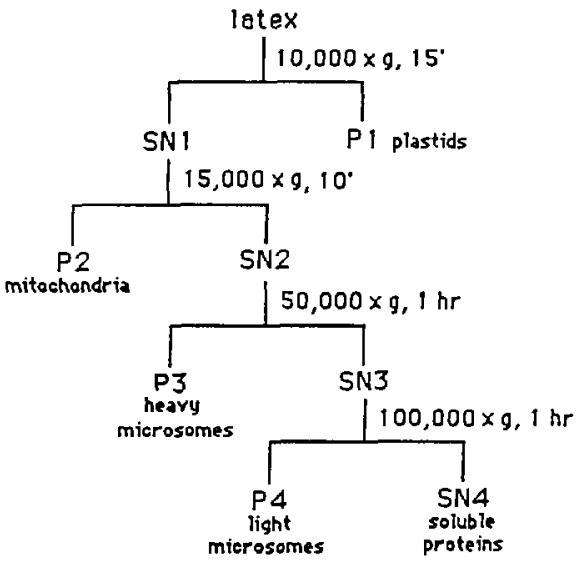

Fig. 3 Fractionstion of latex for anal ysis of the distribution of HMG-COA reductage activity. 
Aliquots of $100 \mu$ were analyzed for labelled MVAL by TLC $\left(\mathrm{CHCl}_{3}\right.$ : acetone, 2:1) followed by chromatography by HPLC using the ODS-potassium phosphate system.

HMGR activity of $100,000 \mathrm{~g}$ Mix. A $1.5 \mathrm{ml}$ sample of latex was centrifuged at $100,000 \mathrm{~g}$ tor 1 h. The supematant and pellet were mixed, and various volumes of the mixture were incubated with the HMG-COA substrate and cofactors which had been dried in the incubation vials (Table III).

Table III. Incubation Components for Determination of HMG-CoA Reductase Activity versus Volume of $100,000 \mathrm{~g}$ Mix

\begin{tabular}{|c|c|c|c|c|}
\hline & 1 & 2 & 3 & 4 \\
\hline $100,000 \mathrm{~g}$ Mix & 50 & 100 & 175 & 275 \\
\hline $\begin{array}{l}\mu\left[\left[^{3} \mathrm{H}\right] \mathrm{HMG}-\mathrm{CoA}\right. \\
\left(12.2 \mathrm{Ci} \mathrm{mmol}{ }^{-1}\right. \\
\left.0.1 \mathrm{mCi} \mathrm{ml}^{-1}\right\rangle\end{array}$ & 2.5 & 5 & 8.75 & 13.75 \\
\hline$\mu 2 \mathrm{mM}$ HMG-CoA & 7.5 & 15 & 26.25 & 41.25 \\
\hline W $0.1 \mathrm{M} \mathrm{DTE}$ & 5 & 10 & 17.5 & 27.5 \\
\hline 山 $50 \mathrm{mM}$ NADPH & 2.5 & 5 & 8.75 & 13.75 \\
\hline
\end{tabular}

The final concentrations in all incubations were $300 \mu \mathrm{M} \mathrm{HMG}-\mathrm{COA}$ at a specific activity of $17 \mathrm{mCi}$ $\mathrm{mmol}^{-1}, 10 \mathrm{mM}$ DTE, $30 \mathrm{mM}$ EDTA, and $2.5 \mathrm{mM} \mathrm{NADPH}$. Each incubation was quenched after $1.5 \mathrm{~h}$ with concentrated $\mathrm{HCl}:{ }^{14} \mathrm{C}$ MVA $(20520 \mathrm{dpm})$ and aliquots of a mixiure containing 1.25 $\mathrm{mg} \mathrm{mi} \mathrm{I}^{-1}$ each of HMG, sodium acetate, and MVAL and $0.25 \mathrm{mg} \mathrm{m}^{-1}$ lithium acetoacetate were added as carriers. The samples were centrifuged; the supernatants were diluted to $0.5 \mathrm{ml}$, and $50 \mu$ was analyzed by organic acid HPLC.

TIme course of HMGR activity of $100,000 \mathrm{~g}$ supernatant. Latex $(0.5 \mathrm{ml})$ was diluted with an equal volume of butfer containing $0.4 \mathrm{M}$ MOPS pH6.5, $60 \mathrm{mM}$ EDTA, $0.4 \mathrm{M}$ 50rtiol, and $20 \mathrm{mM}$ DTE and was ceritrifuged for $30 \mathrm{~min}$ at $100,000 \mathrm{~g}$. Four $200 \mu$ samples of the $100,000 \mathrm{~g}$ supematant were each incubated with $30 \mathrm{w} 2 \mathrm{mM}$ HMG-CoA, $\left.10 \omega]^{3} \mathrm{H}\right] \mathrm{HMG}-\mathrm{CoA}[12.2 \mathrm{Ci}$ 
$\left.\mathrm{mmol}^{-1}\right\}$, and 100 ul $5 \mathrm{mM}$ NADPH in methanol which had been taken to dryness under a stream of $\mathrm{N}_{2}$. After time periods of $30 \mathrm{~min}, 1,2$, and $3 \mathrm{~h}$, the incubations were quenched with $50 \mu \mathrm{l}$ concentrated $\mathrm{HCl}, 100 \mu{ }^{14} \mathrm{C}$ MVA, DBED salt, and $100 \mu$ containing standards. The samples were analyzed by OA.HPLC.

Ammonlum sulfate fractionation of HMG-CoA reductase of latex. A volume of latex $(1.5 \mathrm{ml})$ was diutsd with an equal volume of buffer (20 mM MES pH 6.5, $60 \mathrm{mM}$ EDTA, $20 \mathrm{mM}$ DTE, $0.4 \mathrm{M}$ sorbitol) and was centrifuged at $100,000 \mathrm{~g}$ for $30 \mathrm{~min}$. The supernatant was removed, and two aliquots each $150 \mu \mathrm{l}$ were taken for HMGR and protein assays. The remaining sample was brought to $30 \%$ saturation in ammonium sulfate and was stirred for $15 \mathrm{~min}$. The sample was centrifuged for $15 \mathrm{~min}$ at $10,000 \mathrm{~g}$. The supernatant was removed, brought to $70 \%$ saturation with ammonium sulfate, and centrifuged as before. Both pellets were resuspended in $300 \mu$ bufter comfaining $10 \mathrm{mM}$ MES pH 6.5, $30 \mathrm{mM}$ EDTA, $10 \mathrm{mM}$ DTE, and 0.4 M sorbitol. HMGA activity was measured by incubation of $150 \mu$ of sample with $\left.\left.10 \mu]^{3} \mathrm{H}\right] \mathrm{HMG}-\mathrm{CoA}\left(12.2 \mathrm{Ci} \mathrm{mmol}^{-1}\right), 22.5 \mu\right) 2$ mM HMG-CoA, and $7.5 \mu 50 \mathrm{mM}$ NADPH; all had been taken to dryness under a stream of $\mathrm{N}_{2}$. After $1.5 \mathrm{~h}$ incubation the samples were quenched in a boiling water bath. They were analyzed for labelled MVA by OA-HPLC. Protein content was determined by PROTEIN ASSAY 2.

pH effect on latex HMGF. Latex $(1.5 \mathrm{~mL})$ was added to $112.5 \mu \mathrm{l} 0.4 \mathrm{M}$ EDTA and $60 \mu \mathrm{l} 0.25$ M DTE that had been dried under $\mathrm{N}_{2}$ in the centrifuge tube giving final concentrations of $30 \mathrm{mM}$ EDTA and $10 \mathrm{mM}$ DTE and was centrifuged at $100,000 \mathrm{~g}$ for $30 \mathrm{~min}$. The lipid film was removed, and the clear supematant and white pel!et were mixed giving $950 \mu$ of a solution of pH 4.6. A 200 $\mu l$ aliquot was removed, $150 \mu$ laken for HMGR assay and $50 \mu$ tor protein determination. The mix was brought to $70 \%$ saturation with $0.49 \mathrm{~g}$ pulverized ammonium sullate. The tube was rinsed with buffer (100 mM MES, $30 \mathrm{mM}$ EDTA, $10 \mathrm{mM}$ DTE, $\mathrm{pH} 6.0$ ) also $70 \%$ saturated with ammonium sulfate. The mix and rinse were combined and centrituged $15 \mathrm{~min}$ at $10,000 \mathrm{~g}$. The supernatant was removed, and the peflet was resuspended in $400 \mu$ buffer. The protein fraction was desalted on a $5 \mathrm{ml} \mathrm{G}-25$ column equilibrated with bufter. The $A_{280}$ of the eluant was monitored, and a 1-ml 
fraction containing the protein was collected. Of this fraction. $50 \mu$ was taken for protein analysis and $150 \mu l$ was assayed for HMGR activity $(\mathrm{pH} 6.1$ ). Two $300 \mu l$ aliquots were taken from the remaining protein solution; one was brought to $\mathrm{pH} 5.4$ with $7.5 \mu \mathrm{I} \mathrm{M} \mathrm{HCl}$, and the second was brought to $\mathrm{pH} 6.6$ with $7.5 \mu 1 \mathrm{M} \mathrm{KOH}$. A $150 \mu$ aliquot of each was used for the HMGR assay.

Each $150 \mu \mathrm{l}$ sample selected for HMGR activity assay was incubated with $10 \mu \mathrm{l}$ [3 H]HMG-CoA (0.1 mCi mmol-1, $\left.11.7 \mathrm{Ci} \mathrm{mmol}^{-1}\right), 22.5 \mu \mathrm{l} 2 \mathrm{mM} \mathrm{HMG-CoA}$, and $15 \mu \mathrm{ll} 25 \mathrm{mM}$ NADPH that had been dried under a stream of $\mathrm{N}_{2}$ in the incubation tube. The tinal concentrations were $300 \mu \mathrm{M} \mathrm{HMG-CoA}$ at a specific activity of $22 \mathrm{mCi} \mathrm{mmol}^{-1}$ and $2.5 \mathrm{mM}$ NADPH. The incubations were quenched at one hour with $7.5 \mu$ l concentrated $\mathrm{HCl}$ and $100 \mu l$ [ $\left.{ }^{14} \mathrm{C}\right]$ MVA, DBEB sait (10061 dpm) and $51 \mathrm{M}$ MVA, potassium salt were added as carrier. The samples were then cantrifuged at $12,000 \mathrm{~g}$ for $15 \mathrm{~min}$ and filtered through a $0.45 \mu \mathrm{m}$ filter to remove particulates. A $50 \mu$ aliquot was assayed for labelled MVA by organic acid HPLC. The samples reserved for protein analysis were assayed by PROTEIN ASSAY 2.

Substrate saturatlon for HMGR in desalted $70 \%$ ammonium sulfate fractlon. A 1.5 ml latex sample was mixed with EDTA and DTE to give a final concentration of $30 \mathrm{mM}$ EDTA and $10 \mathrm{mM}$ DTE. The sample was centrituged at $100,000 \mathrm{~g}$ for $30 \mathrm{~min}$. The surface lipid film was removed, and the supematant ano pellet were mixed, giving a solution with a $\mathrm{pH}$ of 4.7. A total of $250 \mu \mathrm{l}$ was removed from the mixture for HMGR activity and protein assays. The remaining volume was brought $1070 \%$ saturation in ammonium sulfate and centrifuged at $10,000 \mathrm{~g}$ for $15 \mathrm{~min}$. The pellet was resuspended in $400 \mu$ buffer (100 mM MES, 30 mM EDTA, $10 \mathrm{mM}$ DTE, pH 5.9) and desalted on a $5.4 \mathrm{ml} \mathrm{G}-25$ column equilibrated with butfer. Out of the $1.15 \mathrm{mi}$ volume which contained the protein, five 150 aliquots were incubated with various amounts of HMG-CoA and $2.5 \mathrm{mM}$ NADPH for $1 \mathrm{~h}$ (Table IV). All ineubations were quenched with $7.5 \mu$ concentrated $\mathrm{HCl}, 5$ $\mu 1$ M MVA, potassium salt, and $100 \mu l\left[{ }^{14} \mathrm{C}\right] \mathrm{MVA}(10,000 \mathrm{dpm})$ and were then centrifuged at $12,000 \mathrm{~g}$ for $15 \mathrm{~min}$. The solutions were filtered through a $0.45 \mu \mathrm{m}$ filter and were analyzed for labelled MVA by organic acid HPLC. Protein content was determined by PROTEIN ASSAY 2. 
Table IV. Quantity of HMG-COA used in HMG-COA Reductase Substrate Saturation Experiment

\begin{tabular}{|c|c|c|c|}
\hline Incubation & $\begin{array}{l}\text { Final Concentration } \\
\qquad \mu M \text { HMG-CoA }\end{array}$ & 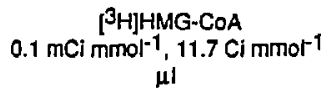 & $\begin{array}{c}2 \mathrm{mM} H \mathrm{HM}-\mathrm{COA} \\
\mathrm{Hl}\end{array}$ \\
\hline $\begin{array}{l}1 \\
2 \\
3 \\
4 \\
5\end{array}$ & $\begin{array}{r}300 \\
150 \\
75 \\
50 \\
25\end{array}$ & $\begin{array}{l}10 \\
5 \\
2.5 \\
1.7 \\
0.8\end{array}$ & $\begin{array}{c}22.5 \\
11.25 \\
5.6 \\
3.75 \\
1.87\end{array}$ \\
\hline
\end{tabular}




\section{RESULTS AND DISCUSSION}

Effect of substrate concentration on trlterpenold biosynthesis. A series of experiments investigating the effect of the concentration of either acetate or mevalonic acid on the biosynthesis of triterpenoids in latex from these precursors were performed. The first two sets of experiments in which the concentration of acetate supplied to the latex was varied established that the maximum biosynthesis of both triterpenols and triterpene esters occured at an acetate level of $0.25 \mathrm{mM}$ (Fig. 4). Above this concentration, triterpenol biosynthesis remained level up to $3 \mathrm{mM}$, the highest concentration tested. Triterpene ester biosyrthesis was relatively level between acetate concentrations or 0.25 to $1 \mathrm{mM}$. Above $1 \mathrm{mM}$ acetate, the incorporation of acetate into the esters dropped steadily as the concentration of acetate increased, until at $3 \mathrm{mM}$ acetate, the incorporation was less than half the maximum incorporation. The maximum amount of acetate incorporated into total triterpenoids was $56 \mathrm{pmol} 100 \mu$ latex ${ }^{-1} \mathrm{~h}^{-1}$ or 9.3 pmol $\mathrm{ml}^{-1} \mathrm{~min}^{-1}$. This tumover rate was two orders of magnitude less than the incorporation of acetate into rubber in Hevea latex where an acetate concentration of greater than $890 \mu M$ was saturating (1).

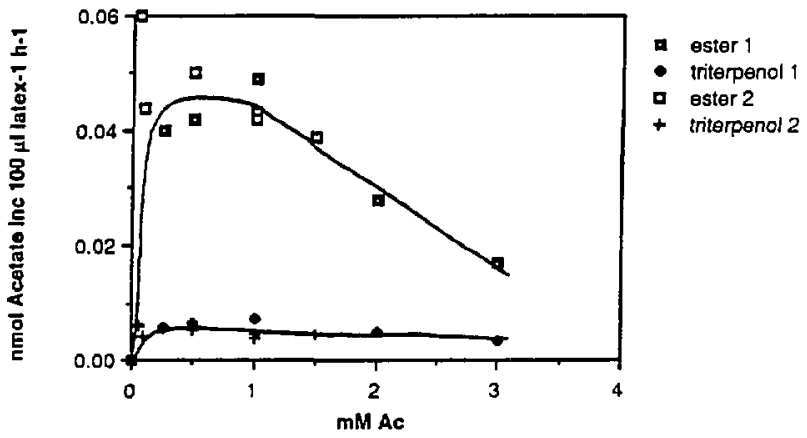

Fig. 4. Effect of concentration of substrate acetate on the biosynthesis of triterpenoids in whole latex. 
The initial experiments testing the effect of MVA concentration on its incorporation into triterpenoids were done with centrifuged latex where the biosynthetic level was greatly reduced compared to later experiments performed with whole latex (Fig. 5). However, these initial experiments did show that the incorporation of MVA into triterpenoids continued to rise as the concentration of MVA was raised to the highest level of $1.1 \mathrm{mM}$. When whole latex was incubated with MVA concentrations varying from 1 to $5 \mathrm{mM}$, the incorporation of MVA into triterpenoids was constant for all levels indicating that $1 \mathrm{mM}$ MVA was probably saturating.
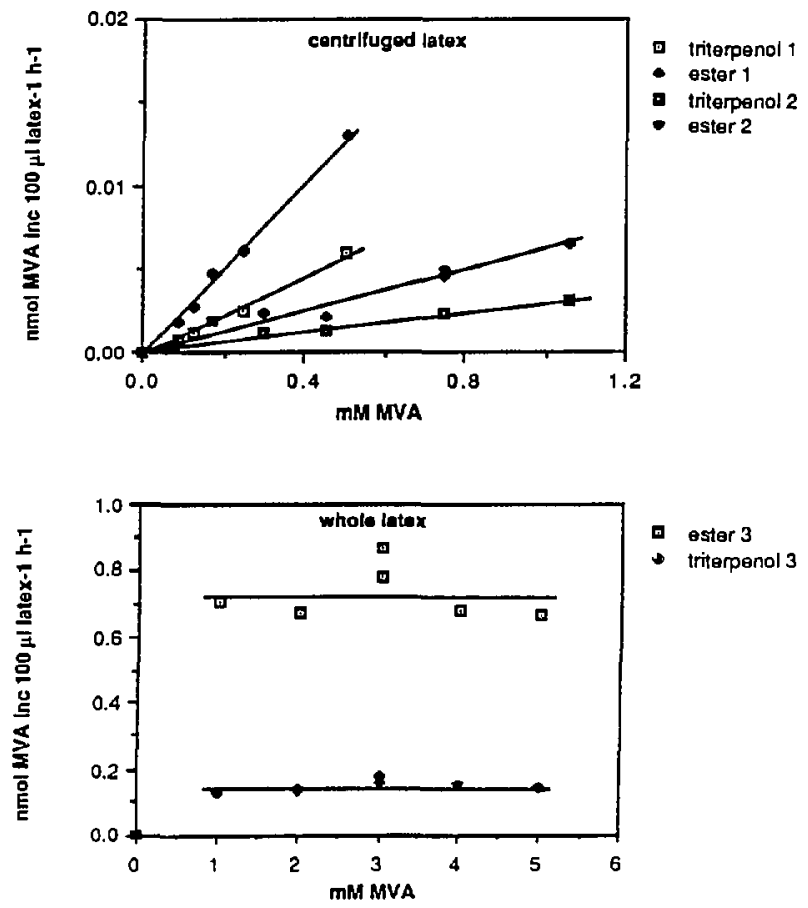

Fig. 5. Effect of concentration of substrate mevalonate on the biosynthesis of triterpenoids in centrifuged and whole latex. 
This was confirmed in a final experiment where different concentrations of both acetate and MVA were incubated with aliquots of latex from the same sample (Fig. 6). MVA incorporation into both triterpenols and their esters levels at 1 mM MVA. Here no acetate inhibition of triterpene ester biosynthesis was seen; incorporation began to level off at $0.25 \mathrm{mM}$ acetate but still increased slowly up to $\$ .5 \mathrm{mM}$ acetale, the highest concentration tested. Acetate incor, oration into triterpenols was level from $0.25 \mathrm{mM}$ acetate on up.

The maximum rate of incorporation of MVA into both the triterpenols and their esters obtained was $0.55 \mathrm{nmol} 100 \mu$ latex $^{-1} \mathrm{~h}^{-1}$ in the third MVA incorporation experiment. For comparison, the saturating concentration of MVA for rubber biosynthesis in Hevea latex is greater than $3.6 \mathrm{mM}$, and the maximum incorporation is $30 \mathrm{nmol} \mathrm{mi}^{-1} \mathrm{~min}-1$, around 300 times greater than the incorporation of MVA into triterpenoids in E. lashyris latex (1).

A comparison of the rates of incorporation of AC and MVA into triterpenoids indicates that the rate-determining step in the pathway occurs prior to MVA. Under saturating substrate conditions, MVA incorporation is 25 times greater than AC incorporation (Fig. 7). Taking into account that it takes three acetate molecules to torm one mevalonate and that the triterpenoids are tormed from six mevalonates, the rate of formation of Triterpenoid equivalents" irorr. MVA is one hundred times that from acetate. A similar, but not as dramatic situailon was seen when Acer pseudopatinus suspension cultures were incubated with saturating levels of Ac (1 mM) and MVA ( $5 \mathrm{mM}$ ); sterol biosynthesis was 2.3 times higher with MVA as the precursor (9). Of the four enzymes required to convert acetate into mevalonate: acetyl-CoA synthetase, thiolase. HMG-CoA syntriase, and HMG-CoA reductase, the reductase has been shown to be the rate-limiting step in mammalian cholesteral biosynthesis (4).

Propertles of the site of triterpenold blosynthesis In latex. Ulitimately, a particle capable of converting MVA into triterpenoids was isolated by centrifugation of latex at $5000 \mathrm{~g}$ (24). Attempts to first purify this structure on Percoll gradients were unsuccessiul. Although Percoll is reported 10 be non-toxic to cells, when latex was diluted with buffered Percoll, triterpenoid biosynthesis was reduced 10 -fold compared to the control sample (Table V). 

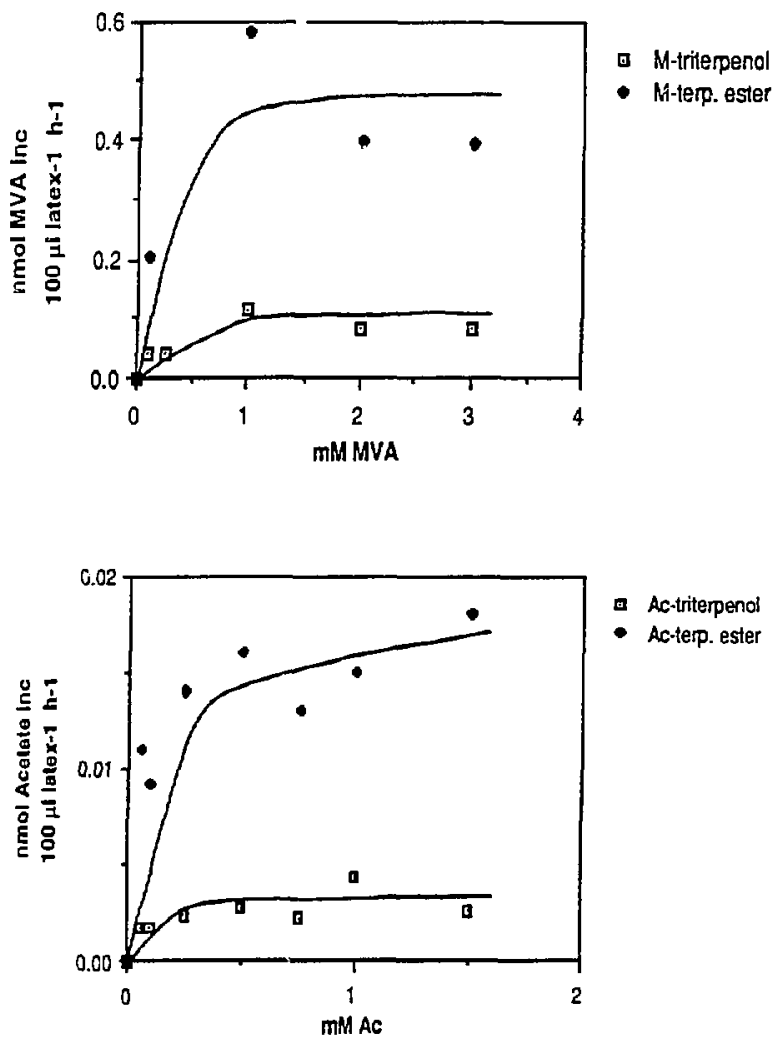

Fig. 6. Elfect of concentration of substrate acetate and mevatonate on the biosynthesis of triterpenoids in aliquots of a single whole latex sample. 

STEPS
ALONG PATHWAY
SUBSTRATE
INCORPORATION!
(nmol $100 \mu$ latex ${ }^{-1} h^{-1}$ )
TRITERPENOID EQUIVALENTS
(nmol $100 \mu$ l latex ${ }^{-1} \mathrm{~h}^{-1}$ )
Ac- $>$ Triterpenoids
0.02
0.001
MVA--> Triterpenoids
0.55
0.09

Fig. 7. Comparison of rates of incorporation of MVA and Ac into latex triterpenoids.

Ester biosynthesis was atfected to a greater degree than that of the free alcohols. Centrifugation of latex samples placed on Percoll showed that removal of the pellet, which contained rod-shaped starch grains ( $\mathrm{Ch}$. 3), did not reduce the amount of biosynthesis. The layer of latex that remained on top of the Percoll atter centrifugation had $20 \%$ of the biosynthetic capability of the whole sample, indicating that a large percentage of the particles responsible for the biosynthesis had a density greater than the Perco!l ( $\left.\delta=1.0975 \mathrm{~g} \mathrm{ml}^{-1}\right)$.

Table V. Efect of Percoll and Centrifugation on the Biosynthesis of Triterpenoids by Latex

\begin{tabular}{lccc} 
Treatment & pmol triterpenols & pmol triterpene esters & I pmol triterpenoids \\
\hline $\begin{array}{l}\text { latex+Percoll } \\
\begin{array}{l}\text { latex+Percoll+ } \\
\text { centritugation }\end{array}\end{array}$ & 0.9 & 2 & 2.9 \\
$\begin{array}{l}\text { latex+Percoll+ } \\
\text { centrifugation- }\end{array}$ & 0.7 & 1.9 & 2.6 \\
$\begin{array}{l}\text { pellet } \\
\text { top layer only of } \\
\text { latex+Percoll+ } \\
\text { cenitritugation }\end{array}$ & 0.9 & 1.9 & 2.8 \\
\begin{tabular}{l} 
latex+buffer \\
\hline
\end{tabular} & 0 & 0.5 & 0.5 \\
\hline
\end{tabular}

When latex was centrifuged for $5 \mathrm{~min}$ at $130 \mathrm{~g}$ on Percoll, the greatest percentage of biosynthetic activity was recovered by combining an aliquot of the material that remained on top of 
the Percoll with the $5000 \mathrm{~g}$ pellet obtained from a second centritugation of the Percoll layer (Fig. 8). Centriftugation of the Percoll Iraction at higher and lower $g$ forces gave lower recoveries of activity. The lower forces may not have sedimented all the particles; with the higher forces used, the particles could have been damaged. The greater amount of activity remaining on top of the Percoll in this experiment (50\%) than in the previous experiment says that the density of the site of triterpenoid biosynthesis is variable.

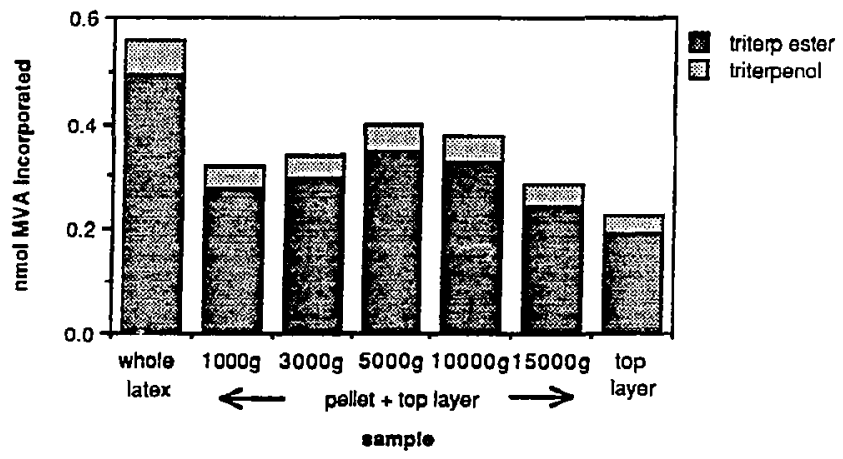

Fig. 8. P.ecovery of triterpenoid-synthesizing activity among fractions of latex centrifuged on Percoll.

Further validation of the particulate nature of the site of triterpenoid-synthesizing activity was obtained by a comparison of the distribution of the activity between the supernatant and pellet of the top layer from a latex sample centrifuged on Percoll which was subsequently centrifuged for $10 \mathrm{~min}$ at $100,000 \mathrm{~g}$ (Fig. 9). The majority of the activity was associated with the pellet, in fact, incubation of the supematam with the pellet reduced the activity. This may have been due to the inhibitory effects of Percolt which would have remained in the supernatant fraction. The duplicate incubations of supernatant with pellet show significant variability, demonstrating the difficulty of dividing pellets into equivalem samples with the same biosynthetic capability. This problem is likely due to the sticky nature of latex. In later experiments this 
variability was reduced by first dividing whole latex into the number of needed fractions and then centrifuging to obtain the pellets.

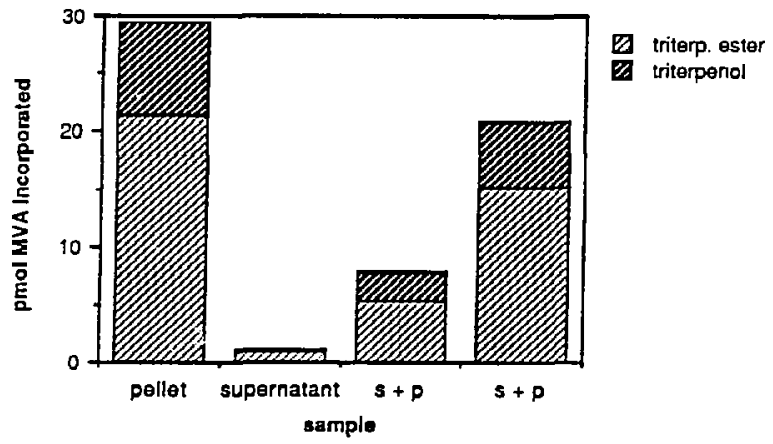

Fig. 9. Distribution of triterpenoid-synthesizing activity between particulate and soluble fractions of the top layer from latex centriluged on Percell.

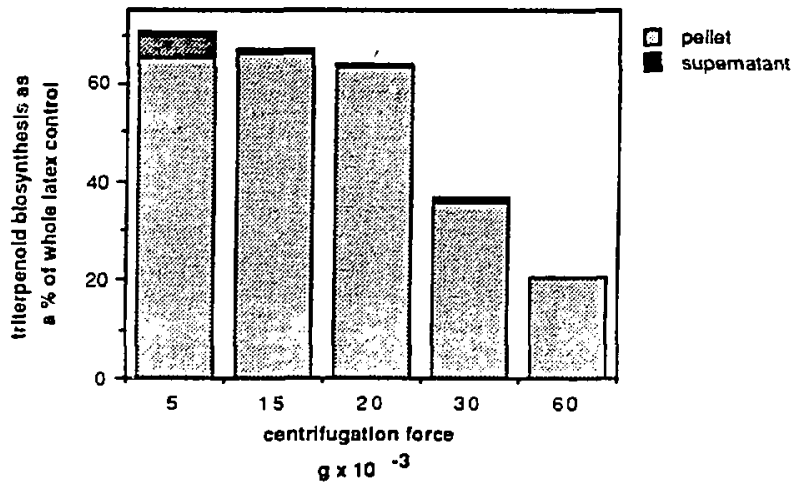

Fig. 10. Distribution of triterpenoid-biosynthetic activity between the supernatant and pellet of latex centriluged at various forces. 
When latex was centrifuged without Percoll at various $g$ forces, the majority of the biosynthetic activity was recovered in the pellet fraction (Fig. 10). As in the experiment where the particle responsible for the biosynthetic activity was recovered by centrifugation of the Percoll layer, a centrifugation at $5000 \mathrm{~g}$ gave the greatest recovery of activity. When latex was centrifuged at $g$ torces in the range of 5000 to 20,000 , the resulting pellet had $65 \%$ of the biosynthetic activity of whole latex. Slightly more activity was sedimented at $15,000 \mathrm{~g}$ than at $5000 \mathrm{~g}$ indicating that forces in this range are required to pellet the significant structure in the time period of $15 \mathrm{~min}$. With centrifugation at higher $g$ values, the recovery of activity is less, probably due to damage to the structure. Since the recovery of biosynthetic activity of in the pellet after this simple centrifugation was as good as centrifugation on Percoll, this procedure was used to obtain a fraction capable of tritemenoid biosynthesis.

When the $15,000 \mathrm{~g}$ pellet was incubated with $0.25 \mathrm{mM}$ [ $\left.{ }^{3} \mathrm{H}\right] \mathrm{Ac}$, the incorporation of label was $4 \%$ of the incorporation when a pellet trom the same latex sample wa: incubated with 0.25 mM [ $\left.{ }^{3} \mathrm{H}\right]$ MVA. The rate of incorporation of MVA was $27 \mathrm{pmol} 100 \mu$ latex $-1 \mathrm{~h}^{-1}$ into triterpene esters and $9 \mathrm{pmol} 100 \mathrm{\mu l}$ latex ${ }^{-1} \mathrm{~h}^{-1}$ into triterpenols. For Ac, the rates of incorporations weret.4 and $0.3 \mathrm{pmol} 100 \mu$ latex ${ }^{-1} \mathrm{~h}^{-1}$ respectively into triterpene esters and triterpenols. Since this is the same ratio of incorporation obtained when AC and MVA incorporation under saturating substrate conditions into triterpenoids in whole latex was measured, it would appear that the pellet was capable of metabolizing both substrates. However, $0.25 \mathrm{mM}$ MVA is not saturating for triterpenoid biosynthesis in latex. When a $5000 \mathrm{~g}$ pellet was incubated with either $1 \mathrm{mM}$ MVA or AC to insure substrate saturation, Ac incorporation was negligible compared to MVA incorporation indicating that the particulate traction is capable of metabolizing MVA but not AC into triterpenoids (12).

LIfetime of the blosynthetlc actlvity of the pellet. Mevalonate incorporation inio triterpenoids by whole latex proceeds at a relatively uniform rate over a period of $6 \mathrm{~h}(20)$. The rate of biosynthesis of triterpenoids from MVA by the pellet obtained by centrifugation of latex at $15,000 \mathrm{~g}$ for $15 \mathrm{~min}$ was measured over a period of $4.5 \mathrm{~h}$ and was lound to be linear over that time 
period (Fig. 11).

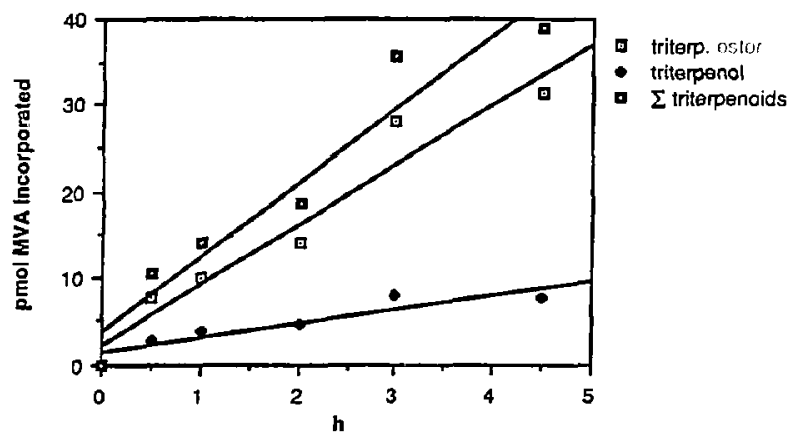

Fig. 11. Biosynthesis of triterpenoids over time by a particulate fraction obtained by centrifugation of latex at $15,000 \mathrm{~g}$ for $15 \mathrm{~min}$.

A second experiment looked at the incomoration of [3 ${ }^{3}$ ] MVA in the triterpenoids by a $15.000 \mathrm{~g}$ peltet of latex which had first been incubated as whole latex with $\left[{ }^{14} \mathrm{C}\right] \mathrm{MVA}$. This experiment allowed comparison of the amount of biosynthesis by whole latex and the 15,0009 pellet of the same sample. An additional incubation was periormed with a $15,000 \mathrm{~g}$ pellet which had been resuspended in bulfer and then resedimented by centrifugation. This process was periormed as a second wash to remove $\left[{ }^{14} \mathrm{CJMVA}\right.$ before the tritiated substrate was added. As a control, whole latex was incubated for $2 \mathrm{~h}$ with [ ${ }^{14} \mathrm{CJMVA}$, then $\left[{ }^{3} \mathrm{H}\right] \mathrm{MVA}$ was added. A second control was incubated $2 \mathrm{~h}$ with [ ${ }^{14} \mathrm{C}$ MVA, separated into supernatant and pellet. and analyzed.

After a $2 \mathrm{~h}$ incubation with $\left[{ }^{14} \mathrm{C}\right] \mathrm{MVA}$, labelled triterpenoids distributed about equally between the supernatant and pellet (Fig. 12). The amount of labelled triterpenoids found in the supernatant is fairly constant in the three samples analyzed. Whole latex showed twice the amount of triterpenoids labelled with ${ }^{14} \mathrm{C}$ compared to the sum of ${ }^{14} \mathrm{C}$-labelled terpenes in the supernatants and pellets of either the sample which was quenched at $2 \mathrm{~h}$ or the samples whose 


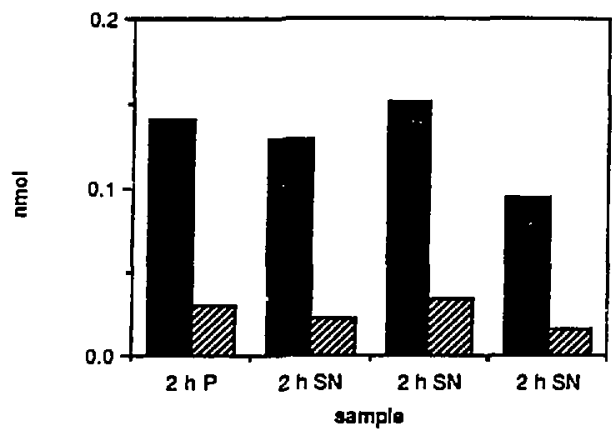

$14 \mathrm{C}$ tri ester

a 14C triterpol

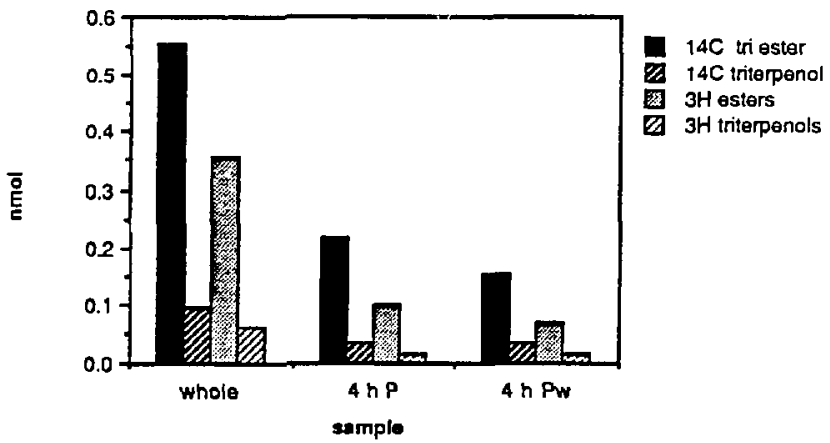

Fig. 12. Comparison of triterpenoid biosynthesis by whole and centrifuged latex.

pellets were incubated an additional $2 \mathrm{~h}$; this is reasonable if the $\left[^{14} \mathrm{C} \mid \mathrm{MVA}\right.$ was removed from the pellets upon centrifugation. The pool of MVA in the pelletable structure is therefore small. Biosynthesis of triterpenoids by the pellet and the washed pellet (Pw) were $30 \%$ and $21 \%$, respectively, of the biosynthesis in whole latex in the second $2 \mathrm{~h}$ incubation so centrifugation 
does diminish the biosynthetic capacity of the structure. This cou!d occur either by damage to the structure or removal of colactor(s) present in the $15,000 \mathrm{~g}$ supernatant. The second centrifugation reduced the biosynthesis of the pellet to two-thirds that of the pellet that was only centrifuged once, but as there were less ${ }^{14} \mathrm{C}$-labelled triterpene esters in the pellet, the second wash and centrifugation may be important to insure removal of $\left[{ }^{14} \mathrm{C}\right] \mathrm{MVA}$.

In the tinal experiment investigating the lifetime of triterpenoid biosynthesis by the particulate fraction, a washed, pre-incubated $(2 \mathrm{~h}$ ) pellet showed a linear rate of biosynthesis up to $4 \mathrm{~h}$ (Fig. 13). The amount of [ 3 HIMVA -labelled triterpenoids in the sample at each time point was nearly equal indicating that the substrate had been successfully removed by the two washes of the pellet. The race of biosynthesis by the pellet was $32 \%$ of that of whole latex again indicating either damage to the structure or removal of cofactors by centrifugation.

Effect of soluble factors in latex on triterpenold blosynthesis. Soluble noncatalytic proteins have been lound to be irvolved in the transfer of phospholipids and squalene between membranes of subcellular structures( 8,14$)$. In addition, these types of proteins have been found to stimulate the oxidation of squalene and kaurene, a step required for further metabolism of these terpenes $(8,19)$. The possible involvement of like factors in $E$. lathyris latex was investigated. It was thought that the reduced biosynthesis seen in the isolated particulate fraction compared to whole latex could be due to the removal of soluble cofactors which could stimulate biosynthesis. A second possible role in the remioval of triterpenoids from the particulate site of synthesis was also considered since labelled triterpenoids had been found distributed equally in the pellet as.J supernatant when whole latex was labelled and then centrifuged (Fig.12).

In an initial experiment in which whole latex was incubated with $\left[{ }^{3} \mathrm{H}\right.$ ]acetate then fractionated and the fractions analyzed for their labelled triterpenoid content, the majority of labelled terpenes were tound in the the top lipid tilm and the $100,000 \mathrm{~g}$ pellet (Fig. 14). The presence of labelled triterpenes in the top film which is composed of latex particles (Ch. 3) after a $3 \mathrm{~h}$ incubation indicates that the newly synthesized compounds are rapidly removed from the site 

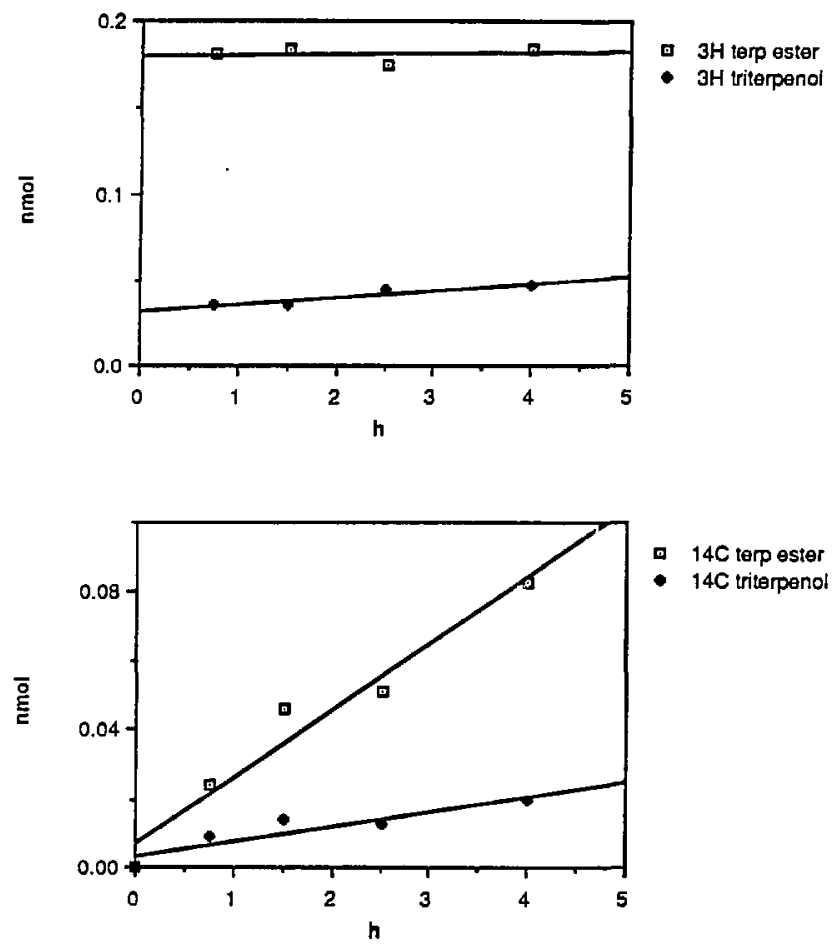

Fig. 13. Biosynthesis of triterpenoids over time by a pre-incubated, washed particulate fraction obtained by centrifugation of latex at $15.000 \mathrm{~g}$ for $15 \mathrm{~min}$.

of synthesis.

After a $100.000 \mathrm{~g}$ pellet had been loaded with labelled triterpenoids by preincubation as whole latex with $\left[3_{H}\right.$ IMVA, incubation of it with unlabelled MVA and $100,000 \mathrm{~g}$ supernatant rasulted in a greater efflux of labelled triterpenoids into the supematant than when the 


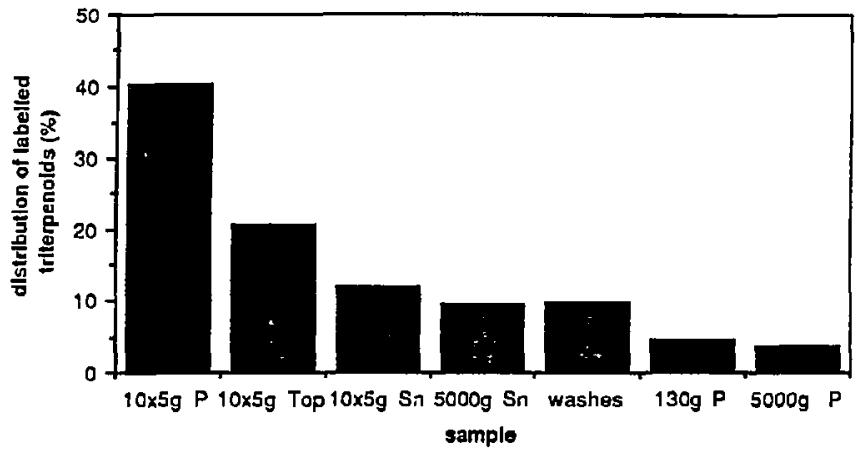

Fig. 14. Distribution of labelled triterpenoids in latex fractions.

supernatant was replaced by butfer or butfer + BSA (Fig. 15). When no unlabelled MVA was added before incubation of the $100,000 \mathrm{~g}$ pellet with the $100,000 \mathrm{~g}$ supematant, more labelled triterpenoids were found in the supernatant after $2 \mathrm{~h}$ than when the MVA was added suggesting that newly synthesized unlabelled triterpenoids were being removed from the pellet pool as well

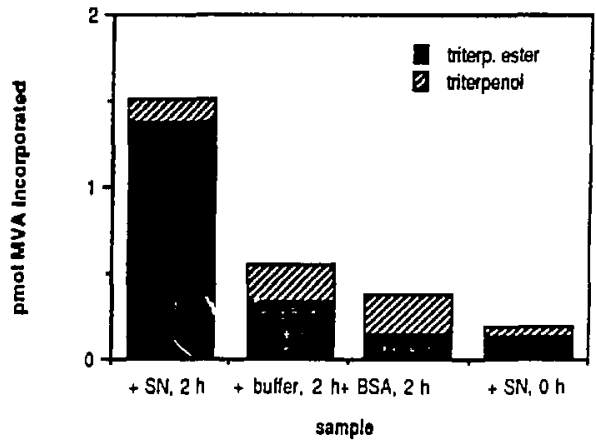

Fig. 15. Effect of soluble fractions on efflux of labelled triterpenoids from $100,000 \mathrm{~g}$ pellet of latex. 


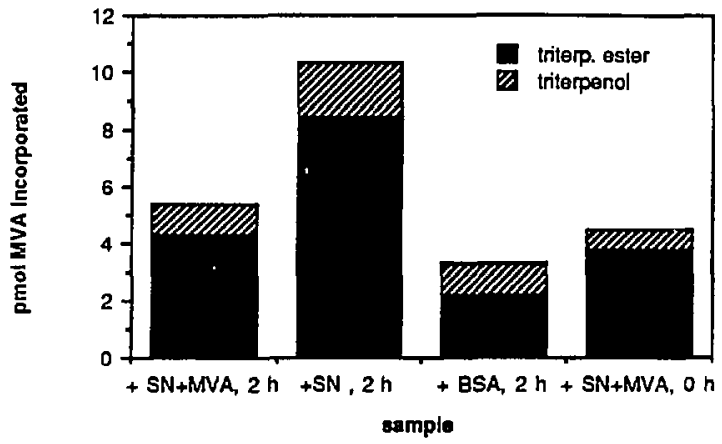

Fig. 16. Effect of soluble fractions with and without added MVA on efilux of labelled triterpenoids from $100,000 \mathrm{~g}$ pellet of latex.

as the previously labelled material (Fig. 16).

When a $15,000 \mathrm{~g}$ pellet which had been incubated as whole latex with $\left.~^{14} \mathrm{C}\right] \mathrm{MVA}$ was incubated with [ $3 \mathrm{H}$ ]MVA and either buffer or $100,000 \mathrm{~g}$ supernatant for different time periods, no difference in the amount of $\left({ }^{14} \mathrm{C}\right)$-labelled triterpenoids found in the soluble fraction was seen between the different time points and treatments (Fig. 17). The amount of newly synthesized, $3 \mathrm{H}$-labelled triterpenoids found in the soluble portion did increase with time in the presence of $100,000 \mathrm{~g}$ supernatant: however, the significance of this is questionable since the amounts of labelted triterpenoids found in the soluble fraction were below picomolar levels. The amount of ${ }^{14} \mathrm{C}$-labelled triterpenoids in the pellet remained constant over the time period indicating as seen previously that labelled MVA can be elfectively removed from the pellet by two washes and centrifugations (Fig. 18). The presence of the $100,000 \mathrm{~g}$ supernatant did not affect the amount of newly synthesized triterpenols $\left(3^{H}\right.$-labelled) in the pellet which remained relatively constant over the time points assayed in both the supernatant and buffer treatments. The amount of tritium-labelled triterpene esters increased with time under both treatments, but the incubations with supernatant contained an average of 2.5 times more labelled material than their counterpan 

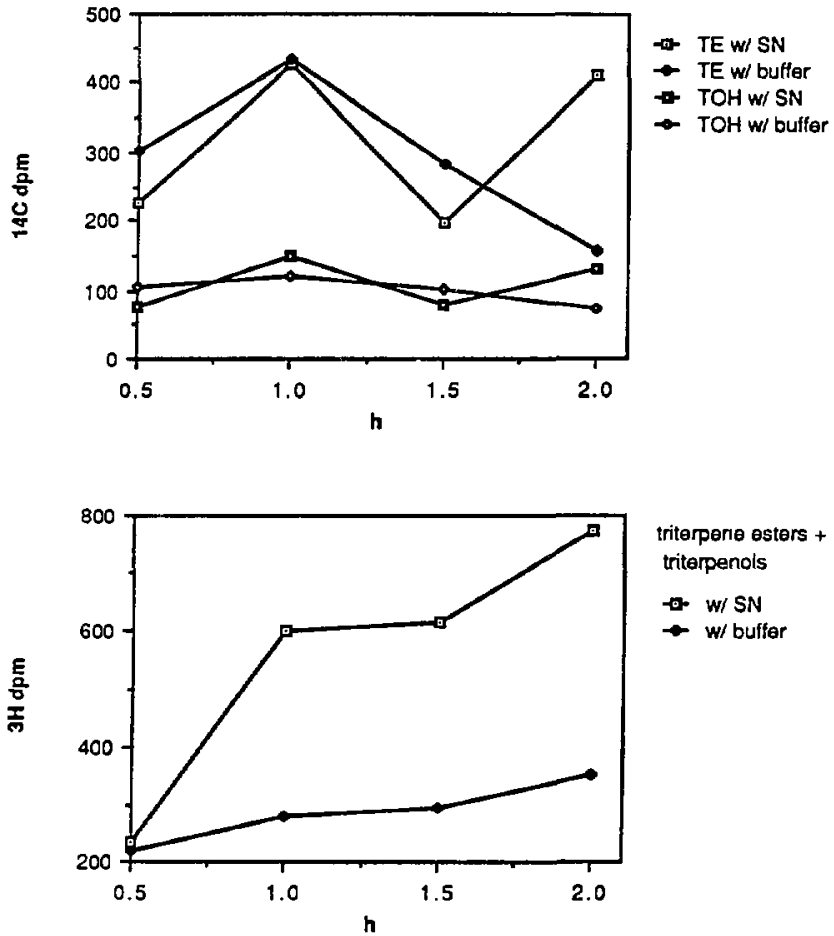

Fig. 17. Time course of effect of supernatant or buffer on efflux of labelled triterpenoids from $15,000 \mathrm{~g}$ pellet of latex.

incubations with busfer.

A final experinient investigated the elfect of the amount of $100,000 \mathrm{~g}$ supernatant on the biosynthesis of triterpenols and triterene esters by the $15,000 \mathrm{~g}$ pellet (Fig. 19). No difference was seen in the amount of biosynthesis of either class of triterpenoid under the different treatments. 

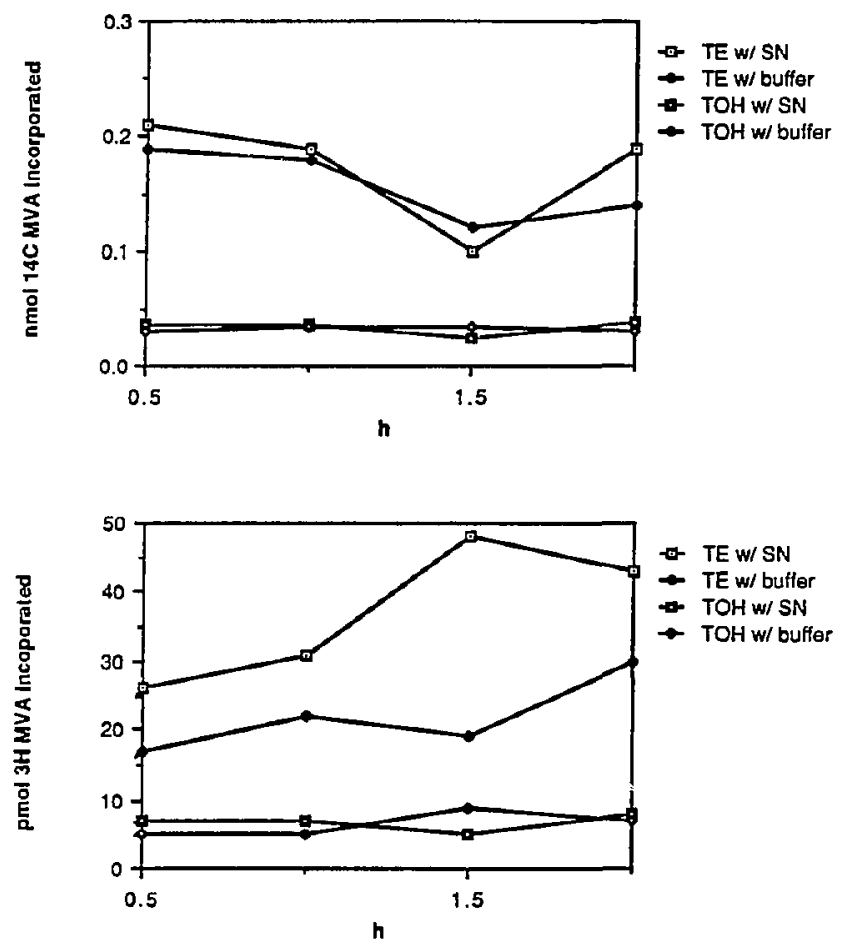

Fig. 18. Time course of effect of supernatant or buffer on labelied iriterpenoid content of $15,000 \mathrm{~g}$ pellet.

The most dramatic effects of supernatant on transfer of triterpenoids into the the soluble fraction were seen in the experiments pertormed with a $100,000 \mathrm{~g}$ pellet; only an increase in the arnount of newly synthesized triterpene esters in the pellet was seen when supernatant was incubated with the $15,000 \mathrm{~g}$ pellet. Since centrilugation at higher $g$ forces appears to disnupt the structure capable of converting MVA into triterpenoids, the effects seen with the $100,000 \mathrm{~g}$ pellet 


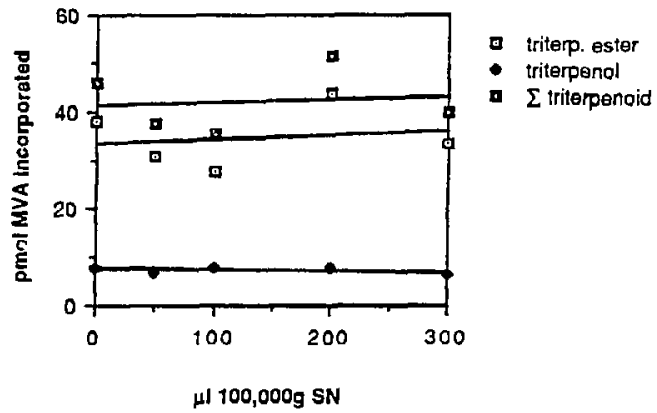

Fig. 19. Elfect of 100,000 gupernatant concentration on triterpenoid biosynthesis by $15,000 \mathrm{~g}$ pe!let.

may well be the result of adding back something lost from the structure due to the harsh treatment. Considering just the experiments with the $15,000 \mathrm{~g}$ pellet, the supernatant does not appear to be capable of removing triterpenoids from the pellet in this in vitro system. Neither does it appear to enhance triterpenoid biosynthesis in general. Based on these results, further investigation into the possible role of soluble proteins in triterpenoid biosynthesis and transport was curtailed. The effect of supematant on triterpene ester biosynthesis by the pellet was subsequently correlated with the need for phospholipids present in the supernatant to serve as donors for the fatty acid mciety of the ester (21).

HMG-CoA metabolIsm In latex. The determination that the rate-limiting step in triterpenoid biosynthesis in latex occurs prior to MVA led to an investigation of HMG-CoA metabolism in latex since the enzyme HMG-COA reductase (HMGR) was a likely candidate for the rate-determining role (Fig. 20). Exogenously-supplied HMG-COA was not incorporated into triterpenoids by whole latex, indicating that HMGR was possibly sequestered in latex (20). Allhough the enzyme converts a soluble substrate to a soluble product, it has been found to be a membrane-bound 
enzyme. In mammalian systems it is a transmembrane protein of the ER with its active site present on the cyloplasmic side of the membrane (16).

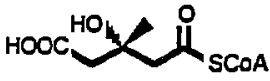

HMG-CoA

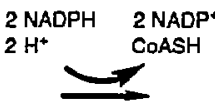

HMG-COA

reductase

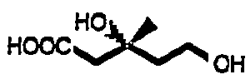

MYA

Fig. 20. Reaction catalyzed by HMG-CoA reductase.

Numerous incubations of fractionated latex with radiolabelled HMG-CoA were performed; the results of these experiments are tabulated in Table $V /$ with individual experiments presented separately since the biosynthetic capacily of latex can vary daily. Included in the listed conditions under which each incubation was perf med is the way in which the labelled MVA was detected. This is crucial since it was discovered that while a compound labelied from HMG-CoA did coelute with MVA on the HPLC organic acid column, this material did not coelute with MVAL either using TLC or on the HPLC ODS column. Analysis of HMG-COA metabolism using the organic acid colurin was desirable since conversion of HMG-CoA to acids other than mevalonic acid could also be determined. Since many experiments were analyzed only using the organic acid column HPLC, the results of these experiments are not conclusive. However, since in some experiments, another form of chromatography verified the results determined by OA HPLC. these experiments are being reported so as to indicate possible routes further investigation of HMG-CoA metabolism in latex might follow. The nature of this second HMC-CoA metabolite was not deterrnined; however, it is not acetate, acetoacetaie, or mevaldic acid. An enzymatic activity in rat liver microsomes which converts HMG-CoA into a product which coelutes with MVAL by anion-exchange chromatography but not on TLC has been reported (22), but the product has not been identified. Washing of the microsomes removed the competing activity. 
Table VI. HMG-CoA mefabolism of various latex fractions

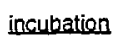

samole

conversion rate

(nmol $100 \mu$ latex $^{-1} h^{-1}$ )

senditions

1

$100,000 \mathrm{~g}$ pellet

$\rightarrow A C+A C A C$

$\rightarrow$ MVA

0.22

0.1

$\rightarrow A C$

0.8

treated with base. OA analysis

$100,000 \mathrm{~g}$ supernatant

$\begin{array}{lll}\rightarrow \text { AC } & 0.3 & \text { OA analysis } \\ \rightarrow \text { ACAC } & 6 & \\ \rightarrow \text { MVA } & 0.06 & \end{array}$

$\begin{array}{ll}>A C & 2.7\end{array}$

$\rightarrow$ ACAC

treated with base, $\mathrm{OA}$ analysis

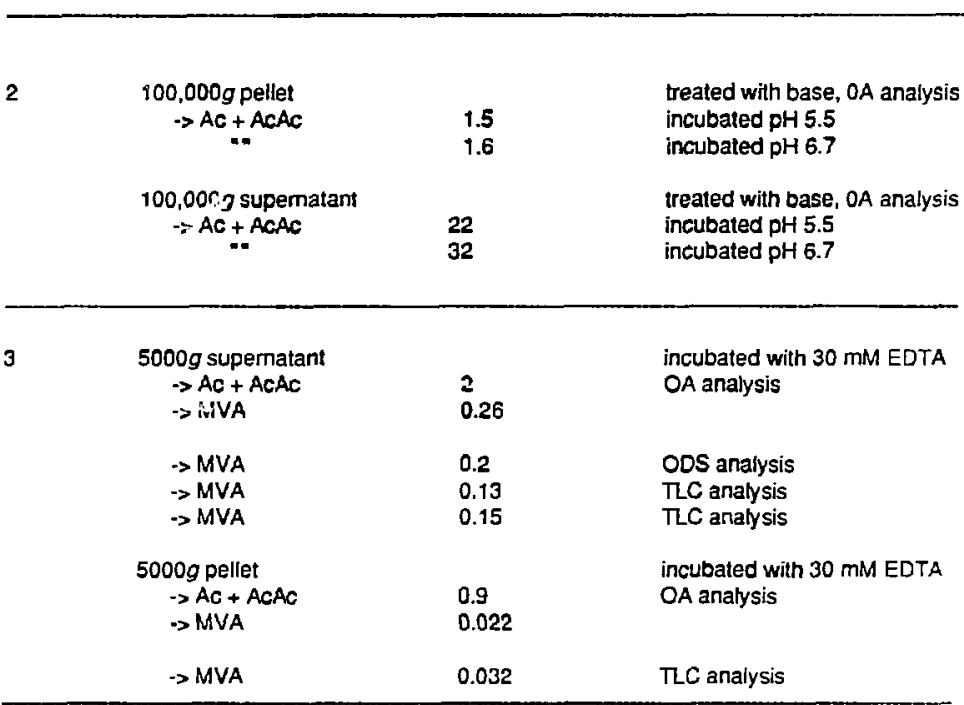


4

7500 g pellet

$\rightarrow A C+A C A C$

$\rightarrow$ MVA

$\rightarrow$ MVA

$40,000 \mathrm{~g}$ supernatant

$\rightarrow A C+A C A C$

0.35

$\rightarrow M V A$

$\rightarrow$ MVA

$40,000 \mathrm{~g}$ pellet

$\rightarrow A C+A C A C$

$\rightarrow$ MVA

0.042

0 incubated with $50 \mathrm{mM}$ EDTA

$\mathrm{OA}$ analysis

$\mathrm{TLC}+\mathrm{ODS}$ analy:is

incubated with $50 \mathrm{mM}$ EDTA

$O A$ analysis

TLC analysis

incubated with $50 \mathrm{mM}$ EDTA

$O A$ analysis mM EDTA

5

$40,000 \mathrm{~g}$ supernatant $>$ MVA $\quad 0.012$

TLC analysis

$100,000 \mathrm{~g}$ supernatant-> MVA $\quad 0.009$

TLC analysis

100,000g pellet- MVA

0.003

ILC anatysis

6

$40,000 \mathrm{~g}$ supernatant $\rightarrow \mathrm{MVA}$

0.018

RC analysis

$100,000 \mathrm{~g}$ supernatant-> MVA $\quad 0.010$

TLC analysis

$100,000 \mathrm{~g}$ pellet $\rightarrow \mathrm{MVA}$

0.002

TLC anahysis

7

$100,000 \mathrm{~g}$ supernatant $>$ MVA

0.16

OA analysis

$100,000 \mathrm{~g}$ pellet $\rightarrow \mathrm{MVA}$

0.05

$O A$ analysis

$100,000 \mathrm{~g}$ mix $\rightarrow$ MVA

0.24

QA analysis

8

$5000 g$ supernatant $>>$ MVA

0.011

$\mathrm{TLC}+\mathrm{OA}$ analysis

$5000 \mathrm{~g}$ pellet $\rightarrow \mathrm{MVA}$

0.009

$50,000 \mathrm{~g}$ supernatant $\rightarrow$ MVA

0.009

$50,000 \mathrm{~g}$ pellet $\rightarrow \mathrm{MVA}$

0.001

$100,000 \mathrm{~g}$ supernatant $\rightarrow$ MVA

0.016

$100,000 \mathrm{~g}$ pellet $>\mathrm{MVA}$

0.002 


\begin{tabular}{|c|c|c|c|}
\hline 9 & $\begin{array}{l}5000 \mathrm{~g} \text { supematant }->\text { MVA } \\
100,000 \mathrm{~g} \text { supematant of } \\
\text { sonicated } 5000 \mathrm{~g} \text { pellet }=>\text { MVA } \\
100.000 \mathrm{~g} \text { pellet of sonicated } \\
5000 \mathrm{~g} \text { pellet } \rightarrow>\text { MVA }\end{array}$ & $\begin{array}{l}0.005 \\
0.001 \\
0.026\end{array}$ & $\pi \mathrm{C}+$ ODS analysis \\
\hline 10 & $\begin{array}{l}5000 \mathrm{~g} \text { supernatant } \\
100,000 \mathrm{~g} \text { pellet of sonicated } \\
5000 \mathrm{~g} \text { pellet } \rightarrow \mathrm{MVA}\end{array}$ & $\begin{array}{l}0 \\
0.019\end{array}$ & $\pi C+$ ODS analysis \\
\hline
\end{tabular}

HMG-COA lyase activity in latex. When latex was incubated with radiolabelled HMG-CoA (incubations $1 \& 2$ ), the label incorporated into acetate and acetoacetate predominated over that incorporated into MYA. This activily was greatest in the $100,000 \mathrm{~g}$ supernatant and increased when the pH of the incubation was raised from 5.5 to 6.7 . These facts indicate that the enzyme HMG-CoA lyase (EC 4.1.3.4) is present in E. lathyris latex (Fig. 21). Avian lyase is a soluble protein with a $\mathrm{pH}_{\mathrm{optimum}}$ of 8.9 . It requires a divalent cation ( $\mathrm{Mg}^{2+}$ or $\mathrm{Mn}^{2+}$ ) for activity (15). Lyase activity has been detected in Hevea brasiliensis latex (13). The significance of lyase presence in latex is uncertain. Since it serves to essentially decompose HMG-COA to its precursors, it may play a role in the regulation of the level of HMG-COA in latex. The detection of lyase activity in latex explains why exogenously supplied HMG-CoA was not incorporated into the triterpenoids, however, some mechanism must exist to channel endogenously produced HMG-COA to HMG-COA reductase since acetate is incorporated into triterpenoids by latex.

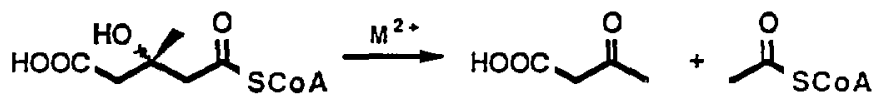

$\operatorname{MSG} \sin A$

Iyoge

Fig. 21. Reacticn catalyzed by HMG-CoA lyase.

Effect of EDTA on HMG-COA metabollsm In latex. In order to funther investigate HMGR, a 
mechanism was needed to inhibit lyase activity. Since lyase requires divalent cations for activity and HMG-COA reductase does not, inclusion of EDTA in the incubation mixture to chelate the metal inhibited lyase activity without affecting HMGR (incubations 3 \& 4)(27). Comparing incubations 1 and 3, with EDTA the ratio of lyase activity/ HMGR activity decreased 14-told in the supernatant fractions. All further investigations of HMG- COA reductase were performed by including $30 \mathrm{mM}$ EDTA in the buffer.

HMG-COA reductase activity In latex. The localization of HMG-CoA reductase to a specific latex fraction was hampered by both the presence of lyase and the second HMG-COA metabolizing activity. HMGR was detected in both soluble and particulate fractions (incubations 5 to 10). However, in the most carefully analyzed experiments where the labelled MVA was analyzed by TLC followed by ODS-HPLC (incubations 9 \& 10), HMGR was associated with the membrane fraction of the $5000 \mathrm{~g}$ pellet $(100.000 \mathrm{~g}$ pellet of sonicated $5000 \mathrm{~g}$ pellet). This location for HMGR is consistent with the results of an experiment investigating the specific activity of HMGR in latex fractions (Table VI). The $10,000 \mathrm{~g}$ pellet had the highest specific activity of any fraction. The majority of HMGR activity was found in the supernatant but with a lower specific activity; it is possibte that this activity is derived from the membrane-bound HMGR. In mamnialian systems, it has been found that the soluble subunit of HMGR can be cleaved trom the membrane-bound subunit by proteases. This soluble truncated HMG-CoA reductase retains its catalytic activity (23). Hevea brasiliensis latex HMG-CoA reductase has also been localized to a particulate fraction $\left(40,000 \mathrm{~g}\right.$ pellet) but had a higher specific activity of $17 \mathrm{nmol} \mathrm{h}^{-1} \mathrm{mg}$ $\operatorname{protein}^{-1}(30)$.

The activity of HMG-COA reductase measured in the $5000 \mathrm{~g}$ pellet fraction \{average of 4 experiments) is comparable to the overall rate of conversion of acetate into triterpenoids in latex (Fig. 22). This result suggests that HMG-CoA reductase is indeed the rate-determining enzyme in the pathway to triterpenoid biosynthesis in latex. Artempts to confirm this by showing that the rate of conversion of acelate to HMG-CoA in latex was greater than HMG-CoA reductase activity 
Table VI. Disfribution of HMG-CoA Reductase Activity in Latex Fractions.

\begin{tabular}{lccc}
\hline & $\frac{\text { Total Activity }}{\left(\mathrm{pmol} \mathrm{h}^{-1}\right)}$ & $\frac{\text { Total Protein }}{(\mathrm{mg})}$ & $\begin{array}{c}\text { Soecific Activity } \\
\text { (pmol h-1 } \mathrm{mg}^{-1} \text { protein }\end{array}$ \\
$10,000 \mathrm{~g}$ pellet & 54 & 0.62 & 87 \\
$15,000 \mathrm{~g}$ pellet & 7 & 0.67 & 10 \\
$50,000 \mathrm{~g}$ pellet & 5 & 0.43 & 12 \\
$100,000 \mathrm{~g}$ pellet & 5 & 1.5 & 3 \\
$100,000 \mathrm{~g}$ supernatant & 160 & 5.5 & 29 \\
\hline
\end{tabular}

were unsuccessful since acetate incorporation into HMG-CoA was not detectable in latex. Lyase activity in latex could be the cause; since the enzymes involved in the conversion of acetate into HMG-CoA also require divalent cations for activity, EDTA could not be used to exclusively inhibit lyase activity in this case.

\begin{tabular}{|c|c|c|c|}
\hline $\begin{array}{c}\text { STEPS } \\
\text { ALONG PATHWAY }\end{array}$ & \multicolumn{2}{|c|}{$\begin{array}{l}\text { SUBSTRATE } \\
\text { INCORPORATION } \\
\left(\mathrm{nmol} 100 \mu \text { latex } \mathrm{x}^{-1} \mathrm{n}^{-1}\right)\end{array}$} & $\begin{array}{l}\text { TRITERPENOID } \\
\text { EOUIVALENTS } \\
\text { (nmol } 100 \mu \text { latex }{ }^{-1} \mathrm{~h}^{-1} \text { ) }\end{array}$ \\
\hline$A C-D$ & oids & 0.02 & 0.001 \\
\hline MVA--> & oids & 0.55 & 0.09 \\
\hline HMG-CoA $>$ MVA & & 0.02 & 0.003 \\
\hline
\end{tabular}

Fig. 22. Comparison of rates of incorporation of MVA and $A C$ into latex triterpenoids with HMG-COA reductase activity in latex.

Purlfication and propertles of latex HMG-COA reductase. The results reported in this section were oblained by analysis of labellea HMG-COA incorporation into MVA by organic acid HPLC only, betorg it was determined that another HMG-COA-derived produc: coeluted with MVA on this column. The experiments were not repeated since $E$. lathyris vegetative tissue proved to 
be a better source of HMG-COA reductase for purification of the enzyme (Ch. 2). These experiments are being reported as a reference for possible further work on latex HMG-COA reductase.

The dependence of HMG-CoA reductase activity on the volume of latex sample and time are shown in Figures 23 and 24. HMG-COA reductase was precipitated by bringing latex $1070 \%$ saturation in ammonium sulfate (Table VII). This did not result in a purification of HMGR, but it did provide a means to remove the enzyme from endogenous latex acids. This fraction was used to determine the optimum pH for latex HMG-CoA reductase (Fig. 25). At pH 6.1 a four-fold purification from the original HMG-COA reductase activity measured in the $100,000 \mathrm{~g}$ mix was obtained. The possible difference in $\mathrm{PH}$ optimum for latex HMGR and HMG-COA reductase from the vegetative tissue ( $\mathrm{pH} 6.8-\mathrm{Ch}$. 2) suggests that isozymes of the enzyme exist in $E$. lathyris. A substrate saturation curve run on the desalted $\left(\mathrm{NH}_{4}\right)_{2} \mathrm{SO}_{4}$-precipitated HMG-CoA reductase sampie gave a $\mathrm{K}_{\mathrm{m}}$ of $82.5 \mu \mathrm{M}$ HMG-CoA, comparable to that determined for $H$. brasiliensis latex HMGR of 56 HM HMG-COA (30) (Fig. 26).

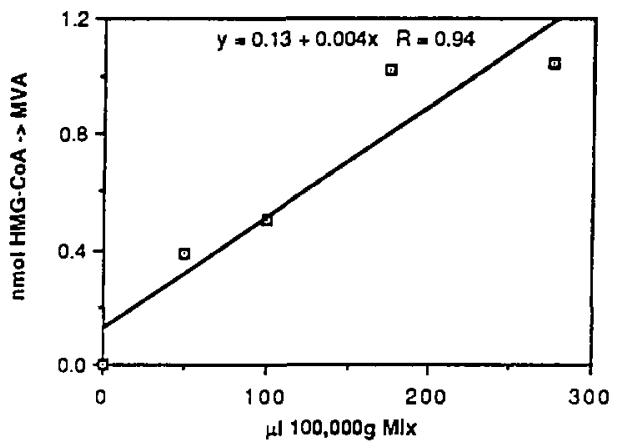

Fig. 23. HMG-COA reductase activity versus $[100,000 \mathrm{~g}$ mix of latex]. 


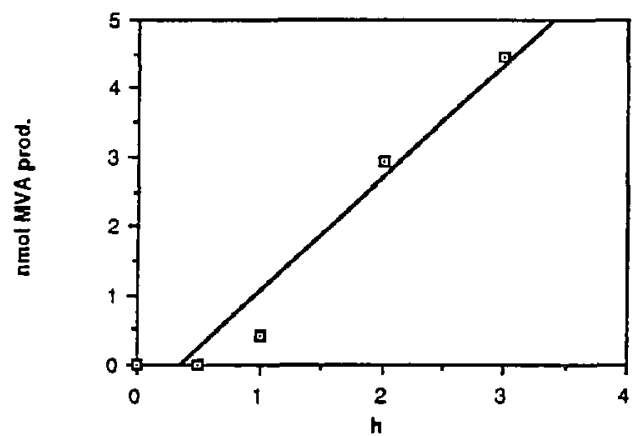

Fig. 24. Time course of HMG-CoA reductase activity in $100,000 \mathrm{~g}$ supernalant.

Table VII. Ammonium Suffate Fractionation of Latex HMG.COA Reductase.

\begin{tabular}{|c|c|c|c|}
\hline FRACTION & $\begin{array}{l}\text { TOTAL } \\
\text { PROTEIN } \\
\text { (mg) }\end{array}$ & $\begin{array}{l}\text { TOTAL } \\
\text { ACTIVITY } \\
\text { (nmol } n^{-1} \text { ) }\end{array}$ & $\begin{array}{l}\text { SPECIFIC } \\
\text { ACTIVTY } \\
\text { (nmol mg protein-1 } h^{-1} \text { ) }\end{array}$ \\
\hline $100,000 \mathrm{~g}$ supernatant & 10.5 & 2.94 & 0.28 \\
\hline $30 \%$ AS pellet & 0.2 & 0 & 0 \\
\hline 30 to $70 \%$ AS pellet & 6.3 & 1.7 & 0.27 \\
\hline $70 \%$ AS supernatant & 0.8 & 0 & 0 \\
\hline
\end{tabular}




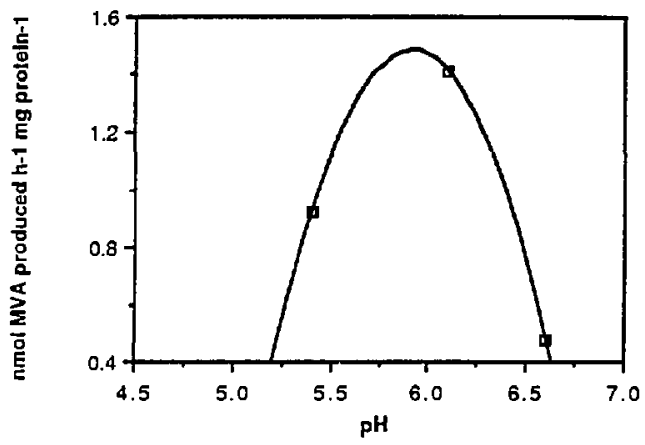

Fig. 25. Elfect of pH on HMG-CoA reductase activity of Jatex.

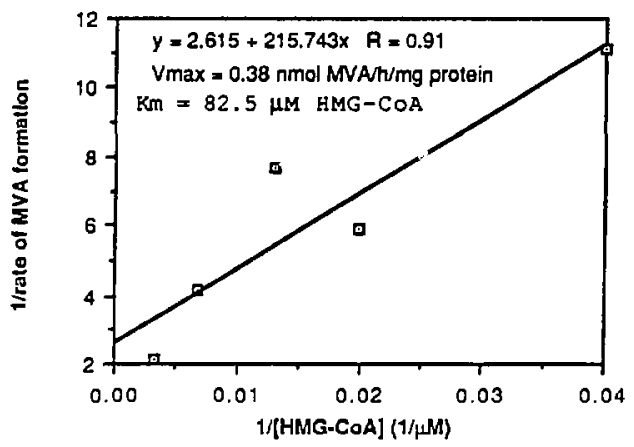

Fig. 26. Double-reciprocal plot of HMG-CoA reductase activity versus [HMG-CoA]. 


\section{CONCLUSIONS}

E. lathyris latex contains all the enzymes needed to convert acetate into triterpenols and their esters. The final enzymes of the pathway, which will metabolize mevalonic acid to the triterpenoids, are segregated within a pelletable structure $(5000 \mathrm{~g})$. Membrane-bound HMG-CoA reductase was also localized to this fraction, but it was not established whether it was contained in the same structure. HMG-COA lyase was present in the soluble fraction of latex, and a second enzymic activity which converted HMG-COA to a mevalonate-like product was also detected.

Measurements of the rates of acetate and mevalonate incorporation into the triterpenoids and the rate of HMG-COA reductase indicate that the conversion of HMG-COA to mevalonic acid is the rate-determining step in the pathway in latex. 


\section{UTERATURE CITED}

1. Bealing FJ 1976 Quantitative aspects of latex metabolism: possible involvement of precursors other than sucrose in the biosynthesis of Hevea nubber. In Proc Int Rubber Conf, Vol 2, Rubber Research institute of Malaya, Kuala Lumpur

2. Bradford MM 1976 A rapid and sensitive method for the quantitation of microgram quantities of protein utilizing the principle of protein-dye binding. Anal Biochem 72: 248-254

3. Brooker JD, DW Russeil 1975 Subcellular localization of 3-hydroxy-3-methylglutaryl coenzyme A reductase in Pisum sativum seedlings. Arch Biochem Biophys 167: 723-729

4. Brown MS, JL Goldstein 1980 Multivalent feedback regulationof HMG-CoA reductase, a control mechanism coordinating isoprenoid synthesis and cell growth. J Lipid Res 21: 505-517

5. Fahn A 1979 Secretory Tissues in Plants, Academic Press, London

6. Fairbaim JW, MJ Steele 1981 Biosynthetic and metabolic activities of some organelles in Papaver somnifenm latex. Phytochem 20: 1031-1036

7. Folin $0, V$ Ciocalteu 1927 On tyrosine and tryptophan deteminations in proteins. $\mathrm{J}$ Biol Chem 73: $627-650$

8. Fuks-Holmberg D, K Bloch 1983 Intermembrane transter of squalene promoted by supematant protein factor. J Lipid Res 24: 402-408

9. Goad LJ 1983 How is sterol synthesis regulated in higher plants? Biochem Soc Trans 1: $548-552$

10. Groeneveld HW 1976 Biosynthesis of latex triterpenes in Euphorbia: Evidence lor a dual synthesis. Acta Bot Neerl 25: 459-473

11. Groeneveld HW, EGM Peters, GW Kroese, C Papenhuyzen 1983 Lipid synthesis and ultrastructure of the laticilers of etiolated Euphorbia lathyris seedlings. Ann Bot 51: 307-315 
12. Hawkins DR unpublished results

13. Hepper CM, BG Audley 1969 The biosynthesis of rubber from $\beta$-hydroxy- $\beta$-methylglutarylcoenzyme A in Hevea brasiliensis latex. Biochem J 114: 379-386

14. Kader J-C, M Julienne, C Vergnoile 1994 Purification and characterization of a spinach-leaf protein capable of transferring phospholipids from liposomes to mitochondria or chloroplasts. Eur $J$ Biochem 139: $411-416$

15. Kramer PR, HM Miziorko 1980 Puritication and characterization of avian liver 3-hydroxy3-methylglutaryl coenzyme A lyase. J Biol Chem 255: 11023-11028

16. Liscum L, RD Cummings, RGW Anderson, GN DeMartino, JL Goldstein, MS Brown 1983 3-hydroxy-3-methylgiutaryl-CoA reductase: a transmembrane glycoprotein of the endoplasmic reticulum with N-linked "high-mannose“ oligosacchanides. Proc Natl Acad Sci USA 80:7165-7169

17. Lynen F 1967 Biosynthelic pathways from acetate to natural products. J Pure Appl Chem 14: $137-167$

19. Markwell MAK, SM Haas, NE Tolbert, LL Bieber 1981 Protein determination in membrane and lipoprotein samples: manual and automated procedures. Meth Enz 72: 296-303

19. Moore TC, SA Barlow, RC Coolbaugh 1972 Participation of noncatalytic "carrier protein in the metabolism of kaurene in cell-free extracts of pea seeds. Phytochem $11: 3225-3233$

20. Nemethy EK, C Skrukrud, GJ Piazza, M Calvin 1983 Terpenoid biosynthesis in Euphorbia latex. Biochem Biophys Acta 760: 343-349

21. Nemethy EK unpublished results

22. Ness GC, MH Motfler 1978 Interterence with the determination of 3-hydroxy-3methylglutaryl coenzyme A reductase activity and its propenties by a microsomal enzymic activity. Arch Biochem Biophys 189: 221-223 
23. Ness GC, SC Way, PS WIckham 1981 Proteinase involvement in the solubilization of 3-hydroxy-3-methylglutanyl-coenzyme A reductase. Biochem Biophys Res Comm 102: 81.85

24. Plazza GJ 1986 Triterpene biosynthesis in the latex of Euphorbia lathyris. (unpublished manuscript)

25. Ponsinet G, G Ourisson 1967 Biosynthèse in vitro des triterpènes dans te latex d'Euphorbia. Phytochem 6: 1235-1243

26. Ponsinet G, G Ourisson 1968 Aspects particuliers de la biosynthèse des triterpènes dans le latex d'Euphorbia. Phytochem 7: 757-764

27. Sabine JR, ed 1983 Monographs on Enzyme Blology: HMG-CoA Reductase, CRC Press, Boca Raton

28. Shapiro DJ, RL Imblum, WW Roctwell 1969 Thin-layer chromatographic assay for HMG-CoA reductase and mevalonic acid. Anal Biochem 31:383-390

29. Shukla OP, CA Krishna Murti 1971 The biochemistry of plant latex. J Sci Ind Res 30: 640-662

30. Sipat AB 1982 Hydroxymethylglutary/ COA reductase (NADPH) in the latex of Hevea brasiliensis. Phytochem 21: 2613-2618

31. Vincent $R, D$ Nadeau 1983 A micromethod for the quantitation of cellular proteins in Percoll with the Coomassie brilliant blue dye-binding assay. Anal Biochem 135: 355-362 


\section{Chapter Il. LOCATION AND SOLUBILIZATION OF HYDROXY-METHYLGLITAAYL-COENZYME} A REDUCTASE FROM EXTRACTS OF EUPHORBIA LATHYRIS STEM AND LEAF TISSUE

In 1985 Michael S. Brown and Joseph L. Goldstein were awarded the Nobel Prize in Physiology or Medicine for their work in uncovering factors involved in the regulation of cholesterol biosynthesis in mammalian cells. Through their work and that of many other researchers, the central role of 3-hydroxy-3-methylglutaryl coenzyme A reductase (mevalonate:NADP oxidoreductase (acylating COA) EC 1.t.t.34) as the major rate-limiting enzyme in sterol biosynthesis was elucidated. It is a membrane-bound enzyme, located primarily in the endoplasmic reticulum, and a trans-membrane protein, glycosylated on the luminal side with a soluble catalytic subunit on the cytoplasmic side (12). Mammalian HMG-CoA reductase is subject to multivalent feedback regulation both at the gene and enzyme level (10). Transcription of the reductase gene is supressed by cholesterol-containing low density lipoproteins. 25-hydroxycholesterol, and mevalonate(17). Tumover of the protein itself in cultured mammalian cells is accelerated by addition of sterols to the media in a process that is mediated by the membrane-bound domain of the enzyme (15), and a phosphorylation/dephosphorylation mechanism converts the enzyme between an active and inactive form (5).

Within the plant kingdom the number of isoprenoid-derived products is staggering. From the ten-carbon monoterpene essential oils to polyterpene rubbers with molecular weights up to four million, plants synthesize a multitude of terpenoid compounds important as growth hormones. phytoalexins. pigments, and membrane components. Yet despite the abundance and diversity of terpenes in plants, the means by which plants control the flow of carbon into these compounds is little understood. Terpenoid compounds, including the carotenoids and the phytyl chain of chlorophyll found within the chloroplast and ubiquinone involved in electron transport in the mitochondria, are essential components of a number of subcellular structures. The question of which enzymes of the terpene pathway these individual organelles contain has become a recent subject of controversy. Work by Kleinig and coworkers with daflodil, spinach. 
and potato fubers suggests that isopentenyfpyrophosphate (IPP) is the central intermediate synthesized in the cytoplasm and transported into the specialized organelles where it is further metabolized to the required sompounds (20). Yet the detection of HMGR and MVA kinase activity in plastid and mitochondrial fractions by other researchers supports the viewpoint that individual organelles contain their own IPP-synthesizing system $(9,11)$.

Propelled by the discove:y of the major role it plays in the regulation of cholesterol biosynthesis in mammalian systems, HMGR has become the focus of study of a number of investigations in various photosynthetic organisms. In 1975 Brooker and Russell were the first to detect HMGA activity in a higher plant Pisum salivum (8). Since then others have reported on the enzyme in radish seedlings, sweet potalo roots. Nepeta cataria leaf tissue, Hevea brasiliensis latex, tobacco seedlings, barley seedlings, spinach, carrot cell culture, soybean, pepper, sycamore tissue culture, and anise cell suspension culiure (14).

We undertook this investigation of HMG.COA reductase from stem and leaf tissue of Euphorbia lathyris because the high percentage of triterpenoids found in this plant suggests that interesting differences in the regulati 1 of this enzyme could be a factor in the greater flow of carbon into these compounds than in other plants. The data on the relative rates of incorporation of AC and MVA into the triterpenoids of latex and the tumover activity of latex HMGR indicate that this enzyme could also be catalyzing the rate-limiting step in triterpenoid biosynthesis in $E$. lathyris (Ch. 1). In order to learn more about E. lathyris HMG-CoA reductase, purification of the enzyme from vegetative tissue was begun. As the tirst acts of this purification, the subcellular location of this enzyme was investigated and steps were taken to solubilize the membrane-bound enzyme and to protect it trom endogenous protease activity. 


\section{material ano methods}

Plant material. Euphorbia lathyris L. plants were propayated from seed collected from wild plants growing near Healdsburg. Sonoma Co., CA. Plants were grown in a soil mix of peat, sand, and perlite in 6 inch clay pots under growth chamber conditions of a $16 \mathrm{~h}$ day at $600 \mu \mathrm{Em}^{-2} \mathrm{~s}^{-1}$ provided by a combination of fluorescent and incandescent lights, $27^{\circ} \mathrm{C} \mathrm{day/} 18^{\circ} \mathrm{C}$ night temperature.

Materlals. DL-3-[glutaryl-3-14 C]-hydroxy-3-methyiglutaryl coenzyme A, R-[5-3 $\mathrm{H}]$-mevalonic acid, triethylammoniun salt, and Aquassure were purchased from New England Nuclear. Polyvinylpyrrolidone MW 40,000 (PVP) was obtained from Calbiochem. Bradiord dye reagent was purchased from Bio-Rad. Silica gel plates were obtained from Analtech. Mevinolin was a gift of A. W. Alberts of Merck, Sharp \& Dohme. All other biochemicals were from Sigma.

Crude homogenate preparation. Approximately $15 \mathrm{~g}$ E. lathyris stem and leal tissue (upper $10 \mathrm{~cm}$ of main stalk; from 4 to 6 month-old plants was quickly chopped into pieces with a razor blade then homogenized with $75 \mathrm{ml}$ BUFFEF A (10 mM potassium phosphate pH7.2, $0.4 \mathrm{M}$ sorbitol, $30 \mathrm{mM}$ EDTA, $10 \mathrm{mM}$ DTE) and $1.5 \mathrm{~g}$ insoluble PVP using a mortar and pesile. The cnude extract was obtained by filtering the homogenate through cheesecioth.

HMGR assay. Fifteen microliters of $25 \mathrm{mM}$ NADPH, $42.9 \mu \mathrm{l} 2 \mathrm{mM}$ D,L-HMG-CoA, and $10 \mu \mathrm{l}$ $\left[{ }^{14} \mathrm{CJHMG}-\mathrm{CoA}\left(47.2 \mathrm{mCi}^{-1 m o l}{ }^{-1}, 0.02 \mathrm{mCl} \mathrm{mi}^{-1}\right)\right.$ were taken to dryness under a stream of $\mathrm{N}_{2}$. then $150 \mu$ of sample was added bringing the final concentrations of substrates to $2.5 \mathrm{mM}$ NADPH and $0.6 \mathrm{mM} \mathrm{HMG-COA}\left(2.2 \mathrm{mCi} \mathrm{mmol}^{-1}\right)$. Samples were incubated 1 to $2 \mathrm{~h}$ at $28^{\circ} \mathrm{C}$ then

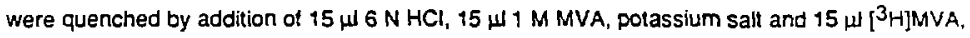
TEA salt (ca 20,000 dpms). Quenched incubations were stored in a freezer until their workup based on the TLC procedure described by Brooker and Russell ( 8 ). Incubations were allowed to sit at room temperature for $10+$ min to ensure MVA lactonization. Samples were centrifuged 20 min at $12,000 \mathrm{~g}$ using a Beckman microluge 11 to pellet precipitated protein, and the supernatant 
was removed. Two hundred microliters of water was added to the pellet; the sample was vortexed then recentrifuged. The supernatant was removed, and the extraction was repeated with $200 \mu 1$ acetone. Supematants were combined and taken to dryness under a stream of $\mathrm{N}_{2}$. A $200 \mu$ volume of acetone was added to the residue; the sample was sonicated 5 min then spotted on a $5 \times 20 \mathrm{~cm}, 250 \mu \mathrm{m}$ silica gel $\mathrm{G}$ plate along with a marker spot of $5 \mu /$ of a $1: 1$ mixture of $6 \mathrm{~N} \mathrm{HCl}$ $1 \mathrm{M}$ MVA, potassium salt. The spotting vial was rinsed with an additional $200 \mu$ acetone and sonicated 5 min, and the acetone extract was applied to the plate. Plates were developed in a solution of 2:1 $\mathrm{CHCl}_{3}$ : acetone, and the marker spot was visualized by treatment with sulfuric acid spray and heat. The silica gef band was scraped, wet with methanol, and the MVAL was eluted with ether and aceione. The eluate was concentrated to 10 to $15 \mathrm{ml}$, and a $10 \%$ aliquot was mixed with $15 \mathrm{ml}$ Aquassure and counted using a Packard 640-C scirtillation counter. The remaining $90 \%$ of the sample was dried under a stream of $\mathrm{N}_{2}$ then redissolved in $150 \mu 10 \mathrm{mM}$ potassium phosphate $\mathrm{pH} 2.5$. Fifty microliters was chromatographed on a Beckman 322 HPLC system using an Altex $4.6 \mathrm{~mm} \times 25 \mathrm{~cm}$ ODS column in $10 \mathrm{mM}$ potassiuin phosphate, $\mathrm{pH} 2.5$ at a flow rate of $1 \mathrm{ml} \mathrm{min}^{-1}$ with detection at $214 \mathrm{~mm}$ using a Hitachi $100-10$ variable wavelength spectrophotometer. One-minute fractions were collected directly into scintillation vials using a LKB 2112 redirac fraction collector; $15 \mathrm{mi}$ Aquassure was added to each vial which was subsequently counted.

Protein determInatlon. METHOD 1 - Protein was analyzed per Bradford(7) as modified by Vincent and Nadeau(28). A volume of $20 \mu$ sample + buffer was added to $80 \mu l 0.1 \%$ Triton $\mathrm{X}-100$, then $50 \mu \mathrm{l}$ of the Triton mix was assayed in $1 \mathrm{ml} 5$-fold dilute Bradford reagent. Absorbance of the samples at $595 \mathrm{~nm}$ and also at $720 \mathrm{~nm}$, where there is less interference from chlorophyll absorbance, was determined using a Hewlett-Packard 8450-A UVIVIS spectrophotometer. METHOD 2-- Protenn was anal,zed by the method of Markwell et al. (22) tor membrane proteins santples using the procedure of Bensadoun and Weinstein (6) for removal of 
intertering substances by initial trichloroacetic acid (TCA) precipitation of protein. Ten microliters $2 \%$ sodium deoxycholate was added to $1.2 \mathrm{ml}$ sample and allowed to stand $15 \mathrm{~min}$, then $0.4 \mathrm{ml}$ $24 \%$ TCA was added and the protein was pelleted by centrifugation at $3300 \mathrm{~g}$ for $30 \mathrm{~min}$. The protein pellet was redissolved in $1 \mathrm{ml}$ reagent $\mathrm{C}\left(100: 1 \mathrm{mix}\right.$ of reagent $\mathrm{A}\left(2 \% \mathrm{Na}_{2} \mathrm{CO}_{3}, 0.4 \%\right.$ $\mathrm{NaOH}, 0.16 \%$ sodium tartrate, $1 \% \mathrm{SDS})$ and reagent $\mathrm{B}\left(4 \% \mathrm{CuSO}_{4} \cdot 5 \mathrm{H}_{2} \mathrm{O}\right)$ ) and incubated 10 min. One hundred microliters reagent $\mathrm{D}\left(1: 1\right.$ Sigma Folin-Ciocalteu $2 \mathrm{~N}$ phenal reagent: $\left.\mathrm{H}_{2} \mathrm{O}\right)$ was added; the mixture was incubated $45 \mathrm{~min}$, and the absorbance at $730 \mathrm{~nm}$ was read against a ieagent blank.

Fractionation 1- Organelle isolation by differential centrlfugation. Crude extract was fractionated by a differential centrifugation scheme using a Beckman L ultracentrifuge with type $50 \mathrm{Ti}$ and type 21 rotors. The centrifugation sequence was $5 \mathrm{~min}$ at $500 \mathrm{~g}$ to remove cell debris, 5 min at $3000 \mathrm{~g}$ to obtain a crude plastid pellet, $15 \mathrm{~min}$ at $18,000 \mathrm{~g}$ for a crude mitochondrial pellet. and $1 \mathrm{~h}$ at $100,000 \mathrm{~g}$ to obtain a microsomal pellet and a soluble protein supernatant. Pellets were resuspended in $300 \mu$ BUFFER B $(0.1 \mathrm{M}$ potassium phosphate, $\mathrm{pH} 7.2$ or $7.9,30 \mathrm{mM}$ EDTA, $10 \mathrm{mM}$ DTE) containing $0.04 \%$ Triton X-100. B:JFFER B of p.4 7.9 was used to resuspend the $3000 \mathrm{~g}$ pellet only. Each pellet Iraction and the soluble protein fraction $(100,000 \mathrm{~g}$ supematant) were assayed tor HMGR activify and protein content (METHOD 1).

Fractionation 2- Concentration of HMGR In a particulate fracion. A pellet fraction containing HMGF activity was obtained by first centrifuging the crude extract at $500 \mathrm{~g}$ for 5 min to remove cell debris and then centrifuging at $18,000 \mathrm{~g}$ for $20 \mathrm{~min}$ to sediment the HMGR-containing organelles (18.000Q Pellet). In this experiment the supernatant was divided into seven tractions before the centritugation at $18,000 \mathrm{~g}$ giving seven different pellets to lest under varıous conditions. Five of the pelleted fractions were resuspended in $250 \mu$ BUFFER $B$ containing $0.04 \%$ Triton $X-100$ at various $\mathrm{pH}$ values to investigate the $\mathrm{pH}_{\text {max }}$ of HMGF; the sixth and seventh tractions were resuspended in 250 and $500 \mu$ BUFFER B pH 7.5 containing $0.04 \%$ 
Triton X-100, respectively. All fractions were sonicated for $30 \mathrm{~s}$, then an $150 \mu$ aliquot of fractions 1-6 was assayed for HMGR activity, the sixth fraction in the presence of $0.5 \mu \mathrm{M}$ mevinolin, potassium salt. Mevinolin was converted from the lactone to its potassium salt foltowing the procedure of Kita, Brown, and Goldstein(19). The seventh fraction was centrifuged at $100,000 \mathrm{~g}$ for $1 \mathrm{~h}$, and the pellet was resuspended in BUFFER B containing $0.04 \%$ Triton $\mathrm{X}-100, \mathrm{pH} 7.5$; $150 \mu$ l each of the supernatant and peliet was assayed for HMGR activity. The remainder of the fractions was saved for protein assay (METHOD 1).

Solubilization of HMGR. The ability of three different detergent treatments ( $1 \%$ Triton $\mathrm{X}-100,1 \%$ Triton $\mathrm{X}-100 \div 2 \%$ SDS, $0.25 \%$ sodium deoxycholate) to solubilize HMGR trom the $18.000 \mathrm{~g}$ Pellet was tested by incubating the pellet with the detergent in $0.5 \mathrm{ml}$ BUFFER $\mathrm{B} \mathrm{pH}$ 6.7 for 20 min at $0-4 C$. diluting the samples to $1.5 \mathrm{ml}$ with BUFFER $B$, centrifuging the samples at $100.000 \mathrm{~g}$ for $1 \mathrm{~h}$ then assaying the HMGR activity and protein concentration (METHOD 1) of the resultant supernatant and pellet fractions. The $100,000 \mathrm{~g}$ pellets were resuspended in $250 \mu$ BUFFER B.

Effect of protease Inhibitors on HMGR actlvity and solubllization. The 18.000 e Peilet was incubated for $1.5 \mathrm{~h}$ with $0.25 \%$ sodium deoxycholate in $1 \mathrm{ml}$ BUFFER B pH 6.8 under two protease inhibitor treatments (1 mM PMSF, $0.1 \mathrm{mM}$ leupeptin) and a control treatment with no inhibitor. Samples were diluted to $1.5 \mathrm{ml}$ with BUFFER B, centrifuged at $100,000 \mathrm{~g}$ for $1 \mathrm{~h}$, and the supernatants and pellets from each incubation were analyzed for HMGR activity and protein content (METHOD B). The $100,000 \mathrm{~g}$ pellets were resuspended in $0.5 \mathrm{ml}$ BUFFEA $\mathrm{B}$.

Further effect of protease Inhibitors and detergents on HMGR actlvilty and solubilization. A cnude extracl was prepared from $16.8 \mathrm{~g}$ E. Jathyris tissue as described giving $75 \mathrm{ml}$ homogenate. This was divided $2: 1$, and $0.5 \mathrm{mi} 10 \mathrm{mM}$ leupeptin and $0.5 \mathrm{ml} 0.1 \mathrm{M}$ PMSF in elhanol was added to the first pan. The second part was treated with only $0.25 \mathrm{ml} 10 \mathrm{mM}$ leupeptin. The finat concentrations of leupeptin and PMSF were $0.1 \mathrm{mM}$ and $1 \mathrm{mM}$, respectively. An $150 \mu$ afiquot of the ende extract cortaining both inhibitors was assayed for HMGR activity, and the remainder of 
that $50-\mathrm{ml}$ portion was divided in hall. The three $25 ., \mathrm{nl}$ samples were centrifuged at $18,000 \mathrm{~g}$ for $20 \mathrm{~min}$, and the supernatants were removed. Two $150 \mu \mathrm{l}$ aliquots of the $18,000 \mathrm{~g}$ supernatant containing both protease inhii yitors were assayed for HMGR activity. One was quenched immediately to serve as a blank. The $18,000 \mathrm{~g}$ pellets were each resuspended iif $1 \mathrm{ml}$ solubilization buffer with differing detergent and protease inhibitar components (Table 1); the pellet from the crude extract containing leupeptin was resuspended in solubilization buffer a. The samples were treated for $1.5 \mathrm{~h}$ at $28^{\circ} \mathrm{C}$, were diluted to $1.5 \mathrm{ml}$ with BUFFER $\mathrm{B}$, and were centrifuged at $100,000 \mathrm{~g}$ for $1 \mathrm{~h}$. The supematants were removed, and the pellets were resuspenged in $0.5 \mathrm{ml}$ BUFFER B. A $150 \mu$ aliquot of the supermatant and pellet from each treatment was assayed for HMGR activity.

\section{Iable L components of Solubilization Buffers a.b. and}

1 misolubilization butter-

$0.5 \mathrm{ml} 2 \times$ BUFFER $8 \mathrm{pH} 6.8$

$0.125 \mathrm{ml} 2 \%$ sodium deoxycholate

$0.01 \mathrm{mi} 10 \mathrm{mM}$ 'aupeptin

$0.01 \mathrm{ml} 0.1 \mathrm{M}$ PMSF in ethanol

$0.335 \mathrm{ml} 6 \%$ polyoxyethylene ether $W-1$

$0.01 \mathrm{ml}$ ethanol

$\begin{array}{lll}a & b & c \\ + & + & + \\ - & + & + \\ + & + & + \\ + & + & - \\ + & - & - \\ - & - & + \\ 0.145 & 0.355 & 0.355\end{array}$

mi water 


\section{RESULTS}

Locatlon of HMG-CoA Reductase. The initial differential centrilugation procedure, based on that used by Brooker and Russell in their study of the subcallular location of HMGR in pea seedlings, separated the lissue homogenate into crude fractions enriched in certain subcellular components (9). While not being purified organellar tractions, the tour ractions abtained roughly represent the chloroplastic, mitochondrial, microsomal and soluble protein components of the crude extract (16). The major portion of HMG-CoA reductase activity was found associated with the $3000 \mathrm{~g}$ plastid-enriched pellet (Table 1). HMGR activity was also found in the other fractions with the soluble protein fraction $(100,000 \mathrm{~g}$ supernatant) containing the next highest level of activity followed by the crude mitochondrial fraction $(18.000 \mathrm{~g}$ pellet) which had the highest specific activity of HMGR. The microsomal pe!let contained the smallest portion of the total activity. The specific activity of HMGR measured in the crude extract and the subcellular fractions was on the order of one thousand times higher than that measured in the latex alone (Ch. 1).

Concentration of HMG-COA reductase in a particulate fractlon. Further purification of HMG-COA reductase was based on these initial findings. Consequently, it was decided to concentrate the $75 \%$ of the recovered activity found in the $3000 \mathrm{~g}$ and $18,000 \mathrm{~g}$ pellets together by centriluging once at $18,000 \mathrm{~g}$. This resulted in a particulate fraction containing $38 \%$ of the

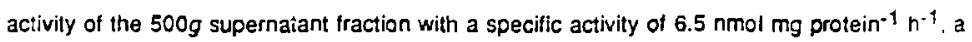
1.4-told puritication based on the $500 \mathrm{~g}$ supernatant fraction (Tablo II). A signilicant portion of HMGR activity was atso found associated with the $500 \mathrm{~g}$ pellet, so in later experiments. this centritugation step was elirninated.

Propentes of particulate HMG-COA reduct.3se. HMG-COA reductase activity of the $18,000 \mathrm{~g}$ pellet has a $\mathrm{pH}_{\max }$ of 6.8 (Fig. 1). Mevinolin (Fig. 2) is a fungal metabolite which has been found to be a nighly spectic competitive inhibitor of HMG-CoA reductase (13). It has been shown to be eflective with higher plant HMGR as well as with the mammalian enzyme (3). E. Iathyris HMG-CoA 
Table I. Distribution of HMG-CoA Reductase Activity in Subcellular Fractions from Euphorbia lathris vegetative tissue

\begin{tabular}{|c|c|c|c|c|c|}
\hline & (nmol h-1) & $\begin{array}{l}\text { Iotal Activ } \\
\text { (\% of total ( } \\
\text { fractions) }\end{array}$ & $\begin{array}{l}\text { (\% recovered of } \\
\text { cude extract) }\end{array}$ & $\frac{\text { Iotal Protein }}{(\mathrm{mg})}$ & $\frac{\text { Specific Activity }}{\text { (nmol mg protein }}-1$ \\
\hline $\begin{array}{l}\text { Crude } \\
\text { Extract }\end{array}$ & 360. & & & 70. & 5.1 \\
\hline $\begin{array}{l}3000 \mathrm{~g} \\
\text { pellet }\end{array}$ & 48. & 62 & 13 & 18. & 2.7 \\
\hline $\begin{array}{l}18,000 \mathrm{~g} \\
\text { pellet }\end{array}$ & 10. & 14 & 3 & 1.4 & 7.1 \\
\hline $\begin{array}{l}100,000 \\
\text { pellat }\end{array}$ & 5. & 6 & 1 & 1.4 & 3.6 \\
\hline $\begin{array}{l}+00,000 \mathrm{~g} \\
\text { supenatant }\end{array}$ & 14. & 18 & 4 & 17. & 0.8 \\
\hline$\Sigma$ all fractions & 76 & $100 \%$ & $2+\%$ & & \\
\hline
\end{tabular}

Table II. Concentration of HMG-CoA Reductase in a Particulate Fraction

\begin{tabular}{|c|c|c|c|c|}
\hline & $\begin{array}{r}\text { Iota } \\
\left(\mathrm{nmol} \mathrm{h}^{-1}\right)\end{array}$ & $\begin{array}{l}\text { Activity } \\
\text { (as \% of } 500 \mathrm{~g} \\
\text { supematant) }\end{array}$ & $\begin{array}{l}\text { Total Protein } \\
\text { (mg) }\end{array}$ & $\frac{\text { Specificectivity }}{(\mathrm{nmol} m g \text { protein }} \mathrm{n}^{-1}$ ) \\
\hline $\begin{array}{l}500 g \\
\text { supernatant }\end{array}$ & 252. & & 53. & 4.8 \\
\hline $\begin{array}{l}500 \mathrm{~g} \\
\text { pellet }\end{array}$ & 35. & & 15. & 2.3 \\
\hline $\begin{array}{l}18,000 \mathrm{~g} \\
\text { supernatant }\end{array}$ & - & & 32. & - \\
\hline $\begin{array}{l}18,000 \mathrm{~g} \\
\text { peliet }\end{array}$ & 96. & 38. & 15. & 6.5 \\
\hline
\end{tabular}




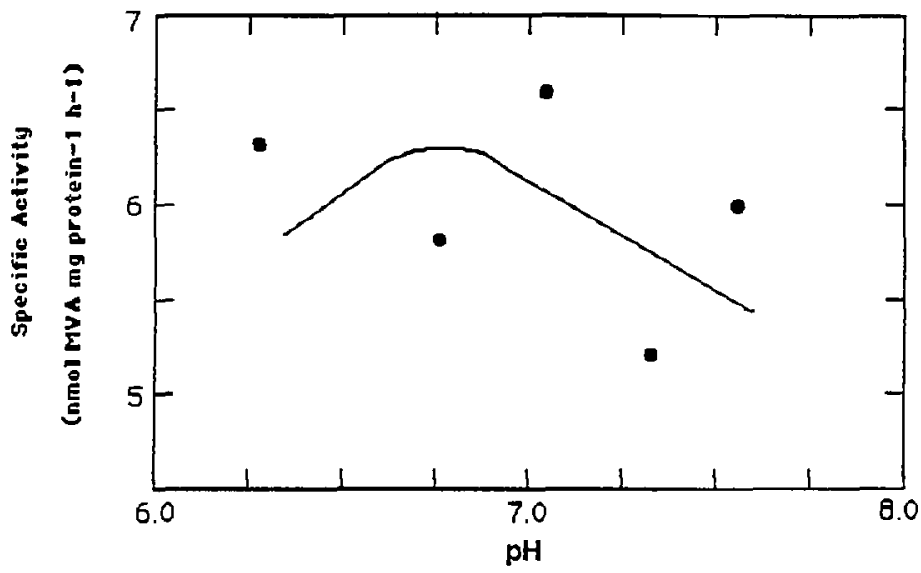

Fig.1. Effect of pH on the specific activity of particulate HMG-CoA reductase from E. lathyris.

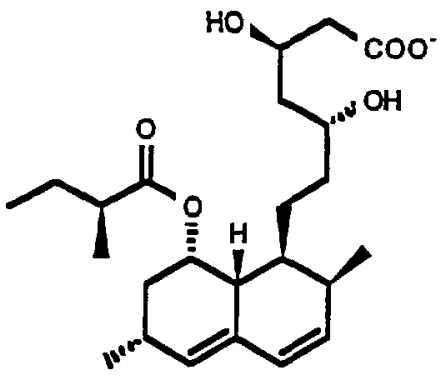

Fig. 2. Structure of the fungai metabolite mevinolin, a competitive inhibiter of HMG-CoA reductase. 
reductase is sensitive to inhibiticn by mevinolin, HMGR activity being reduced by $80 \%$ in the presence of $0.5 \mu \mathrm{M}$ mevinolin (Table III). HMG-CoA reductase localized in this heavier organellar fraction $(18,000 \mathrm{~g}$ pellet) is membrane-bound as demonstrated by the fact that $75 \%$ of the HMGR activity was found to be associated with the particulate traction after a $18,000 \mathrm{~g}$ pellet was sonicated to rupture the organelles and then centrituged for $1 \mathrm{~h}$ at $100,000 \mathrm{~g}$ (Table III).

Solubilization of HMG-CoA Reductase. In an experiment testing the effect of different detergents on the solubilization of HMGR, deoxycholate treatment was the most effective of the detergents tested (Table IV). In addition to showing the highest ratio of HMGR activity in the supernatant versus in the particulate fraction, the combined activity measured in the $100,000 \mathrm{~g}$ supernatant and pellet with this treatment was an order of magnitude greater than that measured for the two other treatments, $1 \%$ Triton $X-100$ and $1 \%$ Triton $X-100+2 \%$ SDS. In a second experiment comparing deoxycholate treatment with polyoxyethylene ether $W_{1}(B r i)$ in the presence of protease inhibitors, total recovery from the deoxycholate treatment was higher, but the ratio of solubilized to particulate HMGR activity was higher in the case of the Brij treatment since the activity detected in the pellet was so low (Table VI).

EHect of Protease inhibltors on HMG-CoA reductase. The effect of prorease inhibitors was investigated to assess the role that proteolytic enzymes might play in the recovery of activity and the solubilization of HMGR from $E$. lathyris. Upon sitting for 140 min at $0-4 C$, the HMGR activity of a $500 \mathrm{~g}$ supernatant decreased trom $2.6 \mathrm{nmol} \mathrm{mg}$ protein-1 $\mathrm{h}^{-1}$ to $1.8 \mathrm{nmol} \mathrm{mg}$ protein-1 $\mathrm{h}^{-1}, \mathrm{a}$ $31 \%$ loss in activity, indicating the possible action of proteases (Table IV). While the $3000 \mathrm{~g}$ and $18,000 \mathrm{~g}$ pellets of the onginal Iractionation of the crude extract did represent $75 \%$ of the recovered activity, only $21 \%$ of the total activity of the crude extract was recovered among all the fractions (Table 1). Treatment of the $18,000 \mathrm{~g}$ pellet with either serine or thiol protease inhibitors improved the recovery of HMGR activity in both the soluble and particulate tractions ; leupeptin treatment gave the greatest improvement (Table V). The PMSF-treated sample had a lower ratio of supematant 10 pellet activity than untreated sample did, while leupeptin treatment 
Table Ilt. Effect of Mevinolin on Activity and Distribution of Activity between Soluble and Membrane-Bound Fractions of HMG-CoA Aeductase from a Particulate Fraction

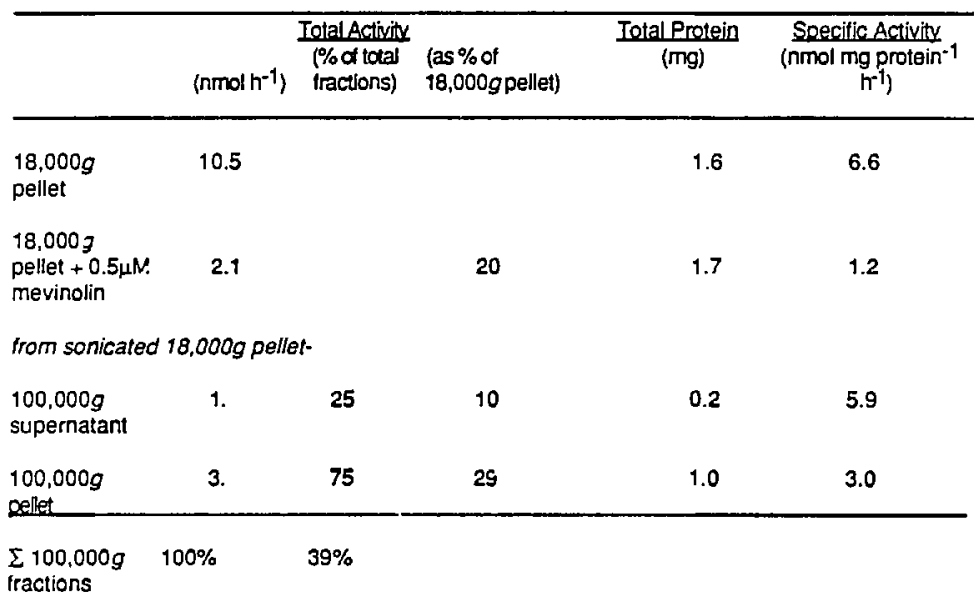


Table IV. Effect of Detergent Trearment on Solubilization and Activity of HMG-CoA Reductase from a Particulato Fraction

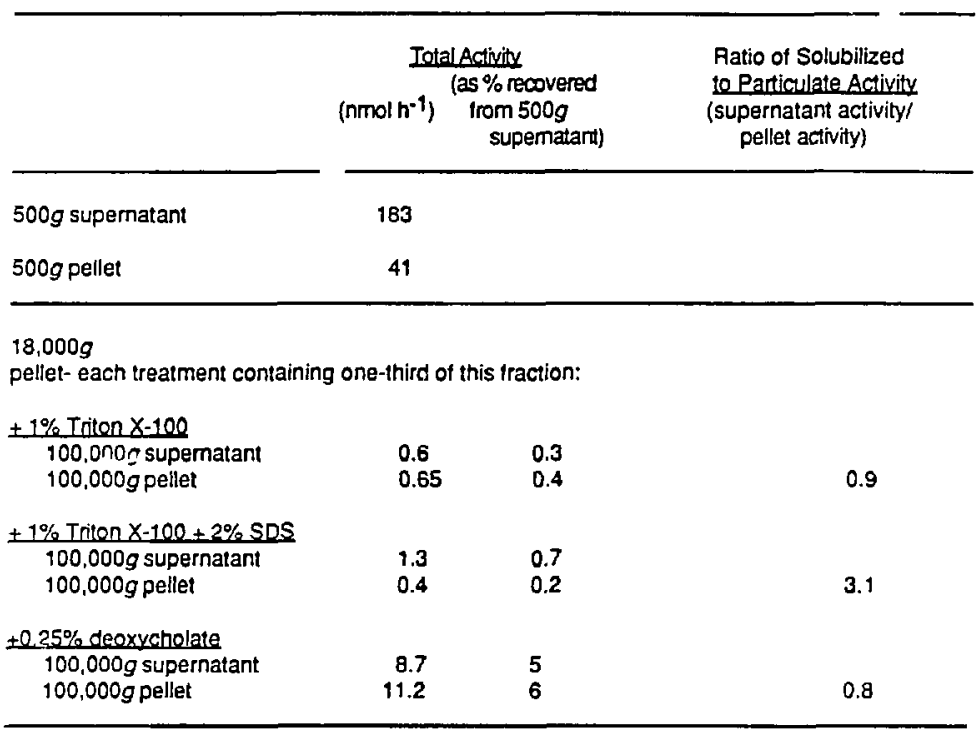

$500 \mathrm{~g}$

supernatant- atter sitting $140 \mathrm{~min}$ at $0-4^{\circ} \mathrm{C}$ : 
Table V. Effect of Protease Inhibitors on Recovery and Solubilization of HMG-CoA Reductase from a Particulate Fraction

\begin{tabular}{|c|c|c|c|}
\hline & $\begin{array}{l}\text { Specilic Activity } \\
\text { (supernatant+pellet } \\
\text { nmol mig protein }{ }^{-1} h^{-1} \text { ) }\end{array}$ & $\begin{array}{c}\text { Iotal Activity } \\
\left.\text { (nmol } h^{-1}\right)(\text { as } \% \text { of } \\
\text { cude extract) }\end{array}$ & $\begin{array}{l}\text { Ratio of Solubilized to } \\
\text { Particulate.Activity } \\
\text { (supernatant activity/ } \\
\text { pellet activity }\end{array}$ \\
\hline crude extract & 1.6 & 198 & \\
\hline
\end{tabular}

$18,000 g$

pe let-each treatment containing one-third of this fraction:

$\pm 0.25 \%$ deoxycholate

$100,000 \mathrm{~g}$ supernatant

$100,000 g$ pellet

3.9

5.8

2

1.8

0.67

$+0.25 \%$ deoxycholate,

$1 \mathrm{MMPMSE}$

$100,000 \mathrm{~g}$ supernatant

$100,000 \mathrm{~g}$ pellet

$\begin{array}{rr}6.1 & 3 \\ 12.8 & 6\end{array}$

3.9

6

$\begin{array}{lll}12.8 & 0.48\end{array}$

$+0.25 \%$ deoxycholate,

2.1 mM leupeptin

$100,000 \mathrm{~g}$ supernatant

$100,000 \mathrm{~g}$ pellet

21.7

10.6

11

5 
Table VI. Elfect of Protease Inhibitors on Recovery of HMG-CoA Reductase Activity and Comparison of Solubilization of HMG-CoA Reductase by Deoxycholate or Polyoxyethylene Ether (Brij)

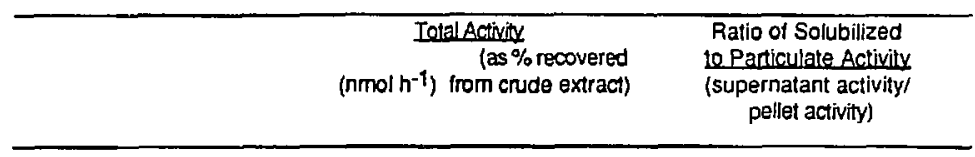

crude extract 278

$18,000 \mathrm{~g}$

supernatant

189

68

$18,000 \mathrm{~g}$

pellet- each treatment containing one-third of this traction:

$+2 \%$ Brii.

$1 \mathrm{mM}$ PMSF,

Q.110Mleupentin

$100,000 \mathrm{~g}$ supematant

$100,000 \mathrm{~g}$ pellet

28

0.05

10

0.02

560

$+0.25 \%$ deoxycholate,

$1 \mathrm{mM}$ PMSF,

$0.1 \mathrm{mM}$ leuperotin

$100,000 \mathrm{~g}$ supematant

$100,000 \mathrm{~g}$ pellet

22

8

114

2

$+0.25 \%$ deoxycholate,

0. $\mathrm{mM}$ leureptin

$100,000 \mathrm{~g}$ supematant

$100,000 \mathrm{~g}$ pellet

12

4

83

1.5

$\Sigma$ all fractions

$270 \quad 97 \%$ 
improved the ratio by a factor of three. In a later experiment where both protease inhibitors were added to the crude extract. the total recovery of the activity of the crude extract among the subsequent fractions was $97 \%$ (Table VI.). Here $68 \%$ of the activity was associated with the $18,000 \mathrm{~g}$ supematant, a traction containing microsomal and soluti:s proteiris. Treatment of the $18.000 \mathrm{~g}$ pellet with both inhibitors improved the recovery of HMGR, both solubilized and membrane-bound, as compared to treatment with leupeptin alone.

\section{D:SCUSSION}

Distribution of HMG-CUA reductase activity among subcellular fractlons of $E$. lathyris tissue. Gased on the initial differential centrifugation fractionation of the $E$. lathyris tissue homogenate, it appeared that the major portion of HMGA was located in the heavy, organellar traction. Thirty-eight percent of the activity of a $500 \mathrm{~g}$ supernatant sedimented when that fraction was centrifuged at $18,000 \mathrm{~g}$ lor $20 \mathrm{~min}$ (Table 2). Both plastids and mitochondria appear to contain their own HMG-COA reductase since the plastid-enriched fraction had the highest level of activity and the mitochondrial pellet had the highest specific activity of any fraction (Table 1).

The paucity of HMGR activity in the microsomal faction is most interesting since the endoplasmic reticul' $m$ is the putative site of triterpenoid biosynthesis. Since only $21 \%$ of the HMGR activity of the crude extract was recovered among the differential centrifugation tractirns. the low activity of the microsomal fraction could be a result of isolation conditions. In the chrysophycean alga Ochromonas nahamensis which contains $1 \%$ dry weight of poriferasterol, $90 \%$ of the HMGR activity was localizet in the microsomal pellet, but HMGR activity was only deteciable in the presence of $>1 \%$ (WN) BSA (23). In a later experiment with $E$. lathyris, it was demonstrated that the inclusion of protease inhibitors during the fractionation improved the recovery of the activity of the crude extract $1097 \%$; the majority of this activity $(70 \%)$ was in the $18,000 \mathrm{~g}$ supernatant (Table VI). Whether this activity was microsomal or soluble is not known. 
however, the HMGR in the supernatant appears much more susceptable 10 proteolytic inactivation than the HMG-CoA reductase found associated with the organellar fractions. Based on these fractionation experiments, $E$. lathyris contains HMG-CoA reductase in a number of subcellular locations with up to $40 \%$ of the activity associated with the plastids and mitochondria. The remainder of the activity is microsomal or soluble. The distribution of HMGR among various organelles suggests the possibility of different isozymes of the enzyme and does not suppont the belief that IPP is synthesized in the cytoplasm and distributed to the different subceilular structures for further metabolism.

These findings can be compared with results of investigations into the subcellular location of HMGR in other onganisms. In mammalian systems HMG-CoA reductase has been thought to be exclusively localized to the endoplasmic reticulum (10), atthough recently its presence in the peroxisomes of rat liver celis has been demonstrated both enzymatically and immunolugically (19). Yeast HMGR is located in the mitochondra (26). In higher plants HMG-CoA reductase has been localized in a number of different subcelfular sites. In pea seedlings $80 \%$ of the HMGR activity was found to be associated with the microsomal fraction with the remaining activity equally divided between the plastid and mitochondrial tractions (9). Two separate HMGR activities were located in Nepeta cataria leaf tissue, one activity associated with the chloroplast and a second activity that could be sedimented by centritugation at $100,000 \mathrm{~g}$ (11). In radish seedling extracts, HMG-COA reductase was found in both the organellar $(16,000 \mathrm{~g}$ pellet) and microsomal (100,000 gellet) fractions, with the $16,000 \mathrm{~g}$ pellet activity co-migrating on Percoll gradients with the mitochondrial marker enzyme cytochrome oxidase (2). The presence of HMG-CoA reductase in the $\$ 8,000 \mathrm{~g}$ pellet is consistent with its location in the $5000 \mathrm{~g}$ pellet of E. lathyris latex (Ch. 1) and in Hevea brasiliensis latex where it was found in a $40,000 \mathrm{~g}$ pellet (27).

Properties of organellar HMG-CoA reductase. The optimum pH found for HMG-CoA reductase of the $18,000 \mathrm{~g}$ pellet of 6.8 is comparable to that found for HMGR in other vegetative tissue. In pea seedlings, the plastid HMGR has a pH optimum of 7.9 while the microsomal enzyme 
has a $\mathrm{pH}_{\text {max }}$ of 6.9 (29). Purified HMG-CoA reductase frem a heavy-membrane fraction of radish seedlings was consistently assayed at $\mathrm{pH} 7.5$, presumably the optimum pH for that enzyme (4). The difference in the optimal pH measured for HMGR from stem and leaf tissue (pH 6.8) from that measured in latex alone (pH 5.9, Ch. 1) is a further indication of the existence of different forms of HMG-CoA reductase from the two tissue types in $E$. lathyris, although a more detailed analysis of the effect of $\mathrm{pH}$ on purified enzyrne is needed to confirm this.

Solubilization of HMG-CoA reductase. in the presence of protease inhibitors, Brij was the best solubilizing agent for HMGR of the $18,000 \mathrm{~g}$ pellet, although deoxycholate treatment gave a greater recovery of total HMG-CoA reductase, both solubilized and still membrane-bound (Table VI). Since the recovery of the activity of the crude extract among all fractions in that experiment totaled $97 \%$, no activation of HMGR was evident. In the absence of protease inhibitors, deoxycholate treatment increased total HMGR activity compared to treatment with Triton $x-100$ or Triton-X 100 + SDS (Table IV). While activation of HMGR upon deoxycholate treatment has been seen with the mammalian enzyme, Bach found that deoxycholate inhibited HMGR activity in radish seedlings (4). Maurey et al. found that microsomal HMG-CoA reductase activity from $O$. malhamensis was stimulated $c a 60 \%$ in the presence of $0.5-1 \%$ Triton $X-100$ (23). These diflerences may represent variability in the makeup of the membranes containing HMGR in the various organisms. In the case of the initial experiment comparing the effects of different detergents on E. lathyris HMGR activity (Table IV), what appears to be an activation by the deoxycholate treatment may well instead represent the ability of deoxycholate to better protect HMGR from proteolytic inactivation than the other detergents tried.

Elfect of protease Inhibitors on organellar HMG-CoA reductase. In mammalian systems, solubilization of HMG-COA reductase has been achieved with detergents and also through the action of proteolytic enzymes which have been shown to cleave the soluble catalytic domain from the membrane-bound domain (24). The truncated soluble portion of the enzyme retains its catalytic activity. Whether this kind of action was affecting the solubilization of E. lathyris 
organellar HMGR was investigated. While $E$. lathyris latex has been reported to contain serine proteases (21), it is thiol proteases that are responsible for the solubilization of HMGR in mammalian systems. The presence of leupeptin or PMSF during homogenization did not affect HMGR recovery in either radish or Cchromonas $(4,23)$. With $E$. lathyris, when either the thiol protease innibitor leupeptin or the serine protease inhibitor PMSF was added to the deoxycholate treatment for the solubilization of HMG-COA reductase from the $18,000 \mathrm{~g}$ pellet, higher HMGR activity was obtained than without any protease inhibitor added (Table V). Neither inhibitor significantly decreased the ratio of solubilized HMGR activity to particulate activity indicating that proteolytic action is not responsible for the solubilization of $E$. lathyris $\mathrm{HMG}-\mathrm{COA}$ reductase. In fact, leupeptin treatment increased the ratio probably because the detergent-solubilized HMGR is niore susceptable to protease action than the protein that is still membrane-bound, and the protease inhibitor is reducing the inactivation of the solubilized enzyme. Both endogenous serine and thiol proteases are responsible for the inactivation of $E$. lathyris HMGR since the addition of both inhibitors together improved the recovery of HMGR activity as compared to treatment with leupeptin alone (Table VI).

\section{CONCLUSIONS}

Euphorbia lathyris vegetative tissue appears to contain at least one iso-enzyme of HMG-CoA reductase that differs in its optimum $\mathrm{pH}$ from the HMGR detected in the latex. In addition, it is likely that there exist different forms of the enzyme associated with the plastids, mitochondria, and endoplasmic reticulum. The enzyme(s) located in the organellar fraction (plastids + mitochondria) is membrane-bound and is best solubilized by treatment with Brij. Endogenous proteases are capable ot inactivation of this organellar enzyme but do not act to solubilize HMGR activity.

Inclusion of protease inhibitors in the homogenization and solubilization media is an 
important requirement for further purification work. As further purification is achieved and HMG-COA reductase is separated from the proteolytic enzymes, the inhibitors can be removed from the preparation. The first steps in purification of this enzyme, concentration of the organellar HMGR in a particulate fraction by centrifugation at $18,000 \mathrm{~g}$ and solubilization of the enzyme from the membrane with $2 \%$ Brij have been delineated here. Possibilities for additional puritication steps present themselves. An ammonium sulfate precipitation of the enzyme is a good next step. A HMG-COA aftinity column has been used with great success in a number of purifications of this enzyme (25). If the plant enzyme is glycosylated as is its mammalian counterpart, a concavalin A column would be useful in its ability to bind glycoproteins. 


\section{LITERATURE CTTED}

1. Alberts AW, J Chen, G Kuron, V Hunt, J Huff, C Hoffman, J Rothrock, M Lopez, H Joshua, E Harris, A Patchett, R Monaghan, S Cuffie, E Stapley, G Albers-Schonberg, O Hensens, J Mirschtield, $K$ Hoogsteen, J Liesch, J Springer 1980 Mevinolin, a highly potent competitive inhibitor of HMG-COA reductase and cholesterol lowering agent. Proc Natl Acad Sci USA 77: 3957-3961

2. Bach TJ, HK Lichtenthaler, J Retey 1980 Properties of membrane-bound 3-hydroxy-3-methylglutaryl coenzyme A reductase (EC.1.1.1.34) from radish seedlings and some aspects of its regulation. Dev Plant Biol 6: 355-362

3. Bach TJ, HK Lichtenthaler 1982 Mevinolin: a highly specific inhibitor of microsomal 3-hydroxy-3-methylglutaryl-coenzyme A reductase of radish plants. Z Naturforsch $37 \mathrm{c}$ : 46-50

4. Bach TJ, DH Rogers, H Rudney 1986 Detergent-solubilization, purification, and characterization of membrano-bound 3-hydroxy-3 - methylglutaryl coenzyme A reductase from radish seedlings. Eur $\mathrm{J}$ Biochem 154: 103-111

5. Beg ZH, JA Slonik, HB Brewer, It 1980 In vilo and in vio phosphorylation of rat liver 3-hydroxy-3-methyiglutaryl coenzyme $A$ reductase and its modulation by glucagon. $J$ Eiol Chem 255: 8541-8545

6. Bensadoun A, D Weinstein 1976 Assay of proteins in the presence of intertering materials. Anal Biochem 70: 241.50

7. Bradfond MM 1976 A rapid and sensitive method for the quantitation of microgram quantities of protein utilizing the principle of protein-dye binding. Anal Biochem 72: 248-254

8. Brooker JD. DW Russell 1975 Propenies of microsomal 3-hydroxy-3-methyigiutaryl coenzyme A reductase from Pisum sativum seedlings. Arch Biochem Biophys 167: 723-729

9. Brooker JD, DW Russell 1975 Subcellular localization of 3-nydroxy-3-methylgiutary! coenzyme A reductase in Pisum sativum seedlings. Arch Biochem Biophys 167: 730-737 
10. Brown MS, JL Goldstein 1980 Mulitivalent feedback regulation of HMG-CoA reductase, a control mechanism coordinating isoprenoid synthesis and cell growth. $J$ Lipid Res 21: $505-517$

11. Cerebalo RE, ED Mitchell Jr 1984 Cellular distribution of 3-hydroxy-3-methylglutaryl coenzyme A reductase and mevalonate kinase in leaves of Nepeta cataria. Phytochem 23: 13-18

12. Chin DJ, KL Luskey, JR Faust, RJ MacDonald, MS Brown, JL Goldstein 1982 Molecular cloning of 3-hydroxy-3-methylglutaryl coenzyme A reductase and evidence for regulation of its mRNA. Proc Nall Acad Sci USA 79: 7704-7708

13. Endo A, Y Tsujita, M Kroda, K Tanzawa 1977 Inhibition of cholesterol synthesis in vitro and in vivo by ML-236A and ML-236B, competitive inhibitors of 3-hydroxy-3-methylglutaryl coenzyme A reductase. Eur J Biochem 77: 31-36

14. Garg VK, TJ Douglas 1983 Hydroxymethylglutaryl CoA reductase in plants. In JR Sabine, ed, Monographs on Enzyme Biology: HMG-CoA Reductase, CRC Press, Boca Raton

15. GjJ G, JR Faust, DJ Chin, JL Goldstein, MS Brown 1985 Membrane-bound domain of HMG-CoA reductase is required for sterol-enhanced degradation of the enzyme. Cell 41: 249-258

16. Goodwin TW, ED Mercer 1983 introduction to Plant Biochemistry, 2nd ed, Pergamon Press, Oxtord

17. Faust JR, JL Goldstein, MS Grown 1979 Synthesis of ubiquinone and cholesterol in huinan fibroblasts: regulation of a branched pathway. Arch Biochem Biophys 192: 86-99

18. Keller GA, MC 8arton, DJ Shapiro, SJ Singer 1985 3-hydroxy-3-methylglutaryl coenzyme A reductase is present in peroxisomes in nomal rat liver cells. Proc Natl Acad Sci USA 82: $770-774$

19. Kita T, MS Brown, JL Goldstein 1980 Feedback regulation of 3-hydroxy-3- methyiglutaryl coenzyme A reductase in livers of mice treated with mevinolin, a competitive inhibitor of the reductase. J Clin Invest 66: 1094-1100 
20. Kreuz K, H Kleinig 1984 Synthesis of prenyl lipids in cells of spinach leaf. Compantmentation of enzymes for formation of isopentenyl diphosphate. Eur J Biochem 141: 531-535

21. Lynn KR, NA Clevefte-Radford 1983 Isolation and characterization of euphorbain 1, a proteinase from the latex of Euphobia lathyris. Biochim Biophys Acta 746: 154-159

22. Markwell MAK, SM Haas, NE Tolbert, LL Bieber 1981 Protein determination in membrane and lipoprotein samples: manual and automated procedures. Meth Enz 72: 296-303

23. Maurey K, F Wolf, J Goldbeck 1986 3-hydroxy-3-methylglutaryl coenzyme A reductase activity in Ochromonas malhamensis. Plant Physiol 82: 523-527

24. Ness GC, SC Way, PS Wickham 1981 Proteinase involvement in the solubilization of 3-hydroxy-3-methylglutaryl coenzyme A reductase. Biochem Biophys Res Comm 102: 81-85

25. Rogers DH, SR Panini, H Rudney 1980 Rapid, high-yield puritication of rat liver 3-nydroxy-3-methyl-glutaryl-coenzyme A reductase. Anal Biochem 101: 107-111

26. Shimizu 1, J Nagaj, It Hatanaka E Saito, H Katsuki 1971 Subcelkular localization of 3-hydroxy-3-methylglutanyl CoA reductase in Saccharomyces cerevisiae. J Biochem 70: 175

27. Sipat $A B 1982$ Hydroxymethylglutaryl CoA reductase (NADPH) in the latex of Hevea brasiliensis. Phytochem 21:2613-2618

28. Vincent R, D Nadeau 1983 A micromethod for the quantitation of cellular proteins in Percoll with the Coomassie brilliant blue dye-binding assay. Anal Biochem 135: 355-362

29. Wong RJ, DK McCormack, DW Russell 1982 Plastid 3-hydroxy-3-methylglutaryl coenzyme A reductase has distinctive kinetic and regulatory leatures: properties of the enzyme and positive phytochrome control of activity in pea seedlings. Arch Biochem Biophys 216: 631.638 


\section{Chapter III. ULTRASTRUCTURE OF EUPHORBIA LATHYRIS LATEX}

While the extrusion of latex produced upon the cutting of laticifer-bearing plant tissue has been beneficial to the study of the metabolism of these cells, it can hamper ultrastructural investigations. Due to the fube-like structure and high turgor pressure of laticifer cells, often these cells can emply of their contents, leaving no observable structures within the cells in micrographs of the tissue. If splure of the tonoplast occurs, allowing the contents of the cytoplasm and vacuole to mix, the inve location of any structure within the cell is difficult 10 assess. The latex itself poses an unique problem in botanical microscopy; it is essentially a mix of the vacuolar contents and the cytoplasm of the lariciler, a solution of subcellular structures without the benefit of a cell wall to contain them.

Despite these difficulties, the cytology of the laticiter cell has been detailed. Once again, Hevea is the prototype. Hevea laticifers contain the normal cellular substructures such as nuclei, mitochondria, endoplasmic reticulum, and ribosomes, but wo other particles were also observed in these cells. Lutoids are structures bound by a single membrane, with a diameter of 0.5 to 5 $\mu \mathrm{m}$. The second, less abundant component unique to Hevea latex is the Frey-Wyssling complex, a particle of diameter 4 to $6 \mu \mathrm{m}$ bounded by a double membrane and containing lipid globules and various membranous structures; it is thought to be a type of plastid. In addition, numerous minute polyisoprene latex particles constitute the rubber phase of the laticifer and distinguish these cells (1).

In tapped latex Gomez found rubber particles, lutoids, and Frey-Wyssling complexes; mitochondria and nuclei were rarely seen ( 7$)$. Upon centritugation the lutoids sediment; they can comprise up to $20 \%$ of the latex volume (2). The biochemistry of these organelles has been well-studied, and they are considered to be lysosomal vacuoles. They contain acid hydrolases as well as peroxidase, lysozyme, and $\alpha$-mannosidase (2). The lutoid membrane is composed primarily of phosphatidic acid which accounts for greater than $80 \%$ of the total lipid (4).

Studies of Euphorbia species have shown that their laticifers resemble those of Hevea. 
Although the major terpenoid components of the latices of these plants are triterpenoid compounds, not nubber as in Hevea, their latexes are aiso characterized by the presence of small particles. Groeneveld used gel filtration chromatography to purify particles from numerous species including a number of Euphorbias and showed that the particles were indeed composed of triterpenoids (8). Fineran examined the laticifers in both mature and developing tissue of Euphorbia oulcherrima $(5,6)$. Laticifers in mature tissue had a wall-lining layer of cytoplasm with a large central vacuole, indicating that the mature laticifer is still a living cell. The latex particles were contained within the vacuole. Nuclei and plastids with single starch grains were present in the cytoplasm, but mitochondria were poorly diflerentiated, and ribosomes were scarce. Based on his observations of the presence of abundant vacuoles containing latex particles in the cyloplasm of the sub-apical region of developing laticifers, he hypothesized a developmental scheme for the production of the latex particles within these vacuoles. Mitochondria and ribosomes are present in the cytoplasm of these laticifers. Groeneveld et al, noted the regular occurence of mitochondria in the laticifers of the cotyfedons and hypocotyl of etiolated Euphorbia lathyris seedlings (9).

Investigation of the exuded latex of Euphortias has cemered in a largo part on their unique rod-shaped starch grains. Mahlberg has used the starch grain morphology along with the triterpene composition of the latex of succulent African Euphorbias to determine phylogenetic relationships within the genus (12). In thin sections of fixed E. pulcherrima latex, latex particles have no discernible membrane but do show a boundary-type layer (5).

While there is ample understanding of the structure of laticifer cells and some information on the nature of expelled latex, the view on how latex is formed is still speculative. The theories that the latex particles are synthesized in the parietal cytoplasm and then Iransfered into the central vacuole are based purely on structural studies. The stnctural work described here was undertaken in order to compliment the information obtained on the biosynthesis of the triterpenoids in isolated latex(Ch. 1). The goal was to correlate structure with function. 


\section{MATERIAL ÁND METHODS}

Plant Materlal. Euphorbia lathyris L. plants were propagated from seed collected from wild plants growing near Healdsburg, Sonoma Co., CA. Plants were grown in a soil mixture of peat. sand, and Perlite in 6 inch clay pots in a growth chamber under conditions of a $16 \mathrm{~h}$ day at $600 \mu \mathrm{E}$ $\mathrm{m}^{-2} \mathrm{~s}^{-1}$ provided by a combination of fluorescent and incandescent lights, $27^{\circ} \mathrm{C}$ day, $18^{\circ} \mathrm{C}$ night temperature. Latex was obtained by the collection of droplets expelled when shallow incisions were made with a razor blade at the bases of petioles. The latex was stored briefly on ice until it was used.

Processing of $5000 \mathrm{~g}$ pellet for SEM. A $0.75 \mathrm{mi}$ sample of latex was centriluged at $5000 \mathrm{~g}$ for $15 \mathrm{~min}$, and the supernatant was removed. The pellet was gently resuspended in $1.5 \mathrm{ml}$ buffer (50 mM MES, $0.4 \mathrm{M}$ sorbitol, $5 \mathrm{mM} \mathrm{MgCl} 2,5 \mathrm{mM}$ OTE, pH 5.5) using a sott paintbrush. The sample was recentrifuged, and the supematant was removed. Buffer was added to just cover the pellet, and the peller was broken into $1-\mathrm{mm}$ pieces. A $1-\mathrm{ml}$ volume of fixative $(2 \%$ glutaraidehyde. $1 \% \mathrm{OsO}_{4}$ in $0.1 \mathrm{M}$ cacodylate $\mathrm{pH} 6$ ) was added to the pellet, and the sample tube was incubated for $1 \mathrm{~h}$ in the dark on ice. At that time the sample was again centriduged at $5000 \mathrm{~g}$ for $15 \mathrm{~min}$, and the supematant was removed. The pellet was washed three times with buffer and was then incubated for 30 min at room temperature with $1 \mathrm{ml}$ of $1 \%$ glutaraldehyde in $0.1 \mathrm{M}$ cacodylate, $\mathrm{pH}$ 6. The glutaraldehyde solution was removed, and the sample was rinsed three times with buffer

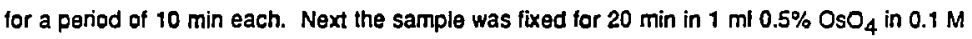
cacodylate $\mathrm{pH} 6$. The osmium solution was removed, and the sample was rinsed three times with distilled water. The sample was stored overnight in the refrigerator.

Before beginning the dehydration scheme, the sample was rinsed with an additional five changes of water and broken up into 1-mm pieces. The sample was dehydrated using an athanol series: $30 \%, 50 \%, 70 \%$, and $90 \%$ ethanol, each for 10 min. Next the sample was ineubated with wo changes of $100 \%$ ethanol for 20 min each. 
The sample was placed in a envelope of filter paper in ethanol and dried from liquid $\mathrm{CO}_{2}$ in a critical point apparatus. The dried sample was stored over dessicant under vacuum and then mcented on stubs by shaking the powdery sample onto drying graphite glue. The samples were sputher-coated with a $15 \mathrm{rm}$ layer of Pt using a Polaron sputter coater equipped with a quanz crystal thickness monitor. The sample was viewed with a ISI DS-130 SEM.

Prccessing of $5000 \mathrm{~g}$ pellet for TEh. Latex $(0.5 \mathrm{ml})$ was centrifuged at $5000 \mathrm{~g}$ for $15 \mathrm{~min}$, and the pellet was resuspended in $\mathbf{2 5 0} \mu \mathrm{H}$ of the supernatant of latex that had been centrifuged at $100,000 \mathrm{~g}$ for $1 \mathrm{~h}$. The pellet was fixed in the dark for $\mathrm{th}$ at 0 to $4{ }^{\circ} \mathrm{C}$ in $1 \%$ glutaraldehyde, $0.5 \%$ $\mathrm{OsO}_{4}$ in $0.1 \mathrm{M}$ cacodylate $\mathrm{pH}$. The sample was ceritrifuged for $5 \mathrm{~min}$ at $1000 \mathrm{~g}$, and the pellet was rinsed in $0.1 \mathrm{M}$ cacodylate $\mathrm{pH} 7$. The pellet was postixed in $2 \%$ glutaraldehyde in $0.1 \mathrm{M}$ cacodylate $\mathrm{pH} 7$ for $0.5 \mathrm{~h}$ and was then rinsed three times with $0.1 \mathrm{M}$ cacodylate $\mathrm{pH} 7$. Next the sample was fixed for $45 \mathrm{~min}$ in $0.5 \% \mathrm{OsO}_{4}$ and rinsed three times with distilled water. The sample was dehydrated for $15 \mathrm{~min}$ each in $30 \%$ ethanol then in $50 \%$ othanol. The sample was next subjected to two changes of $70 \%$ ethanol for $30 \mathrm{~min}$ each. The sample was placed in a $1: 1$ mixture of $70 \%$ ethanol and LR White resin (Polysciences, Inc.) for $30 \mathrm{~min}$. The sample was infiltrated with three changes of LR White for $45 \mathrm{~min}, 1 \mathrm{~h}$, and then $2.5 \mathrm{~h}$ bofore being placed in BEEM capsules. The capsules were degassed for $1 \mathrm{~h}$ and then hardened for $18 \mathrm{~h}$ in a vacuuni oven at $60^{\circ} \mathrm{C}$.

Thin sectiens were cut from the resin blocks using a Porter-Blum MT-2 microtome and a freshly-made glass knife. Sections were collected on formvar-coated 200 mesh copper grids. Sections were poststained with 5\% UPAC in water for 20 to 30 min and Reynolds's iead citrate Stain for 5 min. Specimens wers examined using a Zeiss 109 TEM.

Processing of percoll gradlent samples for SEM. Poly-L-Jysine-coated coverslips were prepared as mounts for the samples (14). Glass coverslips were broken into quariers, cleaned by sonication in a detergent solution, ninsed with distilled water, and placed in ethanol. Each was dried in an alcohol flame, then inme.Jiately after the slip had cooled, a small drop of poly-L-lysine 
solution ( $\left.1 \mu \mathrm{g} \mathrm{ml}^{-1}\right)$ was placed on the coverslip and was spread over the surface with a wooden applicaior. The coversips were coated no more than a few hours before the simple was to be applied.

Ten fractions from a sample of latex centrifuged on a Percoll gradient were obiained trom Dr. Scott Taylor. Each sample was placed on a separate coverslip, and a blank was made by placing a drop of the Percoll solution abne on an eleventh coverslip. The coverslips mere allowed to sit 20 min over ice to allow particles in the samples to sediment and were then rinsed 3 to 4 times with buffer (50 mM MES, $0.4 \mathrm{M}$ sorbitol, $5 \mathrm{mM} \mathrm{MgCl}, 5 \mathrm{mM}$ DTE, gH 6.1). Next the sarmples were fixed for $1 \mathrm{~h}$ in $2 \%$ glutaraldehyde in $0.1 \mathrm{M}$ cacodylate, $\mathrm{pH} 6$, were rinsed with $0.1 \mathrm{M}$ cacodylate, $\mathrm{pH} \mathrm{6,} \mathrm{and} \mathrm{were} \mathrm{postlixed} \mathrm{in} 1 \% \mathrm{OsO}_{4}$ in $0.1 \mathrm{M}$ cacodylate, $\mathrm{pH} 6$.

The samples were rinsed with distilled water and dehydrated using a graded ethanol series. The samples, now in $100 \%$ ethanol, were dried from liquid $\mathrm{CO}_{2}$ using a critical point apparatus; each coverslip was contained in a mosh basket. Each dried coverslip with sample was mounted on a stub with silver glue. The samples were coated with $15 \mathrm{~nm}$ Pt.

Processing of Percoll gradlent samples for TEM. A total of $111-\mathrm{ml}$ fractions of a Percoll gradient of latex was obtained from Dr. Scott Taylor. Each fraction was fixed at $0.4 \mathrm{C}$ lor $1.5 \mathrm{~h}$ with $0.5 \mathrm{ml}$ of a solution of $1 \% \mathrm{OsO}_{4}$ and $3 \%$ glutaraidehyde in $0.3 \mathrm{M}$ cacodylate pH 6 giving a final concentration in $1.5 \mathrm{ml}$ of $0.3 \% \mathrm{OsO}_{4}$ and $1 \%$ glutaraldehyde in $0.1 \mathrm{M}$ cacodylate $\mathrm{pH}$. The samples were next centrifuged for $15 \mathrm{~min}$ at $5000 \mathrm{~g}$, and the supernatant was removed. The pellets were washed three times with $0.1 \mathrm{M}$ cacodylate $\mathrm{pH}$ 6, followed by wo washes of distilled water. Each sample was dehydrated to $70 \%$ ethanol using a graded series of $5,10,20,30,40$, 50, 60 and $70 \%$ ethanol. The samples remained in each solution for 15 to 20 min to allow the particles to sediment. Next the samples were infitrated with a $1: t$ solution of $70 \%$ ethanol and LA White resin for 45 min and with $100 \%$ LA Whita overnight. The next day the samples were incubated with fresh LA White for $1.5 \mathrm{~h}$ and were then placed in BEEM capsules. The capsules were evacuated for $2 \mathrm{~h}$ to remove gases from the resin, and the resin was hardened in a $60^{\circ} \mathrm{C}$ 
vacuum oven for $20 \mathrm{~h}$.

Thin sections were cut from the resin blocks using a Porter-Blum MT-2 microtome and a freshly-made glass knife. Sections were collected on naked 300 mesh copper grids. Sections were poststained with $5 \%$ UrAc in water for 20 to $30 \mathrm{~min}$ and Reynolds's lead citrate stain for 5 min. Specimens were examined using a Zeiss 109 TEM. 


\section{RESULTS}

SEMs of the $5000 \mathrm{~g}$ pellet of latex, which is the fraction capable of incorporating MVA into triterpenoids, are dominated by the presence of elongated starch grains of lengths $B$ to $34 \mu \mathrm{m}$ (Fig. 1). These rod-shaped grains resemble those of other Euphorbia species characterized by Mahlberg (11). The grains are coated by an amorphous material, possibly lipid in nature. Upon closer examination, other regular ovoid stuctures (length 8 to $12 \mu \mathrm{m}$ ) are seen in this fraction (Fig. 2). SEM does not allow characterization of these structures as the nature of any possible limiting membrane(s) and intemal structures is not discemable. The helerogeneous nature of the fraction prevents correlation of the terpenoid-synthesizing activity with a particular structure.

Examination of thin sections of the $5000 \mathrm{~g}$ pellet by TEM shows numerous ovoid structures with diameters in the range of 0.5 to $4 \mu \mathrm{m}$ (Figs. 3 \& 4). Some have intemal osmophilic substructures; other substructures have a more dispersed matrix. Many small osmophilic particles are found external to these more well-defined structures. They are found singly and also clumped. Their size is in the range of 0.125 to $0.3 \mu \mathrm{m}$, consistent with that of other Euphorbia species triterpenoid latex particles (8).

Latex was fractionated by density gradient centritugation using Percoll in order 10 isolate the triterpenoid-synthesizing structure from other latex components. SEMs of fractions taken from the gradient strowed that the starch grains were found exclusively at the bottom of the gradient (Fig. 5). In contrast, the latex particles moved centripetally and were found in the top lour fractions (Fig. 6). The relatively uniform size of the latex particles can be seen; their average diameter was $0.2 \mu \mathrm{m}$. These structures are latex particles not Percoll; Percoll particles are much smaller, ranging in size trom 15 to $30 \mathrm{~nm}$. No other structure was seen in any of the latex tractions. The triterpenoid-synthesizing activity was localized in fractions 3 to 6 (15). Although latex particles were found in these fractions, they were most abundant in fractions nearer the top of the gradient so their presence did not correlate with the biosynthetic activity. The absence of a structure that corresponded to the detected enzymatic activity doos not mean that such a 
structure does not exist. The preparalion of samples for SEM involved adhering the material to polylysine-coated coverslips; this method requires that the structures of interest have a negative surface charge. If the terpenoid-synthesizing structure did not have an overall negative charge, it would not stick to the coverslip and would be rinsed off when the coverslip was washed in buffer before the fixation step. In addition, structures may not survive the drying process required in preparing SEM samples.

In order to insure that no structure was lost during the preparation of Percoll gradient samples for oberservation, the samples were fixed and embedued for TEM. Under these conditions, numerous structures resembling those seen in the TEMs of the $5000 \mathrm{~g}$ pellet were observed in the fraction containing the biosynthetic activity (Figs. 7-9). No such structures were observed in other fractions. They ranged in length from 2 to $9 \mu \mathrm{m}$ and were bounded by a single membrane (Fig. 10).

\section{DISCUSSION}

In this study, three different types of structures were observed in samples of Euphorbia lathyris latex. The first were the unusual rod-like starch grains that cencentrated in the pellet upon diflerential and density gradient centrifugation. High density is a general characteristic of starch grains, and these elongated shapes are distinctive of grains of non-articulated Euphorbia laticifers. Rod-shaped starch grains characterize lealy taxa of the genus (12). The adhesion of the grains to polylysine-coated coverslips indicates that they have a negative surface charge. Mahlberg ascribed the wrinkled surface of grains he observed by SEM to the limiting membrane of the amyloplast (11); plastid envelopes contain a high percentage of galactolipids and phosphotidylcholine, making them not strongly negatively-charged(3). Either some change has occured in the composition of the membrane of latex starch grains giving them an overall negative charge or the density of the grains prevented them from being washed from the coverslips. The bjochemical nature of laticifer starch grains, specifically, the existance and composition of any 
limiting membrane(s) has not been explored; perhaps they differ in this regard from starch grains of parenchyma tissue as well as in their shape.

The second structure seen in the micrographs was the latex particle. The lipid nature of this structure was indicated by its heavy staining by osmium as well as its low density. Like latex starch grains, latex particles adhered to the polylysine-coated coverslips, indicating a negative surface charge. The question of whether latex particles are naked or have a boundary layer has been asked by a number of investigators; membrane-like boundaries have been seen in micrographs of particles from various species. Fineran observed a membrane-like boundary on some latex particles of Euphorbia pulcherrima (5), but Groeneveld saw no envelope on particles trom Euphorbia milii (8). The best chemically characterized latex particles are the triterpene particles of Hoya australis (Asclepiadaceae) which have a protein content of $5.2 \%$ of particle dry weight and an isoelectric point of 3.2; the particles are sumounded by a membrane-like film (8). E. lathyris latex particles. with their negative surface charge, would have a similarly low isoelectric point, indicating that they may be bounded by a membrane. Chemical analysis of purified latex particles is needed to discem the composition of this layer.

The final structure observed in latex associated with the triterpenoid-synthesizing activity and the vacuolar marker enzyme a-mannosidase on Percoll density gradients (15). Its physical characteristics collaborate the biochemical evidence indicating that this structure is vacuolar; it is bounded by a single membrane and is of variable size. The observation that the in vitro triterpenoid biosynthetic activity of $E$. lathyris latex is associated with a vacuolar stucture agrees with Fineran's ultrastructural observations indicating that latex particles are synthesized in fubular vacuoles in the peripheral cytoplasm of developing E. puicherrima laticifers (6).

The relationship of this structure to the well-characterized vacuolar "lutoid" of Hevea brasiliensis latex should also be considered. The size range of 2 to $9 \mu \mathrm{m}$ in diameter of the $E$. lathyris structure is larger than that reported for lutoids which are spherical particles ranging from 1 to $5 \mu \mathrm{m}$ in diameter (2). The inability of the E. Jathyris structure to adher to the polylysine surface may also be indicative of differences between this particle and the lutoid. Lutoids are 
distinguished by the high content of phosphatidic acid of their membranes which would afford them a high negative surface charge and presumably insure their adherence to the cationic surface (4). However, lutoids are also characterized by their extreme osmosensitivity, and the absence of the $E$. lathyris structure on the coated coverslips may be due to breakage of the organelle during sample preparation rather than an inherent inability to adher to the surface.

The observation that triterpenoid biosynthesis occurs in vacuoles of latex contrasts with what is known about sterol biosynthesis in animals and other plants. Mammalian sterol biosynthesis is considered to be a process which occurs exciusively in the endoplasmic reticulum, and experiments with Zea mays support the view that this is also the location of sterof biosynthesis in plants (10). This dichotomy may be resolved by consideration of work by Marty on vacuole biogenesis in Euphorbia characias roots (13). Based on ultrastructural studies, he concludes that the vacuolar membrane arises from the ER membrane through the fusing of provacuoles which are formed in the region where the smooth ER is associated with the Golgi. This common origin of ER and vacuolar membranes reconciles any incongruity regarding triterpenoid biosynthesis occuring in the two sites.

\section{CONCLUSIONS}

Ultrastructural observations of Euphorbia lathyris latex fractions allowed characterization of three latex structures. Rod-shaped starch grains and terpenoid latex particles, similar to those described in other species of Euphorbia. were observed. A third structure was associated with the mevalonate to triterpenoid converting activity of the latex ind was physically and biochemicalty identified as a vacuole. This is the first time that the site of isoprenoid biosynthesis in latex has been linked to a specitic subcellular organelle. 


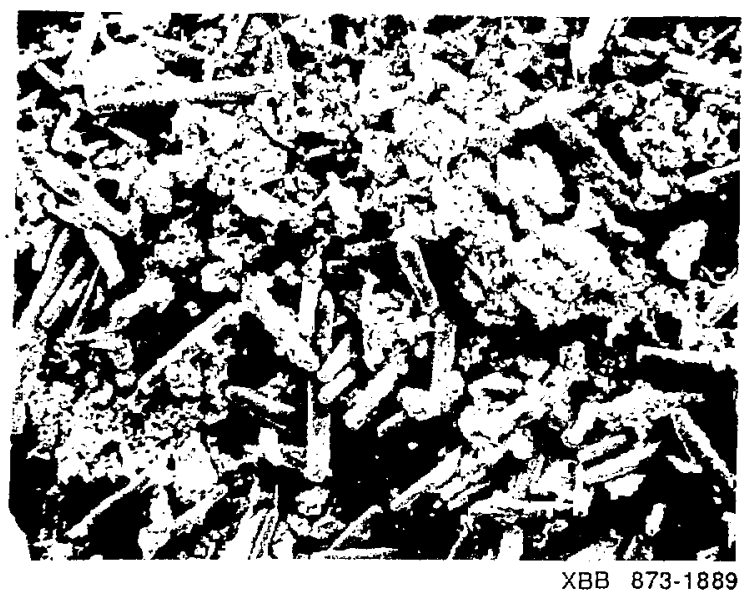

Fig. 1. SEM of dried $5000 \mathrm{~g}$ pellet of E. lathyris latex. Bar equals $10 \mu \mathrm{m}$.

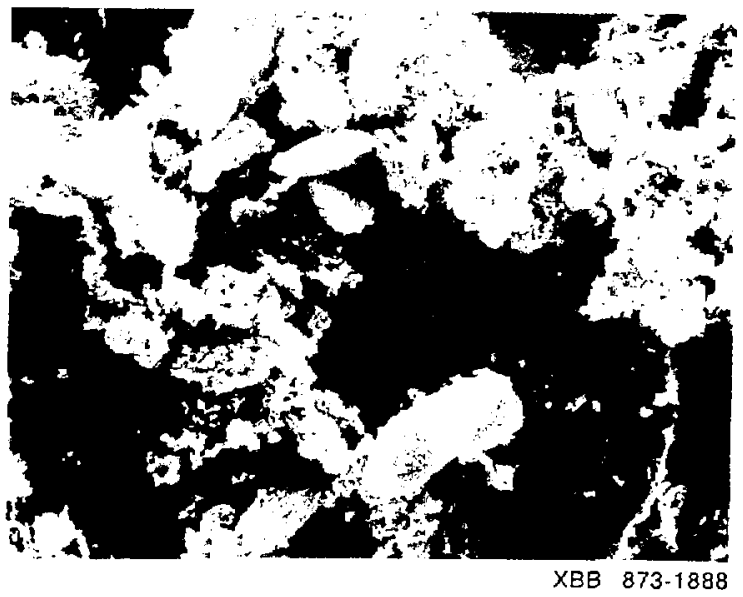

Fig. 2. SEM of dried $5000 \mathrm{~g}$ pellel of E. lathyris latex. Bar is $10 \mu \mathrm{m}$. 


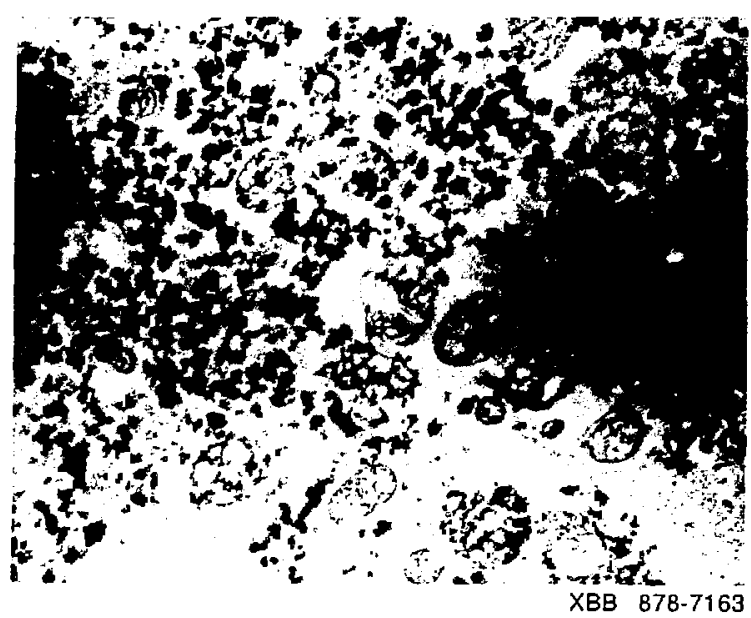

Fig. 3. TEM of resin-embedded $5000 \mathrm{~g}$ pellet of $E$. lathyris latex. Bar equals $1 \mu \mathrm{m}$.

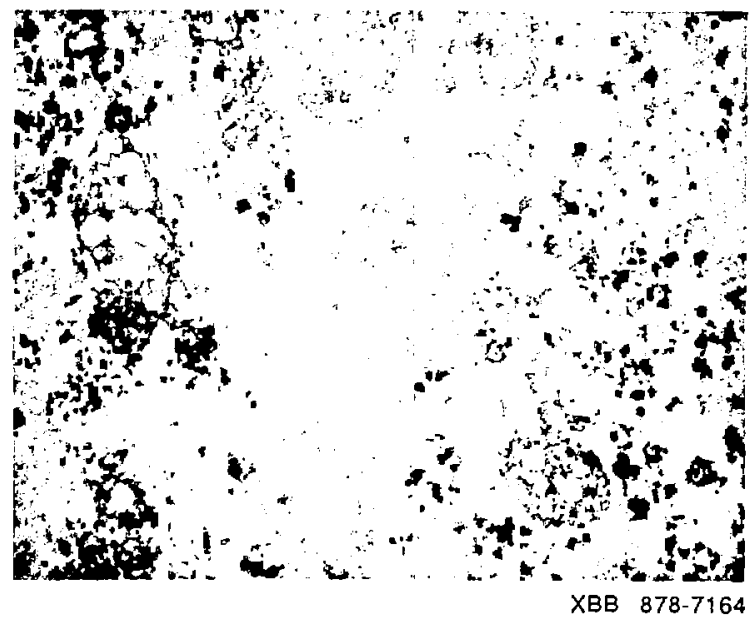

Fig. 4. TEM of resin-embedded $5000 \mathrm{~g}$ pellet of E. lathyris latex. Bar is $1 \mu \mathrm{m}$. 


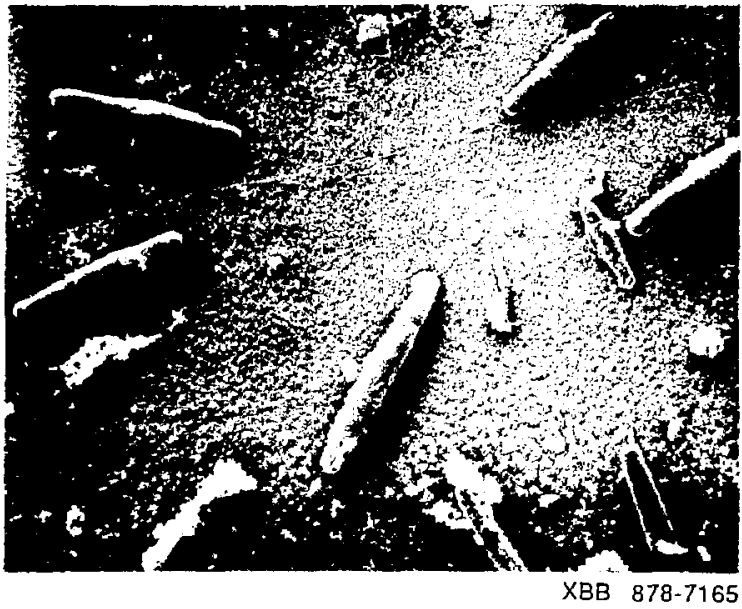

Fig. 5. SEM of peilet from Percoll gradient of E. lathyris fatex. Bar equals $10 \mu \mathrm{m}$.

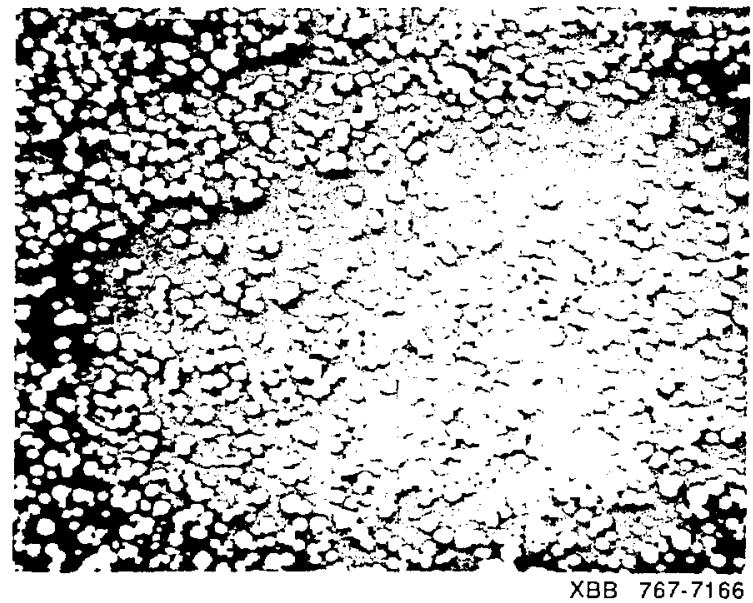

Fig. 6. SEM of latex particles from Percoll gradient of E. lathyris latex. Bar is $1 \mu \mathrm{m}$. 


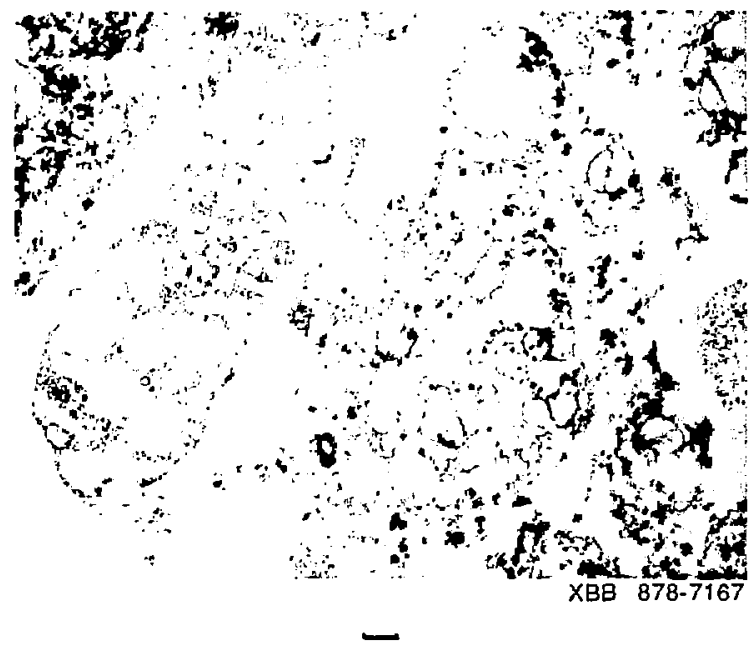

Fig. 7. TEM of triterpenoid-synthesizing fraction of $E$. lathyris latex. Bar equals $1 \mu \mathrm{m}$.

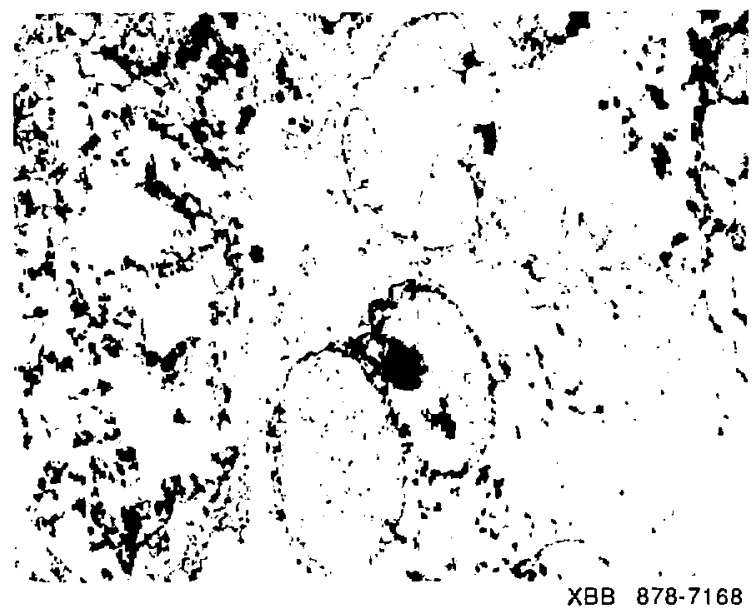

Fig. 8. TEM of triterpenoid-synthesizing fraction of E. lathyris latex. Bar is $1 \mu \mathrm{m}$. 


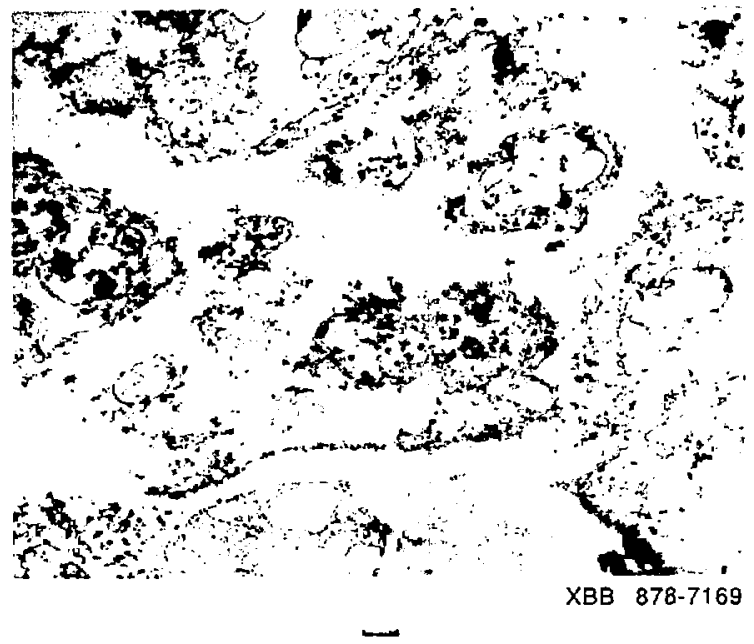

Fig. 9. TEM of tritemenoid-synthesizing fraction of $E$. lathyris latex. Bar equals $1 \mu \mathrm{m}$.

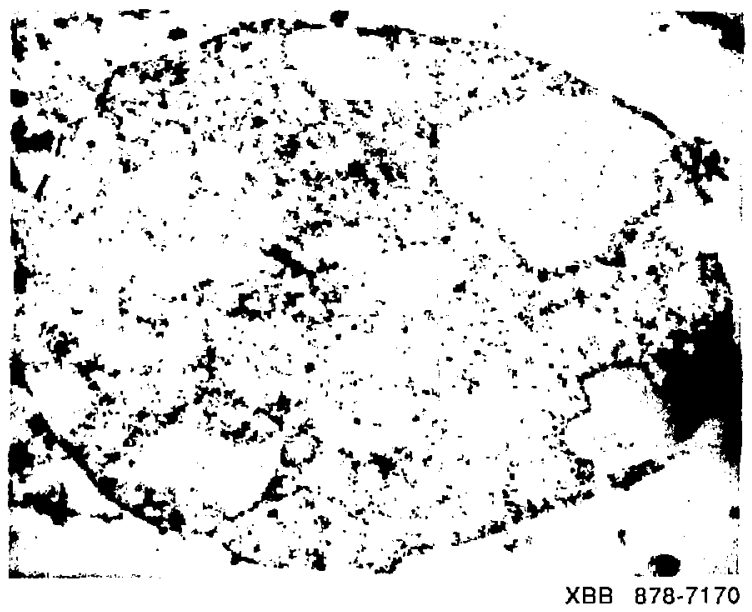

Fig. 10. TEM of triterpenoid-synthesizing structure showing single membrane. Bar is $1 \mu \mathrm{m}$. 


\section{UTERATURE CITED}

1. Archer BL 1980 Polyisoprene. In EA Bell, BV Charhwood, eds, Secondary Plant Products, Encyclopedia of Plant Physiology liew Series, Vol 8, Springer-Verlag, Heidelberg

2. D'Auzac J, H Crétin, B Marin, C Lioret 1982 A plant vacuolar system: the lutoids from Hevea brásiliensis latex. Physiol Veg 20: 311-331

3. Dorne A-J, J Joyard, MA Block, R Douce 1984 Localization of phosphatidylcholine in spinach chloroplast envelope membranes. In P-A Siegenthaler, W Eichenberger, eds Structure, Function, and Metabolism of Plant Lipids, Eisevier, Amsterdam

4. Dupont J, F Moreau, C Lance, J-L Jacob 1976 Phospholipid composition of the membrane of iutoids from Hevea brasiliensis latex. Phytochem 15: 1215-1217

5. Fineran BA 1982 Distribution and organization of non-articulated laticifers in mature tissues of Poinsettia (Euphorbia pulcherrima Willd.). Ann Bot 50: 207-220

6. Fineran 8A 1983 Differentiation of non-articulated laticifers in Poinsertia (Euphorbia pulcherrima Willd.). Ann Bot 52: 27G-293

7. Gomez JB 1975 Comparative ultracytology of young and mature latex vessels in Hevea brasiliensis. In Proc Intl Rubber Cont, Vol 2, Rubber Research institute of Malaya, Kuala Lumpur

8. Groeneveld HW 1976 A comparative investigation of the particle fractions from Hoya, Dischidia, and Euphorbia latices. Acta Bot Neerl 25: 167-178

9. Groeneveld HW, EGM Peters, GW Kroese, C Papenhuyzen 1983 Lipid synthesis and uhrastucture of etiolated Euphorbia lathyris seedlings. Ann Bot 51: 307-315

10. Hartmann-Bouilion M-A, P Benveniste, J-C Roland 1979 Sterol metabolism in purified membrane fractions from maize coleoptiles. Biol Cell 35: 183-194

11. Mahlberg $P 1973$ Scanning electron microscopy of starch grains from latex of Euphorbia terracina and E. tirucali. Planta 110: 77-80 
12. Mahlberg PG, J Pleszczynska, W Rauh, E Schnepl 1983 Evolution of succutent Euphorbia as interpreted from latex composition. Bothalia 14: 857-663

13. Marty F 1978 Cytochemical studies on GERL, provacuoles, and vacuoles in root meristematic cells of Euphorbia. Proc Natl Acad Sci USA 75: 852-856

14. Mazia D, G Schatten, W Sale 1975 Adhesion of cells to surfaces coated with polylysine. J Cell Bio 66: 198-200

15. Taylor SE (unpublished results) 


\section{Chapter IY. BIOSYNTHESIS OF TERPENOIDS IN COPAIFERA}

A most atiractive candidate for uce as a source of hydrocarbons is the tropical tree genus Copaifera which is the source of the oleoresin copaiba balsam. This oil, obtained by tapping the tree trunk, has been used directly as fuel in diesej-engined trucks of the Instituto Nacional du Pesquisas da Amazônia of Brazil. Trees in Ducke Reserve near Manaus are tapped biannually. yielding 20 to 30 liters of the oil in 2 to 3 hours (3).

The genus Copaifera is a member of the Leguminosae family, subfamily Caesalpinioideae, and the tribe Detarieae. It is represented by ca 30 species in the New World and 4 in Western Africa (2). These trees are prominent in the lowland raintorest ecosystem but are also found under drier, more-open thom lorest habitats (12).

Of four commercial samples of the oleoresin, $721090 \%$ of the oil was found to be sesquiterpene hydrocartons (20). Sesquiterpenes are 15-carbon terpenoids constructed of three isoprene units. They compose the largest class of terpenoids with several thousands of individual compourds of ca 200 different carbon skelelon types having been identified (15). Both pure hydrocarbon and oxygenated sinuctures exist. Cf the 24 sesquiterpene hydrocarbons separated by GLC of copaiba balsam oil, 18 have been identified, with caryophyitene and copaene the major components (20). In addition to the wood resin, species of Copaifera alsc contain a leat resin. The sesquiterpene hydrocarbons canyophyllene, r-cadine,le, cyperene, and $\alpha$-copaene have been isolated and identified from leaves of Copaifera officinalis $L$. and $C$. venezuelana var. laxa (2) (Fig. 1). The leat resin is secreted Irom specialized epithelial cells which line small, ovoid, schizogenous pockets in the mesophyll tissue (2). In the wood. the oleoresin is found in concentric rings of canals in the primary stem tissue and seccndary tissue (11).

Mortality of the lepidopteran Spodoptera exigua in feeding experiments with different resin compositions incorporated into an artifical diet was correlated with the concentration of caryophyllene (13), and caryophyllene oxide was the constituent of various leaf resins tested which inhibited the growth of the associated leat fungus Pestalotia subculicularis (1). These 


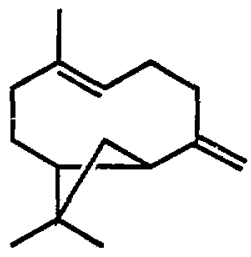

Caryophyllene

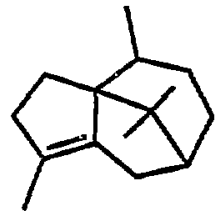

Cyperene

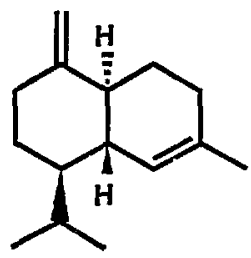

$\gamma$-Cadinene

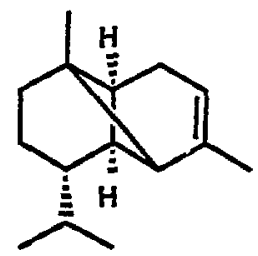

$\alpha$ - Copaene

Fig. 1. Sesquitemene hydrocarbons of Copaifera leaf resin. 
observations support the view that these resins play a role in the defense of the plant against predators.

In the course of structural determinations of sesquiterpenes, Ruzicka developed the Tamesol nule" and the broader "biogenetic isoprene rule" which hypothesized that all terpenoids could be formed biologically by accepted reaction mechanisms from such simple precursors as famesol, geraniol, geranyl-geraniol, and squalene (18). Subsequently, extensive biogenetic schemes have been formulated to account for the variety of sesquiterpene skeletons represented ir zature. Experimental verification of these proposed routes is still in its infancy, but investigations using cell-Iree preparations and ${ }^{13} \mathrm{C}$ or radiolabelled precursors such as acetate, mevalonate, and farnesol have established the mechanism of formation of a number of sesquiterpenes. Much of this work has been carried out with fungi which have p:Jven more amenable to uptake and metabolism of the exogenous suistrates than plants (4).

The mixture of sesquiterpene hydrocarbons in Copaifera resin makes it an ideal system in which to study the interrelationships between the various structures. Proposed biogenetic schemes suggest that certain families of sesquiterpene skeletons are of related origin, but in many cases, a number of logical routes to the same stucture exist (17). Analysis of the quantitative co-occurence of different sesquiterpenes in the leaf pocket resins of species of the closely related genus Hymenaea suggests the close biosynthetic linkage of caryophyllene and $\beta$-humulene as well as $\delta$-cadinene with $\gamma-$ muurolene and the possible intermediate role of germacrene (16).

Besides interest in the relationship between individual compounds, there is the question $c^{2}$. the tumover of sesquiterpenes in general. Essentially nothing is known about their catabolism. However, an investigation of the time course of labelling of sesquiterpenes from [2-14C]mevalonate in peppermint cuttings showed that the maximum incorporation was achieved at $6 \mathrm{~h}$, after which time the amount of label in the sesquiterpenes decreased (5). Likewise, Pogostemon cablin leat discs contained 14 times the label from $\left[\mathrm{U}-{ }^{14} \mathrm{C}\right]$ sucrose in the sesquiterpenes $\alpha$-guaiene, $\alpha$-patchoulene, caryophyllene, $\alpha$-buinesene, and patchouli alcohol 
when incubated for $4.5 \mathrm{~h}$ as opposed to $17 \mathrm{~h}$ (9). These results indicate that sesquiterpenes are metabolically active. Sesquiterpenes of Copaifera seedlings labelled with ${ }^{14} \mathrm{CO}_{2}$ for a period of two weeks were tumed over in $\mathbf{8}$ to 10 days, but metabolism over a shorter time period was not investigated (12).

This preliminary investigation of the incorporation of various exogenous precursors into the sesquiterpenes of Copaifera species was undertaken to see if the radiolabelled substrates would be metabolized sufficiently to allow study of the turnover of these compounds as a group and of the interelationships between individual sesquiterpenes. The results indicate that although the incorporation of terpenoid precursors was low, there was adequate labelling of sesquiterpenes to warrant further investigation of their melabolism in this species. In addition, the even greater labelling of squalene and triterpenoids than the sesquiterpenes from exogenous precursors suggests that Copailera could be a good system in which to study the controls of the allocation of carbon to the different classes of terpenoids. 


\section{MATERIAL AND METHODS}

Plant Material. All species of Copaifera were grown in pots in a porous soil mixture of 1 part UC Davis mix (1:1:1 sand: peat: redwood compost), 1 part sand, 1 part Canadian sphagnum peat, and 1 part perlite under greenhouse conditions at the UC Berkeley Botanical Garden.

Materials. Aquassure, R-[5-3 $\mathrm{H}]$ mevalonic acid, triethylammonium salt, sodium[ $\left.{ }^{3} \mathrm{H}\right]$ acetate, and D-[U-14 C $] g l u c o s e$ were purchased from New England Nuclear. Additional sodium[ $\left.{ }^{3} \mathrm{H}\right]$ acetate was procured from ICN Radiochemicals. Sodium[2-14 Clacetate was obtained from Amersham. Silica gel plates were purchased from Analtech. Carbo-Sorb and Permafluor were obtained from Packard instrumemis Co.

$\left[{ }^{14} \mathrm{C}\right] A$ cetate incorporation by Copalfera officinalis leat. A leaf with two pairs of leaflets was cut from a year-old $C$. officinalis seedling and immediately placed in water. The end of the petiole was cut off under water, and the cutting was placed in the incubation solution containing $50 \mu$ water and $50 \mu$ sodium[2-14 $\mathrm{C}$ ]acetate $\left(57.5 \mathrm{mCi} \mathrm{mmol}^{-1}, 0.1 \mathrm{mCl} \mathrm{ml}^{-1}\right)$. The cutting was incubated for $20 \mathrm{~h}$ at room temperature until the acetate solution was taken up, then the plant material was pulverized with annydrous $\mathrm{Na}_{2} \mathrm{SO}_{4}$ and hexane using a mortar and pestle. The hexane was removed and the process was repeated three more times to give ca $15 \mathrm{ml}$ of a combined clear, bright-yellow hexane extract. Next the plant residue was ground twice with acetone, giving ca $20 \mathrm{ml}$ clear, bright-green acetone extract. Lastly, the residue was washed with water and then removed from the mortar giving water extracts 1 to 4 . One to two drops of concentrated sulturic acid were added to the water extracts to prevent microbial growth. Aliquots of ten percent were taken from each sample; the hexane aliquot was decolorized with activated charcoal; $15 \mathrm{ml}$ Aquassure was added to each aliquot; and the samples were counted. The remaining hexane extract was divided into two halves, and one was concentrated under a stream of $\mathrm{N}_{2}$. The concentrated hexane extract $(45 \%$ of total) was spotied on a $20 \times 20 \mathrm{~cm} 500 \mu \mathrm{m}$ layer silica gel $\mathrm{G}$ plate as a band and an isolated marker spot. The plate was developed in a solvent 
mixture of 3:1 petroleum ether: $\mathrm{CCl}_{4}$ as recommended by Stahl (19) for the separation of the sesquiterpenes humulene, caryophyllene, and isocaryophyllene. The marker spot region was visualized with sulfuric acid spray and heat, and the remainder of the plate was divided into 14 bands which were scraped from the plate, mixed with $5 \mathrm{ml}$ water and sonicated 5 min, and then shaken with $15 \mathrm{ml}$ Aquassure to form an uniform gel. The samples were counted using a Packard 640-C scintillation counter.

Time course of [ $\left.{ }^{3} \mathrm{H}\right]$ Acetate ineorporation by C. officinalls leat dlscs. Fitty microliters of sodiuml ${ }^{3} \mathrm{H}$ lacelate in ethanol $\left(1.6 \mathrm{Cl} \mathrm{mmol}^{-1}, 10 \mathrm{mCi} \mathrm{ml}^{-1}\right)$ was dried under a stream of $\mathrm{N}_{2}$ overnight then redissolved in $5.1 \mathrm{ml}$ sterile water giving a solution $60 \mu \mathrm{M}$ in acetate. A $10 \mu$ aliquot was mixed with $15 \mathrm{ml}$ Aquassure and counted to confirm the concentration of the solution. Ten $C$. officinalis leaflets were collected. surface sterilized with a solution of $10 \%$ bleach, and rinsed in sterile water. Nine millimeter leaf-discs were cut from the leat tissue with a cork-borer, and groups of 30 discs were incubated with $1 \mathrm{ml}$ of the acetate solution for $1,3,6$, and $24 \mathrm{~h}$. A fifth set of discs was incubated in $1 \mathrm{ml}$ pure water, then at $24 \mathrm{~h}$ the water was removed and substituted with $1 \mathrm{ml}$ of the acetate solution. The sample was allowed to incubate an additional 3 h. At the end of each incubation period the acelate solution was removed, and the discs were washed four times with water which was then combined with the acetate solution. The discs were then killed by immersion in liquid $\mathrm{N}_{2}$ and ground with hexane using a mortar and pestle. The hexane extract and remaining leaf-residue were removed from the mortar and further extracted by stirting overnight with $\mathrm{Na}_{2} \mathrm{SO}_{4}$ added as a drying agent. The mortar was next washed 4 times with water to give Washes 1 to 4 . The hexane extract was removed from the residue; the residue was rinsed once with hexane; and the wo hexane fractions were combined. The hexane extract was then backwashed three times with a total volume of ca $15 \mathrm{ml}$ water. A $5 \%$ aliquot of each hexane sample was taken, mixed with $15 \mathrm{ml}$ Aquassure, and counted. Half of the remaining hexane extract (47.5\%) was concentrated, chromatographed, isolated, and counted as described for $\left.7^{14} \mathrm{C}\right] \mathrm{Acetate}$ incorporation by Copailera officinalis leaf." 
Separation and ideniflcation of hexane extractables of Copaffera leaf tissue. C. officinalis, leaf tissue (2.35 $\mathrm{g}$ tresh wt) was pulverized with hexane and anhydrous $\mathrm{Na}_{2} \mathrm{SO}_{4}$ using a mortar and pestle then stirred overnight with hexane. The residue was allowed to settle, and the hexane was decanted. A second hexane wash of the residue was combined with the first extract, and the combined hexane extract was backextracted three times with water. The hexane extract was concentrated under a stream of $\mathrm{N}_{2}$ and applied to two $20 \times 20 \mathrm{~cm} 500 \mu \mathrm{m}$ layer silica gel $\mathrm{G}$ plates which were developed in 3:1 petroleum ether: $\mathrm{CCl}_{4}$. A marker spot on each plate was visualized with sulfuric acid spray and heat. The region of the plate where the sesquiterpene hydrocarbon markers eluted was scraped, and the material was recovered by elution with ca $50 \mathrm{ml} \mathrm{CH} \mathrm{Cl}_{2}$. The fraction was turther analyzed by gas chromatography on a SP2250 capillary column $\{0.5 \mathrm{~mm} x$ $40 \mathrm{~m}$ ) using a Varian model 3700 gas chromatograph. The column was maintained at $100^{\circ} \mathrm{C}$ with an injection temperature of $130^{\circ} \mathrm{C}$. Detection was done with an FID set at $300^{\circ} \mathrm{C}$. The split ratio was 10:1, and the attenuation was $16 \times 10^{-12}$ and $2 \times 10^{-12}$ for fractions 2 and 3 , respectively. One microliter aliquots out of a total volume of $1 \mathrm{mi}$ sample were analyzed. A blank was made by developing two silica gel plates in the petroleum ether/ $\mathrm{CCl}_{4}$ solvent mixture, eluting the same region of the plates with $\mathrm{ca} 50 \mathrm{ml} \mathrm{CH} \mathrm{Cl}_{2}$, combining the extracts irom the two plates, and concentrating the sample volume to $1 \mathrm{ml}$ under a stream of $\mathrm{N}_{2}$. The sample and blank were given to the UC Berkeley Coltege of Chemistry Mass Spectroscopy Lab for GCMS analysis.

$\left[{ }^{14} \mathrm{C}\right.$ Blcarbonate and $\left.\mathrm{l}^{14} \mathrm{C}\right] \mathrm{Acetate}$ Incorporation by Copaltera Leaf discs. Leaflets were collected from 17-month old $C$. officinalis seedlings, were surface sterilized with $10 \%$ bleach, and were rinsed in sterile water. Discs of $8 \mathrm{~mm}$ diameter were cut from the leaf tissue, and 20 randomized discs were used for each incubation. The 20 discs were incubated with $1 \mathrm{ml}$ of solution in $25 \cdot \mathrm{ml}$ Erlenmeyer flasks capped with serum caps to promote a $\mathrm{CO}_{2}$-saturated atmosphere. With this set-up each disc floated freely on the liquid surface. A time course of bicarbonate incorporation was determined by incubating sets of leat discs with the $\left[{ }^{14} \mathrm{C}_{2} \mathrm{H}_{2} \mathrm{CO}_{3}\right.$ 
solution (58.6 mCl mmol-1, $0.02 \mathrm{mCl} \mathrm{ml}^{-1}$ ) for $1,3,6,12,20$, and $24 \mathrm{~h}$. A seventh sel was incubated for $3 \mathrm{~h}$ with the acetate solution $\left(57.5 \mathrm{mCi} \mathrm{mmol}-1,0.1 \mathrm{mCi} \mathrm{ml}^{-1}\right)$. The incubations were stopped and extracted as described above. The hexane extracts were divided into halves and concentrated to $1-\mathrm{ml}$ volume under a stream of $\mathrm{N}_{2}$. Both halves were spotted on $20 \times 20 \mathrm{~cm}$ $500 \mu \mathrm{m}$ layer silica gel $\mathrm{G}$ plates and were devaloped in 3:1 petroleum ether: $\mathrm{CCl}_{4}$. The origin, the region of $A_{f} .43$ to .69 , and the region of $A_{f} .74$ to .94 where material was visualized were scraped from the plates. Compounds were eluted from each silica gel sample from one of the two plates with a 50-ml volume of $\mathrm{CH}_{2} \mathrm{Cl}_{2}$ which was subsequently concentrated under a stream of $\mathrm{N}_{2}$ to 20 $\mathrm{ml}$. A $10 \%$ aliquot was mixed with $15 \mathrm{ml}$ Aquassure and counted. To check it any volatile compounds were being lost during the elution and concentration steps of the workup, silica gel samples from the second plate were snixed with $5 \mathrm{ml}$ water, sonicated $5 \mathrm{~min}$, shaken with $15 \mathrm{ml}$ Aquassure, and counted as silica sols.

All water fractions from the $20 \mathrm{~h}$ incuballon were acidified with $\mathrm{HCl}$ to $\mathrm{pH} 2$ and dried under a stream of $\mathrm{N}_{2}$. A volume of $\mathrm{CH}_{3} \mathrm{OH}$ was added to each vial, and the tractions were stirred overnight. The methanol extracts were combined and dried under a stream of $\mathrm{N}_{2}$. The residue was dissolved in water and was washed three times with ether. The resulting clear water solution was concentrated under a stream of $\mathrm{N}_{2}$ to $0.62 \mathrm{ml}$; a $10 \%$ aliquot was counted. The remaining solution was tiltered through a $0.45 \mu \mathrm{m}$ filter, and a $5 \%$ aliquot was counted. An aliquot was diluted and chromatographed hy HPLC together with fructose, glucose, and sucrose standards to determine the amount of sugars labelled.

Analysis for labelled sugars in water oxtract. An aliquol of water extract of leaf tissue was added to a solution containing $1.25 \mathrm{mg} \mathrm{ml}^{-1}$ each of sucrose, glucose, and fructose adjusted so that $50 \mu \mathrm{l}$ of the resulting mixture contained ca $10,000 \mathrm{dpm}$. Fitity microliters was chromatographed on a $4.6 \mathrm{~mm} \times 25 \mathrm{~cm} \mathrm{NH}_{2}$ column (Erownlee Labs) in $\mathrm{CH}_{3} \mathrm{CN}: \mathrm{H}_{2} \mathrm{O}, 80: 20$ at a flow rate of $1 \mathrm{ml} \mathrm{min}^{-1}$ on an Beckman Model 322 HPLC: detection was by retractive index using a 


\section{Waters Differential Refractometer R401.}

Deteminatlon of chlorophyll content of leaf tissue. A measured weight or surface area of leaf tissue was extracted with hexane, and the residue subsequently extracted with 95\% ethanol. The ethanol extract was centrifuged to give a clear green supernatant and a white peliet. The ethanol extract was kept cold and in the dark until its absorbance was measured using a Hewlett-Packard 8450A UVNIS spectrophotometer. Total chlorophyll content was calculated using the formulas of Wintermans and De Mots (21). The equations used were $C^{1} a+b\left(\mu g \mathrm{ml}^{-1}\right)=$ $6.10\left(A_{665}\right)+20.04\left(A_{649}\right)$ and $C h l_{a+b}\left(\mu g \mathrm{ml}^{-1}\right)=1000\left(A_{654}\right) / 39.8$. An average of the two values was taken as the total chlorophyll content.

Incorporation of [ ${ }^{14} \mathrm{C}$ ]blearbonate by Copaffera leaf dlscs under buffered conditions. Eight $7-\mathrm{mm}$ leat discs cut from a $C$. officinalis seedling were incubated for $20 \mathrm{~h}$ on the surface of $10 \mathrm{ml}$ incubation medium containing $25 \mathrm{mM}$ sodium PIPES pH 6.8, $0.48 \mathrm{mM} \mathrm{NaHCO}$, and $2 \mathrm{mM}$ $\left[{ }^{14} \mathrm{C}_{3} \mathrm{H}_{2} \mathrm{CO}_{3}\left(52.5 \mathrm{mCl} \mathrm{mmol}^{-1}\right)\right.$ giving a final concentration of $\left[{ }^{14} \mathrm{ClH}_{2} \mathrm{CO}_{3}\right.$ of $50 \mathrm{mM}$ at a specific activity of $2.22 \mathrm{mCi}$ mmol-1. The solution was bubbled with $\mathrm{N}_{2}$ lor $45 \mathrm{~min}$ to rernove $\mathrm{O}_{2}$ and $\mathrm{CO}_{2}$ prior to the addition of the bicarbonate solutions and leaf discs. The incubation was performed in a 25-ml Erlenmeyer tlask capped with a senum stopper under eight 32W cool white incandescent lights and was stirred just to the point of swirling the discs on the liquid surface. At the completion of the incubation period, the discs were washed with water, ground up and extracted with hexane ovemight. The hexane extract was removed from the remaining plant residue and backextracted three times with water. It was divided into two halves; one was concentrated under a stream of $\mathrm{N}_{2}$ and spotted on a $500 \mu \mathrm{m} 20 \times 20$ silica gel $\mathrm{G}$ plate and developed in 3:1, petroleum ether: $\mathrm{CCl}_{4}$. The plate was divided into 12 bands which were scraped, mixed with $5 \mathrm{ml}$ water, sonicated 5 min, combined with $15 \mathrm{ml}$ Aquassure, and counted. The second half was chromatographed as with the first, but the no regions of the TLC plate containing peaks in radioactivity were eluted with $\mathrm{CH}_{2} \mathrm{Cl}_{2}$. The eluates were concentrated under a stream of $\mathrm{N}_{2}$, were filtered through a $0.45 \mu \mathrm{m}$ 
filter, and were chromatographed by HPLC using a.4.6 $\mathrm{mm}$ i.d. $x 25 \mathrm{~cm}$ ODS column (Altex) in $100 \% \mathrm{CH}_{3} \mathrm{CN}$ at a flow rate of $1 \mathrm{ml} \mathrm{min}^{-1}$. The column effluent's absorbance was monilored at $228 \mathrm{~nm}$ using a Hitachi 100-10 spectrophotometer. The incubation medium, the water wash, the backext, act water, and the residue were acidilied and dried under a stream of $\mathrm{N}_{2}$; then they were extracted overnight twice with water. One aliquot of the combined water extracts was counted, and a second was analyzed by HPLC for labelled sugars as described previously.

Tlme course of $\left[{ }^{14} \mathrm{C}\right]$ bicarbonate Incorporation into $C$. multijuga leaf discs. Eight-mm leaf discs were cut from a C. multijuga seedling and were kept under $\mathrm{N}_{2}$, in $50 \mathrm{mM}$ MOPS, $10 \mathrm{mM}$ glutathione $\mathrm{pH} 6.5$ in ambient light until placed in reaction flasks. Each $25-\mathrm{ml}$ Eflenmeyer reaction flask contained $6.5 \mathrm{ml}$ of $77 \mathrm{mM}$ MOPS pH 6.5 and $15 \mathrm{mM}$ glutathione that had been bubbled with $\mathrm{N}_{2}$ to remove dissolved $\mathrm{CO}_{2}$ and $\mathrm{O}_{2}$. Eight leaf discs were floated on the liquid surface, and each flask was capped with a serum stopper. Bicarbonate solutions $\left(\mathrm{NaHCO}_{3}(0.141 \mathrm{M})\right.$ and $\left.\left[^{14} \mathrm{C}\right] \mathrm{H}_{2} \mathrm{CO}_{3}\left(52.5 \mathrm{mCi} \mathrm{mmor}-1,7.4 \mathrm{mCl} \mathrm{mil}^{-1}\right)\right)$ were added to each flask via a syringe to bring the total volume of solution to $10 \mathrm{ml}$ and the final concentrations to $50 \mathrm{mM}$ bicarbonale, $50 \mathrm{mM}$ MOPS, and $10 \mathrm{mM}$ glutathione. The specific activities of the incubation media ranged from 0.6 to $12 \mathrm{mCl} \mathrm{mmol}^{-1}$. Different specific activities were used to give managable levels of radioactivity incorporated over the range of time points of incorporation sampled (Table I\}.

The samples were incubated for the designated time under eight $32 \mathrm{~W}$ cool white lights. At the appropriate time points, the incubation medium was removed from the leat discs, and the discs were washed three times with $5 \mathrm{ml}$ water. The discs were then ground with ca $15 \mathrm{ml}$ hexane, giving a light-yellow solution. The tissue residue was removed form the mortar by washing with ca $10 \mathrm{ml}$ water. The solution was centrituged, and the pelleted residue was further extracted by stirning overnight with ca $15 \mathrm{ml}$ hexane. The hexane extracts were combined and backwashed three times with $5 \mathrm{ml}$ water, then they were concentrated under a stream of $\mathrm{N}_{2}$ and applied to a $500 \mu \mathrm{m} 20 \times 20 \mathrm{~cm}$ silica gel $G$ plate which was developed in 3:1, petroleum 
ether: $\mathrm{CCl}_{4}$. The plates were divided inlo 9 bands which were scraped, mixed with 5 ml water, sonicated, and mixed with $15 \mathrm{ml}$ Aquassure to form silica sols that were counted by liquid scintillation.

Table I. Volume of Bicarbonate Solutions added to Each Incubation.

\begin{tabular}{rlcc}
\hline Sample & $\begin{array}{c}\text { Vol } \mathrm{NaHCO}_{3} \\
\mathrm{~m}\end{array}$ & $\begin{array}{c}\text { Vol }\left[{ }^{14} \mathrm{C}_{2} \mathrm{H}_{2} \mathrm{CO}_{3}\right. \\
\mu l\end{array}$ & $\begin{array}{c}\text { Specific Activity } \\
\text { mCimmol }\end{array}$ \\
\hline $1 \mathrm{~h}$ & 2.74 & 810 & 12 \\
$3 \mathrm{~h}$ & 3.28 & 270 & 4 \\
$6 \mathrm{~h}$ & 3.41 & 135 & 2 \\
$12 \mathrm{~h}$ & 3.475 & 68 & 1 \\
$24 \mathrm{~h}$ & 3.5 & 40 & 0.6 \\
\hline
\end{tabular}

All aqueous Iractions and the tissue residue were acidified with $\mathrm{HCl}$ and dried under a stream of $\mathrm{N}_{2}$. The remaining material was then extracted with $\mathrm{CH}_{3} \mathrm{OH}$ to obtain an estimate of the total bicarbonate incorporation.

Determination of light saturation ieval of C multijuga leat discs. A C. multijuga seeding was incubated 5 to $6 \mathrm{~h}$ at a light level of $500 \mu \mathrm{E} \mathrm{m} \mathrm{m}^{-2} \mathrm{~s}^{-1}$. For each experimental point, an 8-mm leat disc was cut out under water from the seedling and was placed in $200 \mu$ incubation medium in a grinding vial. The disc was incubated in the light for 2 min; the $\left[{ }^{14} \mathrm{C}\right]$ bicarbonate was added, and the disc was incubated for 3 additional min. The incubation was stopped by pouring liquid $\mathrm{N}_{2}$ into the grinding tube which was kept in liquid $\mathrm{N}_{2}$ until extracted.

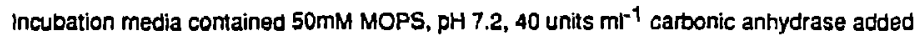
just betore experiment commenced, and $4 \mathrm{mM} \mathrm{NaHCO} 3$. Ten microliters $\left[{ }^{14} \mathrm{C}_{2} \mathrm{H}_{2} \mathrm{CO}_{3}(52.5 \mu \mathrm{Ci}\right.$ $\mathrm{mmol}^{-1}, 87 \mu \mathrm{M}$ ) were added to the $200 \mu$ of media containing each leat disc, resulting in a final specilic activity of available $\mathrm{CO}_{2}$ of $26.25 \mathrm{mGi} \mathrm{mmol}^{-1}$.

The light level, provided by a GE 500W photolamp DXB, was varied by placing various 
combinations of nuetral density screens in front of the lamp. Heat was absorbed by a flask of water placed between the lamp and the grinding tube. Light intensity was measured both in from of and behind the grinding tube.

Each leaf disc was ground successively with $1 \mathrm{ml} 80 \%$ ethanol $\left(0.8 \mathrm{ml} 95 \% \mathrm{CH}_{3} \mathrm{CH}_{2} \mathrm{OH}\right.$ added to $0.2 \mathrm{ml}$ buffer already in tube), $1 \mathrm{ml} 20 \%$ ethanol, and $1 \mathrm{ml}$ water. The extracts were ccmbined and centriluged; the supernatant and a 1-mi water wash of the the grinding tube were combined, acidfied, and dried under a stream of $\mathrm{N}_{2}$. The residue was resuspended in $2 \mathrm{ml} \mathrm{50:50}$ $95 \% \mathrm{CH}_{3} \mathrm{CH}_{2} \mathrm{OH}: \mathrm{H}_{2} \mathrm{O}$, and a $10 \%$ aliquol was taken, mixed with $15 \mathrm{ml}$ Aquassure, and counted. The pellet from the centrifugation was washed from the tube with 5 drops $95 \%$ ethanol and 5 drops $10 \% \mathrm{HCl}$ onto a paper pad and was evacuated overnight. The pellet was oxidized in a Packard Automatic Combustion Apparatus, and the ${ }^{14} \mathrm{CO}_{2}$ was collected in Carbo-Sorb. Permafluor was added and the sample was counted.

$\left[{ }^{3} \mathrm{H}\right]$ acetate and $\left[{ }^{14} \mathrm{C}\right]$ bicarbonate ineorporation by Copalfera leat dises under saturating light conditions. Leaf discs $(7 \mathrm{~mm})$ were cut under water from $C$. mullijuga and $C$. officinalis leaf tissue using a $\# 3$ cork borer. They were vacuum infiltrated three times with $50 \mathrm{mM}$ MOPS, pH 7 and $10 \mathrm{mM}$ glutathione. A set of $8 \mathrm{C}$. mutijuga leaf discs was incubated in $\mathbf{2} \mathrm{ml}$ acetale solution, and a set of 8 leaf discs of each species was incubated with $2 \mathrm{ml}$ bicarbonate solution. The bicarbonate solution contained $50 \mathrm{mM}$ MOPS pH 7, $10 \mathrm{mM}$ glutathione, $90 \mu 10.1 \mathrm{M} \mathrm{NaHCO}_{3}$. and $10 \mu \mathrm{l}\left[{ }^{14} \mathrm{C}\right] \mathrm{H}_{2} \mathrm{CO}_{3}\left(52.5 \mathrm{mCi} \mathrm{mmol}^{-1}, 0.394 \mathrm{M}\right)$ giving a final solution of $6.5 \mathrm{mM}$ bicarbonate at $16 \mathrm{mCi} \mathrm{mmol}^{-1}, \mathrm{pH} 5.75$. The acetate solution contained $50 \mathrm{mM} \mathrm{MOPS} \mathrm{pH} 7,10 \mathrm{mM}$ glutathione, $94 \mu \mathrm{J} 0.1 \mathrm{M}$ sodium acetate, and $100 \mu)$ [3H]sodium acetate $\left(1.6 \mathrm{Ci} \mathrm{mmol}^{-1}, 10 \mathrm{mCi}\right.$ $\mathrm{ml}^{-1}$ ) giving a final concentration of $5 \mathrm{mM}$ acetate at $100 \mathrm{mCi} \mathrm{mmol}^{-1}, \mathrm{pH} 5.5$.

The leat discs were place in 5-ml Fernbach llasks, capped with serum stoppers, with the underside of the leat on the surface of the liquid. They were illuminated from underneath with a GE 500W DX8 photo lamp. A water-cocled if fitter was placed between the lamp and the incubations in order to reduce heating of the flasks. The light intensity at the flasks was kept at 
$1500 \mu \mathrm{E} \mathrm{m}^{-2} \mathrm{~s}^{-1}$ by checking the light intensity during the course of the experiment and moving the vials closer to the lamp as it aged. The incubation media was periodically stirred using $1 / 2 x$ $1 / 8$ inch stir bars in each flask and a magnetic stirrer placed above the vials.

After $5 \mathrm{~h}$ the incubations were stopped by removing the incubation media, washing the discs 3 times with 3-ml volumes of water, and then grinding the discs with $15 \mathrm{ml}$ hexare. The residue was then ground with $5 \mathrm{ml} 95 \%$ ethanol, tollowed by two $5-\mathrm{ml}$ volumes of water. All water and ethanol extracts as well as the residue were acidified; the residue was separated from the liquid by centrilugation and was extracted overnight with hexane. All acidified samples were dried under a stream of $\mathrm{N}_{2}$. The hexane extracts were combined then divided into halves. The remaining residue was resuspended in water and centriluged. The supernatant was aciditied and dried under a stream of $\mathrm{N}_{2}$. The pellet was applied to a combustion pad, acidified, and dried overnight under vacuum. All dried fractions were resuspencied in water, and an aliquot was taken and counted. The residues were combusted.

A $50 \mu$ aliquol of a $11 \mathrm{mg} \mathrm{ml}^{-1}$ mix of sesquiterpene hydrocarbon standards in hexane was added to each hexane extract before chromatography on $20 \times 20 \mathrm{~cm}$ silica gel G plates in 3:1, petroleum ether: $\mathrm{CCL}_{4}$. A spot of the mix of sesquiterpenes was used as a marker spot which was visualized with sulfuric acid spray and heat. The plate was divided into bands, scraped, and counted as silica sols.

Incorporation of varlous substrates by $C$ langsdorfll cuttlings. Four matched leaf cuttings were taken from a 2.5 year-old $C$. langsdorfii, cutting the petioles underwater. Four different substrate treatments were prepared, dried under a stream of $\mathrm{N}_{2}$, redissolved in $0.25 \mathrm{ml}$ water, and added to each culting in $0.6 \mathrm{ml}$ water in an $1-\mathrm{ml}$ vial. The four treatments were $45 \mu$

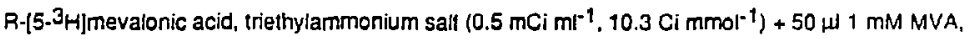
potassium salt giving a final concentration of 52 nmol MVA in $0.825 \mathrm{ml}$ water $(63 \mu \mathrm{M}, 0.43 \mathrm{Ci}$ $\left.\mathrm{mmol}^{-1}\right), 10 \mu$ sodium $\left.\left({ }^{3} \mathrm{H}\right] \mathrm{acelate}\left(50 \mathrm{nmol}, 60.6 \mu \mathrm{M}, 2 \mathrm{Ci} \mathrm{mmol}^{-1}\right), 10 \mu\right)$ sodium[ $\left.{ }^{3} \mathrm{H}\right\}$ lacetate $\{50$ nmol, $\left.60.6 \mu \mathrm{M}, 2 \mathrm{Ci} \mathrm{mmol}^{-1}\right)+50 \mu \mathrm{l} 10 \mathrm{mM}$ sucrose $(0.5 \mu \mathrm{mol}, 0.61 \mathrm{mM})$, and $75 \mu \mathrm{l}$ 
D. [U-14 Clglucose $\left(50 \mathrm{nmol}, 60.6 \mu \mathrm{M}, 296 \mathrm{mCi} \mathrm{mmol}^{-4}\right)$. The cuttings were incubated $24 \mathrm{~h}$ in natural light. Water was added to the vials as needed to keep the petioles immersed. Each leaf was frozen in liquid $\mathrm{N}_{2}$ and then extracted by grinding with hexane. The residue was further extracted by stirring with volumes of hexane until the extracts were no longer yellow. The hexane extracts were combined and concentrated to $8 \mathrm{ml}$ then backextracted with water. The hexane extract was further concentrated to $1-\mathrm{ml}$ volume, and a sample irom each treatment was spotted on a $20 \times 20 \mathrm{~cm} 1000 \mu \mathrm{m}$ silica gel $\mathrm{G}$ plate as a band and a marker spot along with a second $\mathrm{m}$. spot containing a mixture of caryophyllene, cedrene, and cyperene. The plates were developed in petroleum ether: $\mathrm{CCl}_{4}, 3: 1$. The region containing the sesquiterpenes $\left(\mathbf{R}_{\mathrm{f}} 0.49\right.$ to 0.8$)$ was scraped, the silica gel was wet with methanol, and the compounds eluted with $\mathrm{CH}_{2} \mathrm{Cl}_{2}$. A $10 \%$ aliquot of each eluted fraction was mixed with $15 \mathrm{ml}$ Aquassure and counted. Bands above and below the sesquiterpene band were scraped, mixed with $5 \mathrm{ml}$ water and $15 \mathrm{ml}$ Aquassure, and counted as silica sols.

In the case of the MVA incorporation, the remaining sesquiterpene band eluate was concentrated and chromatographed by HPLC on $24.6 \mathrm{~mm} \times 25 \mathrm{~cm}$ ODS columns (Altex) in either $100 \%$ methanol or $95: 5 \mathrm{CH}_{3} \mathrm{CN}: \mathrm{H}_{2} \mathrm{O}$ at a flow rate of $1 \mathrm{ml} \mathrm{min}^{-1}$ and on a $10 \mathrm{~mm} \times 25 \mathrm{~cm} \mathrm{C8}$ column (Altex) in $70: 30 \mathrm{CH}_{3} \mathrm{CN}$ : IPA at a flow rate of $2 \mathrm{ml} \mathrm{min}^{-1}$. The eluate was monitored by its $A_{214}$ and fractions were collected and counted. In addition, the origin of the plate was eluted with acetone, and hall was rechromatographed on a $20 \times 20 \mathrm{~cm} 500 \mu \mathrm{m}$ silica gel $\mathrm{G}$ plate developed in 3:1 ether: petroleum ether, a system for resolving triterpenoids. The plate was divided into bands which were scraped and counted as silica sols. The remainder of the plate on which the hexane extract was spotted was also divided into bands which were scraped and counted.

The squalene and sesquiterpene containing fraction from the glucose-fed cutting was chromatographed by HPLC on $24.6 \mathrm{~mm} \times 25 \mathrm{~cm}$ ODS columns in $100 \%$ methanol at a flow rate of $1 \mathrm{ml} \mathrm{min}-1$. Fractions were collected and counted. 
C. langsdorfil cutting Incubatlon with unlabelled MVA. An analogous incubation to the one where cuttings were incubated with various substrates was performed. A leat was cut from a 2.5 year-old $C$. lansdorfii under water, placed in a $1-\mathrm{ml}$ vial containing $52.2 \mathrm{nmol}$ MVA, potassium salt, and incubated in natural light from 9:50 an until 10:30 am the next day. The leaf tissue was ground with hexane and extrace ed by stiming for $6 \mathrm{~h}$. The residue was reextracted overnight with hexane. All hexane exiracis were combined and concentrated under a stream of $\mathrm{N}_{2}$. The concentrated hexane extract was spotted on a $20 \times 20 \mathrm{~cm} 1000 \mu \mathrm{m}$ silica gel G plate and developed in 3:1 petroleum ether: $\mathrm{CCl}_{4}$. The region encompassing the sesquiterpenes and squalene was scraped and eluted with $\mathrm{CH}_{2} \mathrm{Cl}_{2}$. The eluate was concentrated, filtered through a $0.5 \mu \mathrm{m}$ Millipore fitter, and chromatographed by HN $\mathrm{C}$ in $100 \%$ methanol on $24.6 \mathrm{~mm} \times 25 \mathrm{~cm}$

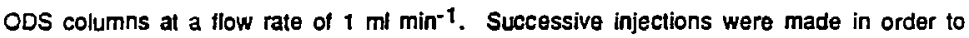
chromatograph all the material recovered by ILC. The pulative squalene peak was collected from each injection, combined, reinjected to confirm its purity, and sent for MS analysis. Since the obtained mass spectrograph was wgak, a sample of commercial squalene was sent for MS analysis to allow comparison of the two.

Analysis tor endogenous pool of squalene in C. langsdorfll. A C. langsdomil leaf of fresh weight $1.06 \mathrm{~g}$ was ground with hexane, and the residue was extracted repeatedly with hexane until in was clear. The hexane extract was sponted on a $20 \times 20 \mathrm{~cm} 1000 \mu \mathrm{m}$ silica gel $\mathrm{G}$ plate which was developed in 3:1 petroleum ether: $\mathrm{CCl}_{4}$. The region containing the sesquiterpenes and squalene was scraped and eluted with $\mathrm{CH}_{2} \mathrm{Cl}_{2}$. The eluate was concentrated to the same volume as in the previous experiments with cuttings, and an aliquot was analyzed for squalene content by HPLC in 100\% methanol on on $24.6 \mathrm{~mm} \times 25 \mathrm{~cm}$ ODS columns at a flow rate of $1 \mathrm{mI}$ $\min ^{-1}$. 


\section{RESULTS}

Identiflcatlon of sesquiterpenes in Copaifera Issue. TLC of hexane extracts made from leaf, stem, and petiole tissue from a seedling showed material coeluting with sesquiterpene hydrocaroon standards. GC-MS analysis of material recovered from the region of the TLC where the sesquiterpene standards coelute $\left(R_{f}, 0.44-0.72\right)$ indicated that sesquitemene hydrocarbons are the predominant components.

Chlorophyll content of Copalfera tissue. Leaf tissue from a 1.5 year-old $C$. officinalis plant had a chlorophyll content of $0.1895 \pm 0.0049 \mathrm{~g} \mathrm{~m}^{-2}(n=2)$. The chlorophyll content of a $C$. mulijuga seedling was $0.293 \mathrm{~g} \mathrm{~m}^{-2}$.

Incorporation of acetate by Copalfera offic/nal/s cutting. In the initial experiment with Copaifera tissue, after 20 hours a $C$. officinalis leal had incorporated $0.61 \mathrm{nmol}$ acetate into hexane-extractable compounds, based on the total recovery of radioactivity from the $45 \%$ hexane extract that was chromatographed by TLC. The $10 \%$ aliquot of the hexane extract that was counted directly gave a lower value of incorporation of $0.28 \mathrm{nmol}$ acetate indicating that the charcoal used to decolorize the solution betore counting had adsorbed labelled material. Of the total hexane extract, $\mathbf{0 . 8 \%}$ or $5 \mathrm{pmol}$ of acetate was incorporated into compounds that coeluted with sesquiterpenes by TLC. $R_{f}$ values for various standard compounds are listed in Table II, indicating that a number of different compounds coslute with the sesquiterpenes in this system.

Metabolle Incorporation by Copalfera leat discs. In the experiment following the time course of incorporation of $\left[{ }^{3} \mathrm{H}\right]$ acetate into $C$. officinalis leaf discs, a maximum of 0.3 nmol acetate was incorporated into the hexane-extractables after $24 \mathrm{~h}$. However, the maximum incorporation of $9 \mathrm{pmol}$ acetate into the sesquiterpene TLC band occured at $6 \mathrm{~h}$; the amount of radioactivity in that traction decreased to $50 \%$ of the maximum after $24 \mathrm{~h}$ incubation (Fig. 2). 
Table II. Rf Values of Standard Compounds chromatographed by $\pi . C$ in $3: 1$ petroleum

$$
\text { ether: } \mathrm{CCl}_{4}
$$

Compound

distearin

cedrene $\left(C_{15}\right)$

2- $\mathrm{CH}_{3}$-pentadecane

eicosane $\left(C_{20}\right)$

nonacosane $\left(\mathrm{C}_{29}\right)$

cyperene $\left(\mathrm{C}_{15}\right)$

pentadecane $\left(C_{15}\right)$

caryophyllene $\left(C_{15}\right)$

squalene $\left(\mathrm{C}_{30}\right)$

$\beta$-carotene $\left(\mathrm{C}_{\mathbf{4 0}}\right)$

palmitic acid $\left(C_{16}\right)$

farnesol ( $\left.C_{15}\right)$

oleic acid $\left(C_{18}\right)$

lanosterol $\left(\mathrm{C}_{30}\right)$
$R_{f}$

0.735

$0.63-0.73$

0.71

0.71

0.71

$0.66-0.71$

0.68

$0.49-0.65$

$0.44-0.55$

$0.47-0.51$

0.09

0.06

0.03

0.01 


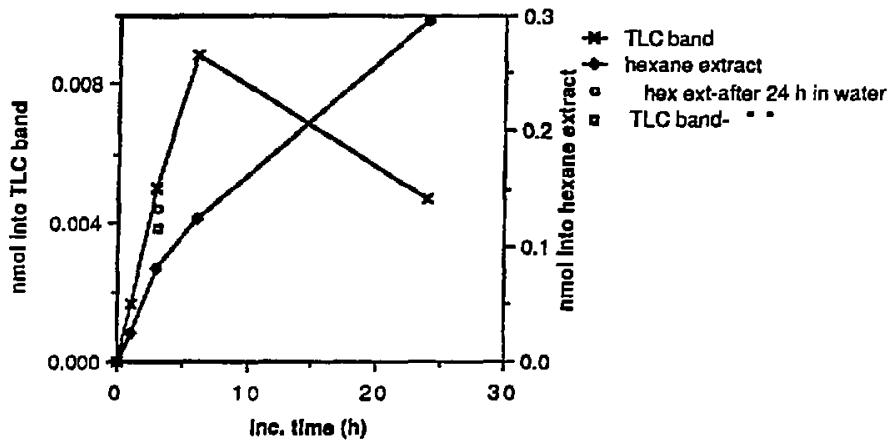

Fig. 2. Time course of acetafe incorporation into Copaitera leaf discs.

In the first experiment testing the time course of incorporation of $\left[{ }^{14} \mathrm{C}\right]$ bicarbonate, an aliquot of the hexane extract of each incubation was not counted as in previous experiments, but an idea of the total incorporation can be obtained by summing the incomoration into the three $\pi \mathrm{C}$ bands analyzed. The whole plate was scraped from the $20 \mathrm{~h}$ incubation giving a value of 9.97 nmol bicarbonate incorporated into the hexarie fraction, demonstrating that a good approximation of the total incorporation into the hexane extract is given by the sum of the scraped bands which gave a value of $9.76 \mathrm{nmol}$ inrorporated. Over the course of the incubation, the incorporation into total hexane-extractables was twenty times the incorporation into the sesquiterpene TLC band (Fig. 3). At $6 \mathrm{~h}$ the incorporation of acetate irito the TLC band was a factor of 6 less than the incorporation of bicarbonate into that band, although acetate incorporation into the total hexane extract was twice the bicarbonate incorporation. A count of the methanol-soluble radioactivity remaining in the water tractions trom the $20 \mathrm{~h}$ incubation after acidification and drying accounted for all the radioactivity added, indicating that all $340 \mathrm{nmol}$ added bicarbonate was metabolized. Analysis of the water soluble components of the methanol extract by HPLC showed that 82 nmol bicarbonate, $24 \%$ of the total incorporation, went into 
sugars.

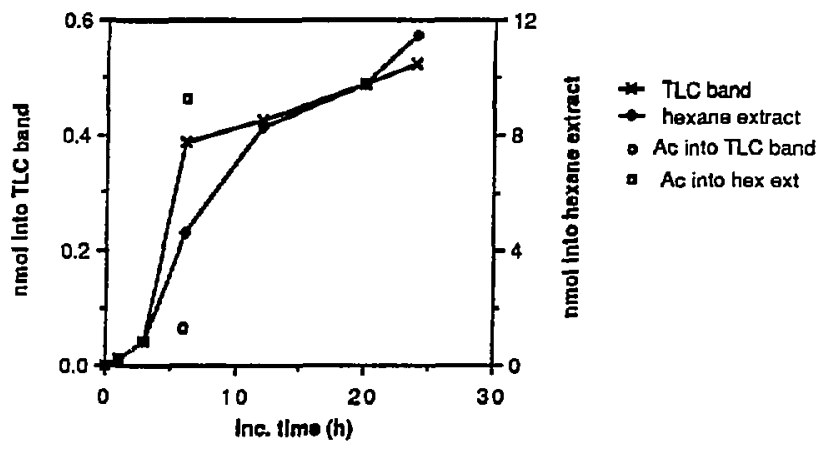

Fig. 3. Time course of bicarbonate incorporation into C. officinalis leaf discs.

A single $20 \mathrm{~h}$ incubation of $\left[{ }^{14} \mathrm{C}\right.$ ]bicarbonate into $C$. officinalis leaf discs was repeated using buffered media and a higher concentration of bicarbonate since all $340 \mathrm{nmol}$ were incorporated in the previous experiment. A total of $16 \mu \mathrm{mol}$ bicarbonate was incorporated into the water-extractable fraction out of the $500 \mu \mathrm{mol}$ supplied. This equals a carbon incorporation rate of $0.71 \mu \mathrm{mol} \mathrm{m} \mathrm{m}^{-2} \mathrm{~s}^{-1}$ or $3.8 \mathrm{nmol} \mathrm{mg} \mathrm{Chl} \mathrm{Cs}^{-1} \mathrm{~s}^{-1}$. Sugars accounted for $35 \%$ of the incorporated radioactivity in the water extract or $5.6 \mu \mathrm{mol}$ total with glucose and fructose being more heavily labelled than sucrose. The incorporation into the hexane extract was $71 \mathrm{nmol}$ with $32 \%$ of that radioactivity eluting in the region of $A_{1} 0.36$ to 0.83 . HPLC analysis of materiat recovered from the region of $R_{f} 0.33$ to 0.63 of a second TLC plate showed that only $10 \%$ of the radioactivity of that fraction or $0.15 \mathrm{nmol}$ total bicartonate was incorporated into the region where the sesquiterpene hydrocarbons elute. The recovery of radioactivity applied to the column was $37 \%$ suggesting that the majority of the label had been incorporated into more nonpolar compounds which remained on the column. 
A second time course of bicartonate incorporation into C. multijuga leaf discs showed incorporation on the pmolar level into the sesquiterpene band with a linear incorporation rate of $3.3 \mathrm{nmol}$ carbon $\mathrm{mg} \mathrm{Chl} \mathrm{Cs}^{-1}$ or $0.93 \mu \mathrm{mol}$ carbon $\mathrm{m}^{-2} \mathrm{~s}^{-1}$ into methanol-extractables. Incorporation into the hexane extract was also linear at a rate of $7 \mathrm{pmol}$ carton $\mathrm{mg} \mathrm{Chl}^{-1} \mathrm{~s}^{-1}$ or 1.9 nmol carbon $\mathrm{m}^{-2} \mathrm{~s}^{-1}$ (Fig. 4).

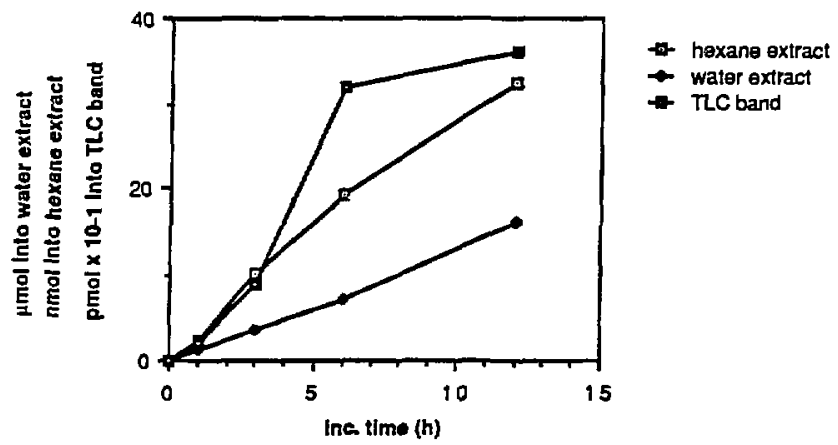

Fig. 4. Time course of bicarbonate incorporation into $C$. muttijuga leaf discs.

Light saturation of Copalfera muftljuga leat discs. The photosynthetic rate of $C$. multijuga leaf discs saturated at a value of $0.175 \mu \mathrm{mol}$ carton incomorated $\mathrm{m}^{-2} \mathrm{~s}^{-1}$ at a light level of 1500 $\mu \mathrm{E} \mathrm{m}^{-2} \mathrm{~s}^{-1}$ (Fig. 5).

A substrate incorporation experiment was subsequently performed at the saturating light level of $1500 \mu \mathrm{E} \mathrm{m}^{-2} \mathrm{~s}^{-1}$ comparing bicarbonate incorporation into C. officinalis and $C$. mullijuga leat discs as well as acetate incorporation by the $C$. munijuga leaf discs. The total bicarbonate incoporation ( $0.9 \mu \mathrm{mol} \mathrm{C} \mathrm{m}^{-2} \mathrm{~s}^{-1}$ ) of the $C$. multijuga leat discs was slightly less than that of the $C$. officinalis tissue $\left(1.2 \mu \mathrm{mol} \mathrm{C} \mathrm{m}^{-2} \mathrm{~s}^{-1}\right)$ with total acetate incomporation being an order of magnitude lower (Fig. 6). Hexane-extractabies accounted for 0.2 to $0.6 \%$ of the total substrate incorporation: acetate-labelling gave the highest percentage of label in hexane-extractables, 


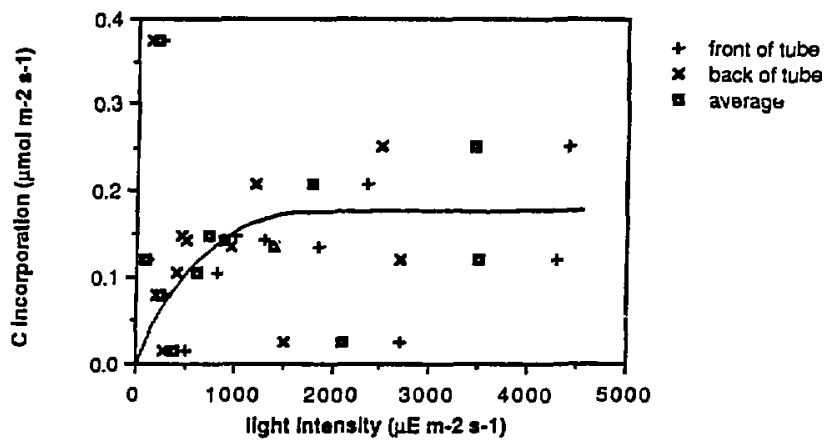

Fig. 5. Light saturation of Copailera leaf discs.

twice that when bicarbonate was used as substrate. TLC analysis of the hexane extracts showed radioactivity coincident with both the sesquiterpene hydrocarton and squalene bands. In all three incubations, squalene was more heavily labelled than the sesquiterpenes, accounting for 4 to $5 \%$ of the label in the hexane extract. A greater percentage of the label in the hexane extract from acetate than from bicarbonate was incorporated into both the sesquiterpene and squalene bands by the $C$. multijuga leaf discs. Incorporation of bicarbonate into "squalene" by the two Copaitera species was comparable, but the incorporation into "sesquiterpenes" was five times higher by $C$. multijuga than by $C$. officinalis.

incorporation of various substrates into C. langsdortll cuttings. Incorporation of various substrales supplied for $24 \mathrm{~h}$ to $C$. langsdorfi cuttings into the sesquiterpene hydrocarbon TLC band $\left(R_{f} 0.49\right.$ to 0.8 ) varied greatly (Table III). The best substrate was mevalonic acid with 5.8 nmol incorporated. Acetate and glucose incorporation was on the pmolar level. Acetate incorporation was $8.5 \mathrm{pmol}$, lowered to $2.6 \mathrm{pmol}$ in the incubation where $0.5 \mu \mathrm{mol}$ sucrose was also supplied to the cutting. Glucose incorporation was 13 pmol. HPLC analysis of the MVA-labelled fraction showed that $1.9 \%$ of the total label elutes with the sesquiterpene 


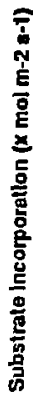

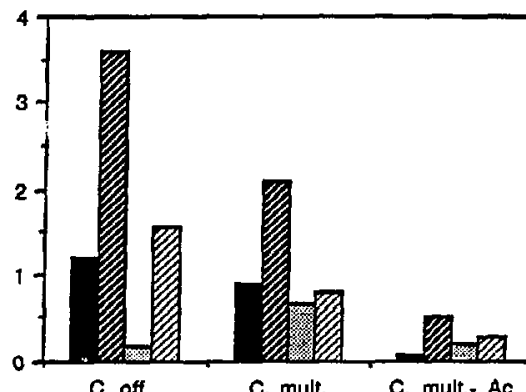

$\mu \mathrm{mol}$ total ine nmol hex. ext. $\mathrm{nmol}$ sesquis $\times 10$ nmol squalene $\times 10$

Tlesue Substrate

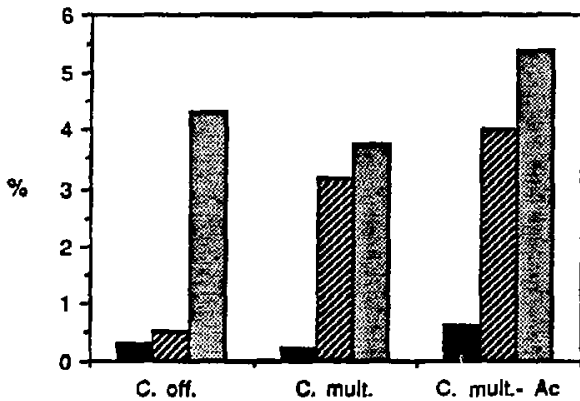

Trawe a Subatrate

Fig. 6. Comparison of bicarbonate and acetate incorporation into total hexane extractables, sesquiterpene hydrocarbons, and squalene by $C$. officinalis and $C$. muttijuga leat discs in $5 \mathrm{~h}$.

hydrocarbons; 0.11 nmol MVA had been incorporated into these compounds. Funther analysis showed that $92 \%$ of the label in the fraction was coincident with a single peak which coeluted with a squalene standard. Similar HPLC analysis of the acetate-labelled fraction established that 55\% 
and $22 \%$ of the radioactivity was associated with squalene and the sesquiterpenes, respectively; for the glucose-labelled sample, the distribution was $61 \%$ and $13.5 \%$. Collection of the putative squalene for MS analysis verilied that the material was squalene. Quantification using HPLC established that the endogenous squalene content of a $C$. langsdorfi leaf was $0.2 \mathrm{mg} \mathrm{g}$ fresh $w t^{-1}$. The origin from the TLC system used to elute the sesquitemenes and squalene was recovered and rechromatographed by a TLC system designed for isolation of triterpenoids. Based on this, 7 nmol MVA was incorporated into triterpenes and their esters. The total incorporation into the hexane extract was 19 nmol MVA.

Table III. Distribution of incorporated substrates among various tractions and components of Conaifera lanasolorii cuttings.

\begin{tabular}{|c|c|c|c|c|c|}
\hline Substrate & hexane extract & ILceraction & Sesquiteroenes & Squalene & Iriterpenoids \\
\hline MVA & $19 \mathrm{nmol}$ & $5.8 \mathrm{nmol}$ & $0.11 \mathrm{nmol}$ & $5.3 \mathrm{nmol}$ & $7 \mathrm{nmol}$ \\
\hline Acetate & & $8.5 \mathrm{pmol}$ & $1.9 \mathrm{pmol}$ & $4.7 \mathrm{pmol}$ & \\
\hline Glucose & & $13 \cdots$ & $1.8 \cdots$ & $79^{\circ}$ & \\
\hline \multicolumn{2}{|c|}{ Acetate + sucrose } & $2.6=n$ & & & \\
\hline
\end{tabular}

\section{DISCUSSION}

The two forms of Copaifera tissue (leat cuttings and leat discs) used in these experiments require different means for the substrates to reach the site of terpenoid biosynthesis. With cuttings, uplake of the metabolites is required; with leaf discs, the substrate is infiltrated into the 
leaf tissue. Francis promoted the use of leaf discs to study essential oil biosynthesis because this technique could reduce the problems involved in getting the metabolites to the site of terpenoid biosynthesis and allows easier manipulation of the conditions under which the incubations are made (9). In the case of these experiments with Copaifera leaf discs, the overall incorporation of ${ }^{14} \mathrm{C}$ ]bicarbonate was taken as a measure of the appropriateness of this system. Under saturating light levels of $1500 \mu \mathrm{E} \mathrm{m}^{-2} \mathrm{~s}^{-1}$, C. officinalis leaf discs incorporated $1.2 \mu \mathrm{mol} \mathrm{C} \mathrm{m}^{-2} \mathrm{~s}^{-1}$ which, aithough lower than the average photosynthetic rate of $C_{3}$ plants of 10 to $25 \mu \mathrm{mol} \mathrm{C} \mathrm{m}^{-2}$ $\mathrm{s}^{-1}$, is in the range of the rate measured by Langenheim of Copaifera in the field of 7 to $8 \mu \mathrm{mol} C$ $\mathrm{m}^{-2} \mathrm{~s}^{-1}(14)$. The light level that was found to be saturating for bicarbonate incorporation agrees with Langenheim's data that Copaifera is a sun plant. On the basis of overall metabolism, the leaf discs appear to mimic well the response of the plant under nomal field conditions.

The time course of acetate incorporation into the "sesquiterpene" TLC band by $C$. officinalis leaf discs indicates that the same short term tumover of sesquiterpenes is occuring in Copailera as was seen with peppermint cuttings and $P$. cablin leaf discs $(5,9)$ (Fig. 2). At the same time, acetate incorporation into total hexane-extractables continued to increase over the course of the experiment. Since the incubation where the leal discs sat $24 \mathrm{~h}$ in water betore the acelate was added and were then incubated an additional $3 \mathbf{h}$ showed incorporation similar to the initial $3 \mathrm{~h}$ time point, the view that this turmover is a natural occurence, rather than due to senescence of the leaf material after $24 \mathrm{~h}$ incubation, is substantiated. That no such turnover, rather a leveling-off of incorporation into the "sesquiterpene" TLC band after $6 \mathrm{~h}$ incubation, was seen when bicarbonate was the added precursor is probably due to the long path to sesquiterpenes from this precursor and the conditions of continuous feeding of the substrate (Fig. 3). In experiments with peppermint cuttings, a maximum of ${ }^{14} \mathrm{CO}_{2}$ incorporation into sesquiterpenes was seen at $9 \mathrm{~h}$ after a $1 \mathrm{~h}$ pulse of the labelled substrate was given to the plant material (6). In this experiment with the C. officinalis leaf discs, acetate incorporation at $6 \mathrm{~h}$ was six times less than the bicarbonate incorporation into the "sesquiterpene" band indicating that there was some factor 
preventing acetate from reaching the site of sesquiterpene biosynthesis. With peppermint cuttings, it was found that glucose and $\mathrm{CO}_{2}$ served as much better precursors for monoterpene biosynthesis than for sesquiterpene synthesis with the accessability of MVA to sesquiterpene biosynthesis being greater than to the site of monoterpene synthesis $(5,6)$. In a second bicarbonate incorporation time course experiment, again a leveling-off of incorporation into the "sesquiterpene" TLC band was seen even as the incorporation into the hexane and water extracts continued to rise linearly (Fig. 4).

Both the age and species differences of the plant material may account for the results of the experiment comparing bicarbonate incorporation into leat discs of $C$. officinalis and $C$. multijuga with an acetate incorporation into C. multijuga leat discs over a period of $5 \mathrm{~h}$ (Fig. 6). That acetate incorporation was again lower than bicarbonate incorporation into terpenoid compounds supports the view that acelate was not able to reach the site of synthesis as easily as bicarbonate. The greater incorporation of bicarbonate into sesquilerpenes of C. mullijuga than in C. officinalis can be attributed to either the species or age differences of the plants. Leat discs were cut from a 1.5 year-old $C$. officinalis and a 5 month-old $C$. multijuga seedling. The younger tissue may be more actively symhesizing sesquiterpenes.

The experiments with leat cuttings further showed what the tinal leaf disc experiment indicated, that incorporation of exogenous precursors into squalene and triterpenoids predominates over incorporation into sesquiterpenes (Table III). This same situation was seen when $\left[{ }^{14} \mathrm{C}\right]$ mevalonate was fed to peppermint leat cuttings (8). The preferential fabelling of squalene seen from all three precursors tested: glucose, acelate, and mevalonate, can be described most simply as a difference in the accessability of the site of synthesis of squalene and triterpenoids trom the site of sesquiterpene biosynthesis. Even with the leaf disc experiments where the need for some mode of transport of the metabolites to the leaf tissue has been eliminated, incorporation into squalene of both bicarbonate and acetate appears to override incorporation into sesquiterpenes. One possible explanation is that the site of sesquiterpene 
synthesis is truly physically compartmentalized which is supported by anatomical data showing that the resin is secreled by specialized epithelial cells into the leaf pockets which hold the resin (11). A second possibility is the flow of carbon into the various terpenes is regulated physiologically. Since the sesquiterpenoids and triterpenoids share the common precursor farnesyl pyrophosphate, regulation may be at this point: this would fit with these results which showed that all precursors tested, from bicarbonate to mevalonate, labelled squalene more heavily than the sesquiterpenes. However, while the ratio of incorporation of acetate and glucose into squalene as compared to incorporation into sesquiterpenes was 2.5 and 4.4 to 1 , respectively, fitty times as much MVA was incorporated into squalene as into sesquiterpenes, suggesting that some control of the flow of carbon into the two sets of compounds may lie on the isoprenoid pathway between acetate and mevalonate.

Mevalonate incorporation Into the sesquiterpenes of a Copailera cutting was 100-fold greater than the incorporation of either acetate or glucose. This again raises the question of the accessability of substrates to the site of sesquiterpene synthesis. Copaifera appears like Mentha in that mevalonate was also the best exogenous precursor for sesquiterpene biosynthesis in that plant (5). Incorporation of ( $\left.^{14} \mathrm{C}\right]$ mevalonate was also ten times greater than ${ }^{14} \mathrm{CO}_{2}$ incoporation into the sesquiterpene hydrocarbons of maritime pine needles, but [ ${ }^{14} \mathrm{C}$ ]acetate incorporation was nearly as efficient as mevalonate's (10). These diHerences suggest that there is no single answer to the nature of the site of sesquiterpene biosynthesis in plants.

Unlike in peppermint cuttings, these resulls indicate that sesquiterpene biosynthesis in Copaifera does not appear to require sugars as an energy source. When unlabelled sucrose was supplied along with ${ }^{3} \mathrm{H}$ jacetate to a $\mathrm{C}$. langsdorfi leal cutting, acetale incorperation into the "Sesquiterpene + squalene" TLC band was less than when a cutting was incubated with acetate alone (Table III). In contrast Croteau. Eurbott, and Loomis tound that added sucrose promoted ${ }^{14} \mathrm{C}$ mmevalonate incorporation into sesquiterpenes of peppermint cuttings, leading them to suggest that sesquiterpene biosymhesis occured in isolated energy-deficient sites and is a 
fermentative process (7). In Copaifera it appears that sucrose can compete with acetate in terpenoid biosynthesis thus diluting the $\left[{ }^{3} \mathrm{H}\right]$ acetate label incorporated. This is further substantiated in that glucose is incorporated into sesquiterpenes as readily as acetate is. However, a direct comparison between the experiments with Copaifera and Mentha cannot be made since sucrose was incubated with different terpenoid precursors in the two cases; while it may be that the incorporation of mevalonate into terpenoids in Copaifera is energy-deficient, with supplied acetate there is sulficient available energy. This would suggest that the energy for the process is achieved through acetate metabolism by the citric acid cycle as opposed to from sugars through glycolysis or the pentose phosphate pathway.

\section{CONCLUSIONS}

The ability of Copaifera tissue to incorporate terpenoid precursors, especially mevalonate, into sesquiterpenes makes further study of this system possible. Because different sesquilerpene-producing plants show different precursor preferences, it appears that there exist significant differences in the nature of the site of sesquiterpene biosynthesis in various plants. Since it is unique in its mass production of sesquiterpene hydrocarbons, Copaifera continues to be of interest. Although tracer incorporation into the sesquiterpenes is on the 0.1 nanomolar level, it would be possible to continue the initial aim of this work to look at turnover of these compounds. This work has shown that turnover of sesquiterpenes in Copaifera does occur in leat discs labelled with acetate or bicarbonate. Since mevalonate incorporation in cuttings was 100-fold greater than acetate incorporation, a time course of mevalonate incorporation should be investigated. Individual sesquilerpene labelling patterns can be analyzed by HPLC or RGLC. The infermediate role of acyclic frans- $\beta$-farnesene in sesquiterpene biosynthesis in maritime pine needles was determined in this manner (10).

The discovery that mevalonate is selectively channeled to squalene and triterpenoid biosynthesis in Copaifera presents an oppontunity to study the controls of the flow of carbon to 
wo sets of isoprenoids, sesquiterpenes and triterpenes. Further work comparing the Incorporation of various precursors, especially farnesyl pyrophosphate, the immediate precursor to both classes of terpenoids, into the two groups of compounds could provide insight into the nature of the regulation of the distribution of carbon.

The differences in incorporation by different species of Copaifera require that further experiments be pertormed with as uniform plant material as possible. It would be interesting to compare incorporation into sesquiterpenes of plant material of different ages. This could best be achieved by using material from the same plant, but of different ages, since the available species and ages of Copaifera are limited. 


\section{LITERATURE CITED}

1. Arthenius SP, JH Langenheim 1983 Inhibitory eflects of Hymenaea and Copaifera leaf resins on the leaf fungus, Pestalotia subcuticularis. Biochem Syst Ecol 11: 361-366

2. Arthenius SF, GE Foster, CG Edmonds, JH Langenheim 1983 Sesquiterpenes in leat packel resins of Copaifara species. Phytochemistry 22: $471-472$

3. Calvin M 1980 Hydrocarbons from plants: analytical methods and observations. Naturwissenschaften 67: 523-539

4. Cane DE 1981 Biosynthesis of sesquitorpenes. In JW Porter, SL Spurgeon, eds, Biosynthesis of Isoprenoid Compounds Vol 1. John Wiley and Sons, Inc, New York, pp 283-374

5. Croteau R, WD Loomis 1972 Biosynthesis of mono- and sesquilerpenes in peppermint from mevalonate-2.14 C. Phytochem 11: 1055-1066

6. Croteau R, AJ Burbort, WD Loomis 1972 Biosynthesis of mono- and sesqui-terpenes in peppermint from glucose- ${ }^{14} \mathrm{C}$ and ${ }^{14} \mathrm{CO}_{2}$. Phytochem 11:2459-2467

7. Croteau R, AJ Butbott, WD Loomis 1972 Apparent energy deficiency in mnio- and sesqui-terpene biosynthesis in peppermint. Phytochem i : : 2937-2948

8. Croteau R, WD Loomis 1973 Biosynthesis of squalene and other triterpenes in Mentha piperita from mevalonate-2.14C. Phytochem 12: 1957-1965

9. Francis MJO 1972 Blosynthesis of sesquiterpenes in Pogostemon cablin leaf discs. Planta Med 22: 201-204

10. Gleizes M, A Marpeau, G Pauly, C Bernard-Dagan 1984 Sesquiterpene biosynthesis in maritime pine needles. Phytochem 23: 1257-1259

11. Langenheim JH 1989 Temenoids in the Leguminosae. In FM Polhill, PH Raven, eds, Advances in Legume Systematics. Royal Botanical Gardens, Kew, pp 627-655 
12. Langenheim JH, SP Amhenius, JC Nascimento 1981 Relationship of light intensity to leaf resin composition and yield in the tropical reguminous genera Hymenaea and Copaifera. Biochem Syst Ecol 9: 27-37

13. Langenheim JH, CE Foster, RB McGinley 1980 Inhibitory eflects of different quantitative compositions of Hymenaea leaf resins on a generalist herbivore Spodoptera exigua. Biochem Syst Ecol 8: 385

14. Langenheim JH, CB Osmond, A Brooks 1983 Photosynthetic responses to light in seedlings of selected Amazonian and Australian rainforest tree species.

15. Loomis WD. R Crateau 1980 Biochemistry of terpenoids. In PK Stumpf,ed, The Biochernistry of Plants, Lipids: Structure and Funclion Vol 4. Academic Press, New York, pp $363-418$

16. Martin SS, JH Langenheim, E Zavarin 1976 Biosynthesis of Sesquiterpenes in Hymenaea interred from their quantitative co-occurrence. Phylochem 15: 113-119

17. Parker W, JS Roberts, R Ramage 1967 Sesquiterpene biogenesis. Quart Rev 21: 331-363

18. Ruzicka $L 1953$ The isoprene rule and the biogenesis of terpenic compounds. Experientia 9: 357-396

19. Stahl E, H Jork 1979 Terpene derìatives, essential oils, balsams and resins. In E Stahl, ed, Thin-Layer Chromatography, Ed 2. Springer-Verlag, New York, pp. 210-211

20. Wenninger JA, RL Yates, M Dolinsky 1967 Sesquiterpene hydrocarbons of commercial copaiba balsam and American cedar wood oïs. J Assoc Off Anal Chem 50: 1304-1313

21. Wintermans JFGM, A De Mots 1965 Spectrophotometric characteristics of chiorophylls a and $b$ and their pheophytins in ethanol. Biochem Biophys Acta 109: $448-453$ 
This report was done with suppon from the Depurtuent of Encray. Any conclusioms or opinion expressed in this report represent solely those of the author(y) and not necesentily those of The Regents of the University of Californin, the Lewrence Berkeley Leboratory or the Department of Eneroy.

Reference to a company or product an does nox imply epproval or recommendation of the product by the University of Califomin or the U.S. Department of Energy to the exclusion of others that may be suiluble. 